NATIONAL LABORATORY

MANAGED BY UT-BATTELLE

FOR THE DEPARTMENT OF ENERGY

\title{
PR-EDB: Power Reactor Embrittlement Database Version 3
}

\section{February 2008}

Prepared by Jy-An John Wang and Ranjit Subramani

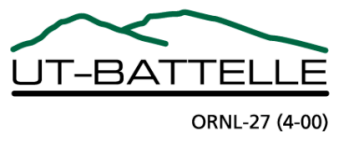




\section{DOCUMENT AVAILABILITY}

Reports produced after January 1, 1996, are generally available free via the U.S. Department of Energy (DOE) Information Bridge.

Web site http://www.osti.gov/bridge

Reports produced before January 1, 1996, may be purchased by members of the public from the following source.

National Technical Information Service

5285 Port Royal Road

Springfield, VA 22161

Telephone 703-605-6000 (1-800-553-6847)

TDD 703-487-4639

Fax 703-605-6900

E-mail info@ntis.gov

Web site http://www.ntis.gov/support/ordernowabout.htm

Reports are available to DOE employees, DOE contractors, Energy Technology Data Exchange (ETDE) representatives, and International Nuclear Information System (INIS) representatives from the following source.

Office of Scientific and Technical Information

P.O. Box 62

Oak Ridge, TN 37831

Telephone 865-576-8401

Fax 865-576-5728

E-mail reports@osti.gov

Web site http://www.osti.gov/contact.html

This report was prepared as an account of work sponsored by an agency of the United States Government. Neither the United States Government nor any agency thereof, nor any of their employees, makes any warranty, express or implied, or assumes any legal liability or responsibility for the accuracy, completeness, or usefulness of any information, apparatus, product, or process disclosed, or represents that its use would not infringe privately owned rights. Reference herein to any specific commercial product, process, or service by trade name, trademark, manufacturer, or otherwise, does not necessarily constitute or imply its endorsement, recommendation, or favoring by the United States Government or any agency thereof. The views and opinions of authors expressed herein do not necessarily state or reflect those of the United States Government or any agency thereof. 
Material Sciences and Technology Division

\section{PR-EDB: Power Reactor Embrittlement Database Version 3}

Manuscript Completed: December 2006

Date Published: August 2007

Prepared by

Jy-An John Wang and Ranjit Subramani

C. J. Fairbanks, NRC Project Manger

M. T. Kirk, NRC Project Manager

Prepared for the

Division of Fuels, Engineering and Radiological Research

Office of Nuclear Regulatory Research

U.S. Nuclear Regulatory Commission

Washington DC 20555-0001

NRC JCN: W6953

Interagency Agreement DOE 1886-N695-3W

Prepared by the

Oak Ridge National Laboratory

Oak Ridge, TN 373831-6069

Managed and Operated by

UT-Battelle, LLC

for the

U. S. DEPARTMENT OF ENERGY

under Contract No. DE-AC05-00OR22725 



\section{CONTENTS}

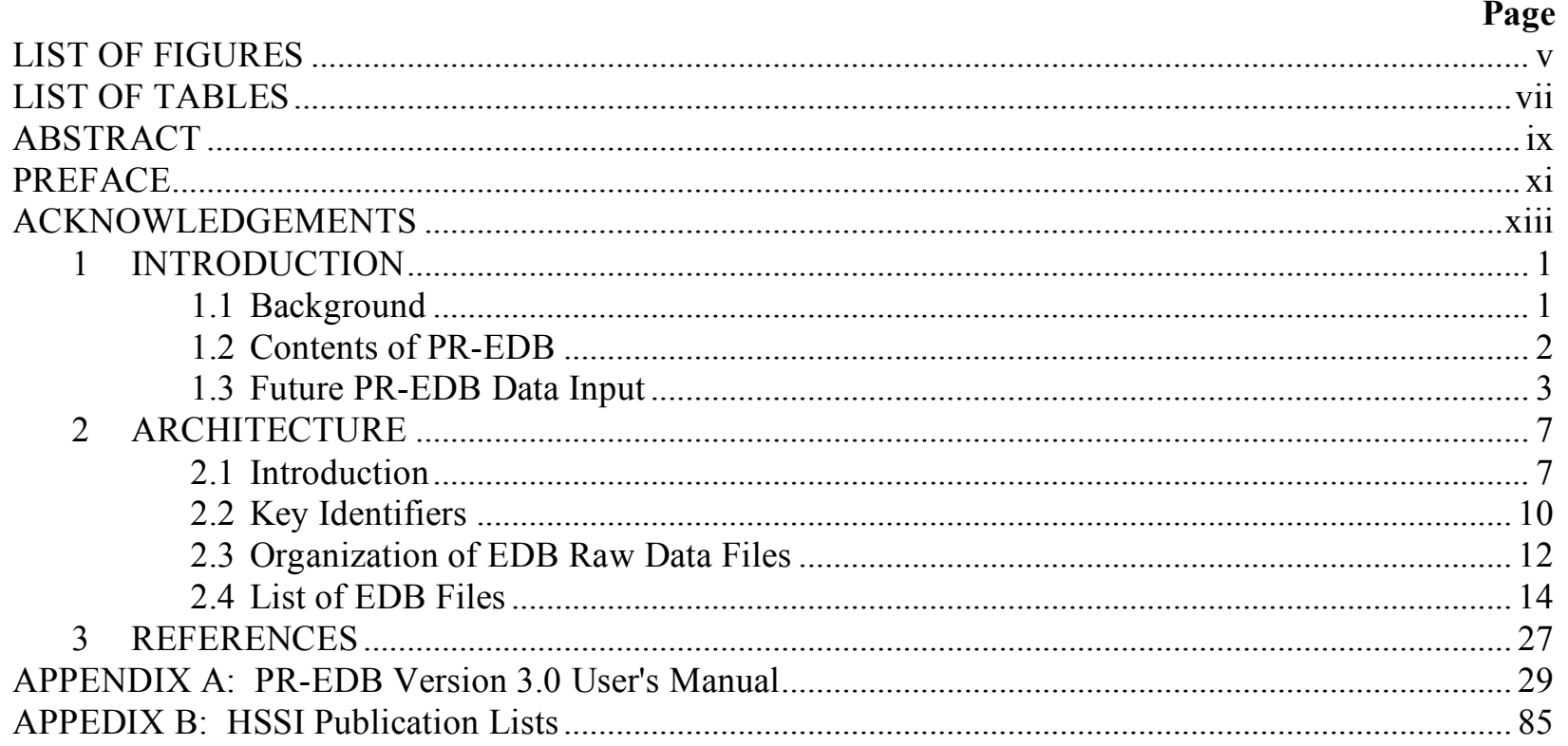





\section{LIST OF FIGURES}

Figure 1. Distribution of power reactor Charpy data for fluence and irradiation temperature for base and weld materials.

Page

Figure 2. Distribution of power reactor Charpy data for copper and nickel content for base and weld

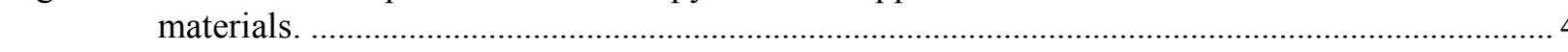
4

Figure 3. RG1.99/R2 residual for surveillance base materials........................................................ 5

Figure 4. RG1.99/R2 residual for surveillance base materials................................................................. 5

Figure 5. An overview of the data flow in the PR-EDB ...................................................................... 10

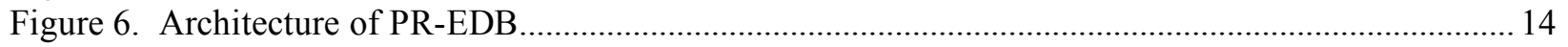





\section{LIST OF TABLES}

Table 1. Units used in Embrittlement Database (EDB) files ...

Page

Table 2. Structure file for SPEC IST dbf Specimen Information.....

Table 3. Structure file for SHFT_PR.dbf Charpy Transition Temperature and Upper-Shelf Energy ....... 16

Table 4. Structure file for RAW_C_PR.dbf Charpy Impact Test ............................................................... 17

Table 5. Structure file for CV_RF_PR.dbf References for Charpy Data Sets ........................................... 17

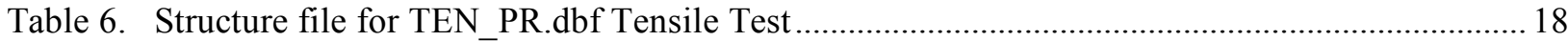

Table 7. Structure file for REAC_PR.dbf Irradiation Environment .......................................................... 19

Table 8. Structure file for REAC_LST.dbf Reactor Identification............................................................. 19

Table 9. Structure file for HEAT_LST.dbf List of Heat Identification......................................................2

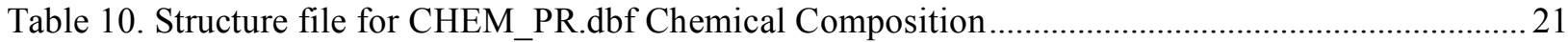

Table 11. Structure file for HEAT PR.dbf Heat Treatment Information ...................................................... 22

Table 12. Structure file for WELD.dbf Weldment Information ............................................................24

Table 13. Structure file for HAZ PR.dbf Identification of Heat-Affected-Zone Materials ........................ 24

Table 14. Structure file for REF_TITL.dbf Reference Information .......................................................25

Table 15. Structure file for REF_LST.dbf Reference List .......................................................................25 



\begin{abstract}
Information from radiation embrittlement research on nuclear reactor pressure vessel (RPV) steels and from power-reactor surveillance reports has been gathered to assist the US Nuclear Regulatory Commission (NRC) effectively monitor current procedures and databases used by vendors, utilities, and service laboratories in the pressure vessel irradiation surveillance program. The radiation embrittlement of reactor pressure vessel materials depends on many factors, such as neutron fluence, flux, and energy spectrum, irradiation temperature, and preirradiation material history and chemical compositions. These factors must be considered to reliably predict pressure vessel embrittlement. Large amounts of data from surveillance capsules are needed to develop a generally applicable damage prediction model that can be used for industry standards and regulatory guides. Furthermore, the investigations of regulatory issues such as vessel integrity over plant life, vessel failure, and sufficiency of current codes, Standard Review Plans (SRPs), and Guides for license renewal can be greatly expedited by the use of a well-designed computerized database. The Power Reactor Embrittlement Database (PR-EDB) is such a comprehensive collection of data for U.S. operated commercial nuclear reactors.

The current version of the PR-EDB lists the test results of 104 heat-affected-zone (HAZ) materials, 115 weld materials, and 141 base materials, including 103 plates, 35 forgings, and 3 correlation monitor materials that were irradiated in 321 capsules from 106 commercial power reactors. The data files are given in dBASE format and can be accessed with any personal computer using the Windows operating system. "User-friendly" utility programs have been written to investigate radiation embrittlement using this database. Utility programs allow the user to retrieve, select and manipulate specific data, display data to the screen or printer, and fit and plot Charpy impact data.
\end{abstract}

The PR-EDB Version 3.0 upgrades Version 2.0. The package was developed based on the Microsoft .NET framework technology and uses Microsoft Access for backend data storage, and Microsoft Excel for plotting graphs. This software package is compatible with Windows (98 or higher) and has been built with a highly versatile user interface. PR-EDB Version 3.0 also contains an "Evaluated Residual File" utility for generating the evaluated processed files used for radiation embrittlement study. 



\section{PREFACE}

The first compilation of the U.S. Power Reactor Embrittlement Database (PR-EDB), Version 1, was completed in October 1989, and the documentation was published in June 1990. Subsequently, in cooperation with the Electric Power Research Institute (EPRI), U. S. reactor vendors performed additional verification and quality assurance of the data. A record-by-record check by the vendors removed some errors and ambiguities and filled many gaps by providing data from additional documents and vendor records not previously available to the authors. Although the reactor vendors have not verified all data, all data entered can be referred in the quoted references. All data from the Allis-Chalmers reactors, Elk River and LaCrosse, are unverified. Also, data from two independent studies that were not under the vendor's control, (the review of fluence calculation in NUREG/CR-3319 by Hanford Engineering Development Laboratory and a report on Babcock \& Wilcox welds (BAW-1803)) were not verified by Westinghouse. Several other reports containing unverified data by the vendors are listed in Appendix B. The changes to the first compilation and documentation have been incorporated into PR-EDB, Version 1, Revision 1 (April 1991).

PR-EDB Version 2, released in January 1994, contains surveillance data that were irradiated in 252 capsules of 96 reactors and consists of 207 data points for heat-affected-zone (HAZ) materials (98 different HAZ), 227 data points for weld materials (105 different welds), and 524 data points for base materials (136 different base materials). The base materials include 297 plate data points (98 different plates), 119 forging data points (35 different forgings), and 108 correlation monitor materials (SRM) data points (one ASTM and two HSST plate materials).

This version of the PR-EDB software was upgraded from the DOS to WINDOWS environment. The raw data structure and file manipulation function are unchanged. The current version also provides a utility, "Evaluated Residual File," which allows the user to generate the evaluated processed data files with a one to one relationship that can be used directly in radiation embrittlement studies. FORTRAN programming was used to develop the Charpy curve fitting features (including the user interface), statistical evaluation, plotting utilities, and data output. The conversion from the DOS to Windows platform required a major overhaul. Due to the current budget constraint, the decision was made to implement the DOS version of data fitting programs into the current Windows version with minimum modifications. Thus, the core program of fitting utilities in the current version remains in the DOS format.

The Windows upgrade of the PR-EDB will pave the way for the future development of the Analytical Program Library (APL) for investigating RPV embrittlement related issues. APL functions are (1) updating the analyses automatically whenever new data or new assumptions for the analysis arise, (2) developing follow-up studies with refined models, optimized procedures, evaluation of "what-if" scenarios and, (3) documentation and opportunity for critical review by regulatory bodies or other interested parties. This recent PR-EDB upgrade is an important step in a broader goal to develop an integrated EDB program, which would include "Generate Common Databases and Application Programs," "Build Networks, Intellectual Interfaces, to carry out Data Sharing and Data Exchange," and "Develop Long Term Archive Methodology." 



\section{ACKNOWLEDGEMENTS}

The research reported here, performed under the auspices of the Heavy-Section Steel Irradiation (HSSI) Program, T. M. Rosseel, Program Manager, was sponsored by the Office of Nuclear Regulatory Research, U.S. Nuclear Regulatory Commission, under Interagency Agreement DOE 1886-N695-3W with the DOE under Contract No. DE-AC05-00OR22725 with UT-Battelle, LLC. That financial support is gratefully acknowledged. The authors especially appreciate R. K. Nanstad for the helpful discussions, encouragement, and review assistance and Alice Rice for preparing this manuscript. 



\section{INTRODUCTION}

\subsection{BACKGROUND}

Information from radiation embrittlement research on nuclear reactor pressure vessel (RPV) steels and from power-reactor surveillance reports has been gathered to assist the US Nuclear Regulatory Commission (NRC) effectively monitor current procedures and databases used by vendors, utilities, and service laboratories in the pressure vessel irradiation surveillance program. The radiation embrittlement of RPV materials depends on factors such as flux, fluence, neutron energy spectrum, irradiation temperature, and preirradiation material history and chemical composition. ${ }^{1,2}$ These factors must be considered to reliably predict pressure vessel embrittlement. Based on embrittlement predictions, decisions must be made concerning operating parameters and issues such as low-leakage-fuel management, possible life extension, and the need for annealing the pressure vessel (PV). ${ }^{3} \quad$ Large amounts of data from surveillance capsules are needed to develop generally applicable damage prediction models that can be used for industry standards and regulatory guides. Furthermore, the investigations of regulatory issues such as vessel integrity over plant life, vessel failure, and sufficiency of current codes, Standard Review Plans (SRPs), and Guides for license renewal can be greatly expedited by the use of a well-designed computerized database. The Power Reactor Embrittlement Database (PR-EDB) ${ }^{4}$ is such a comprehensive collection of data for U. S. designed commercial nuclear reactors.

The scope and purpose of this program is summarized as follows:

- Compile and verify a comprehensive collection of data from power reactor surveillance programs (hereafter referred to as surveillance program/s) of PV materials from U. S. reactors.

- $\quad$ Provide software support for use of the database by furnishing programs and maintaining compatibility with commercially available software.

- $\quad$ Facilitate the development and verification of embrittlement prediction models.

- $\quad$ Facilitate the development and verification of the effects of annealing for pressure PV life extension.

- Interact with standards organizations to provide the technical basis for voluntary consensus standards that can be used in regulatory guides, Standard Review Plans (SRPs), and the American Society of Mechanical Engineers (ASME) Boiler and Pressure Vessel Code and American Society for Testing and Materials (ASTM) Standards.

To achieve these goals, the design of the database architecture was made after much discussion and planning with prospective users and material scientists. The PR-EDB Version 3.0 is designed for use with any personal computer using the WINDOWS-based operating system. Updates are aniticipated to be issued periodically to users. The data format chosen for PR-EDB is dBASE, initially introduced by Ashton-Tate and now the virtual standard for relational databases. This format allows queries and data processing not only with the current dBASE software but also with any of the now numerous "Xbase" developer tools, such as MS ACCESS or Foxpro. The dBase files can be imported into most other database, spreadsheet, and word processing programs that run in the WINDOWS environment. More recent versions of these programs contain extensive facilities for generating reports including statistical, curve fitting, and graphic programs. For frequently performed tasks, a customized PR-EDB utility program based on .NET Framework and FORTRAN can be used. EDB-Utilities is menu driven and self-explanatory, requiring no special training (description is given in Section III). 
The data collections in the PR-EDB originated from the Material Properties Council (MPC) database which contains both power and test reactor data. ${ }^{5}$ From this collection an unpublished version of the PR-EDB was constructed and augmented with more recently reported data. All data are traceable to a reference, including page numbers. The architecture of the database is characteristic of a relational database that makes it relatively simple to maintain and perform quality control. A restricted version containing only power reactor surveillance data was assembled to be used primarily for regulatory purposes. Most of the surveillance data listed in the PR-EDB have been verified by the reactor vendors responsible for the insertion of the material into surveillance capsules, and any changes and corrections have been documented in special files for future reference. Version 1 of the PR-EDB was released to the public in July 1991. Version 2 was released in January $1994 .{ }^{4}$ After the release of Version 2, twelve updates for PR-EDB Version 2 were released. The content of Version 3 of PR-EDB is based on Update_12 of PR-EDB Version 2.

\subsection{CONTENTS OF PR-EDB}

Three major categories of data are included in the EDB: preirradiation material history, irradiation environments, and mechanical test results. These categories contain the following types of data:

- Chemical composition data for each material;

- Preirradiation heat treatment;

- Data concerning the fabrication of weld material;

- Fluence [E > 1.0 MeV, E > 0.1 MeV, and displacements per atom (dpa)], irradiation time, and irradiation temperature for each irradiated capsule;

- Charpy impact test results before and after irradiation, both for individual specimens and for evaluation of transition temperature and upper-shelf energy;

- Tensile test results before and after irradiation;

The contents of the Charpy impact test results listed in the current version of the PR-EDB are as follows.

Power reactor data: The current EDB lists 1,225 Charpy transition-temperature shift data points, which include 381 from plates, 155 from forgings, 121 from correlation monitor materials, 296 from welds, and 271 from weld heat-affected-zone (HAZ) materials, irradiated in 321 capsules from 106 commercial power reactors.

Figure 1 shows the distribution of fast fluences and irradiation temperatures for the power reactor data in the current PR-EDB, while the distribution of copper and nickel content for the represented materials is shown in Fig. 2. The residuals, measured transition temperature shift-NRC Regulatory Guide 1.99/R2's prediction - and the associated two sigma uncertainties are shown in Figs. 3 and 4 for surveillance base and weld materials.

To take full advantage of the information contained in the database, the user of the PR-EDB is expected to have some familiarity with the dBASE philosophy and software. Note that the data in the PR-EDB are taken directly from the quoted documents without any interpretation or evaluation. All numerical values are given in the units of the original documents. All data from any particular record in a PR-EDB file are obtained only from the document quoted in REF_ID, except as noted. More than one record of the same quantities may be included in the files if different documents report different evaluations of the same data. For instance, several determinations of the chemical composition of the same material may be performed or fluences may have been updated based on improved methodology or cross-section data. The user must select or, perhaps, average the different values for the same quantity. Automated analysis of the raw data files in the PR-EDB is not recommended. An additional evaluation, selection, and unit conversion will be necessary whenever 
these data are used for investigations and analysis of RPV integrity issues. The creation of evaluated data files for such purposes is under consideration. The "Process Raw dBASE" utility achieves such a goal, where SHFT_PR, CHEM_PR and REAC_PR files were streamlined and processed to generate a unique data record for a specific heat identifier (either a single identifier or the combined identifiers). Further development of EDB-Utilities is required to allow the user to streamline the raw data and generate evaluated data files more efficiently, to duplicate routine functions on the update analysis, and to develop special routines to incorporate "what-if scenarios" into analysis and selection procedures.

\subsection{FUTURE PR-EDB DATA INPUT}

The proposed PR-EDB data inputs for the irradiation environment are irradiation-time history, group fluence spectra, and dosimetry database, which are essential for the detailed study of the rate effect, spectrum effect, and further investigation of the damage efficiency and residual defects. The degree of embrittlement is usually correlated with fast neutrons or dpa, which are proportional to the production rate of point defects. However, radiation effects are driven not by the total number of atoms displaced but by the small fraction of point defects that avoid annihilation by mutual recombination, either within the displacement cascade or as they diffuse in the material. ${ }^{6,7,8,9,10}$ Therefore, radiation effects are determined by the survival rate of point defects, not by their production rate. The survival rate of point defects (or defect availability) depends on several factors: (1) the temperature of the material, (2) the rate at which the fluence is accumulated, and (3) the energy of the neutrons causing the displacements. Higher temperatures, flux levels, and high energy neutrons all enhance recombination effects and result in lower fractional defect survival. ${ }^{11,12}$ Thus, the development rate of radiation embrittlement under different irradiation environments will not necessarily scale with fast fluence or with dpa unless the survival rate of point defects for each different irradiation also scale with the total defect production rate. Therefore, the previously mentioned proposed radiation environment data are crucial for obtaining a better correlation parameter for the prediction of the radiation embrittlement of RPV steels.

Another important category of data for future PR-EDB data input is nondestructive test data, including indentation and ultrasonic tests. These proposed nondestructive data are essential for the calibration and development of a correlation between the existing destructive mechanical test data and the nondestructive test results. This may prove to be useful in the future, especially for older plants on the verge of exhausting the available mechanical test specimens loaded in surveillance capsules. 


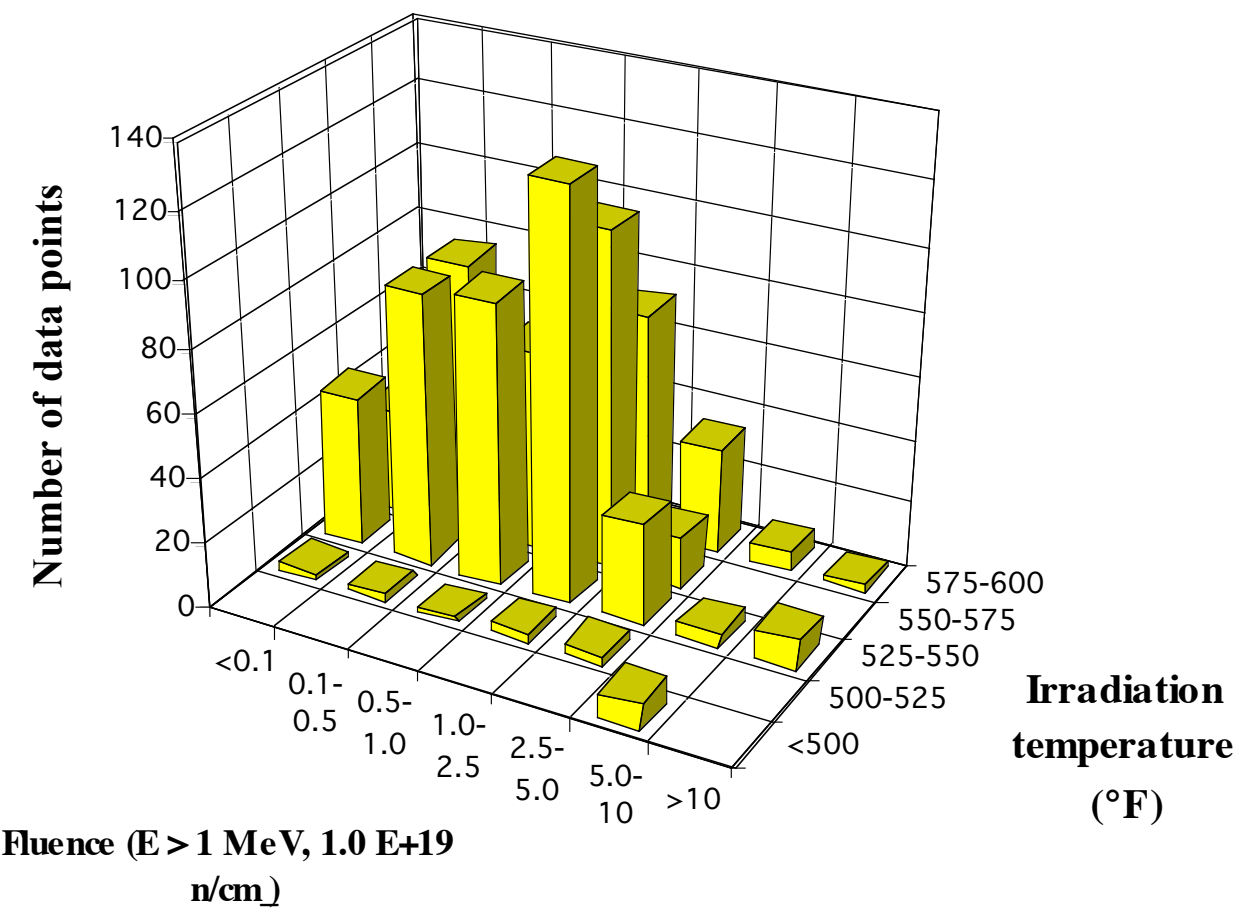

Figure 1: Distribution of power reactor Charpy data for fluence and irradiation temperature for base and weld materials.

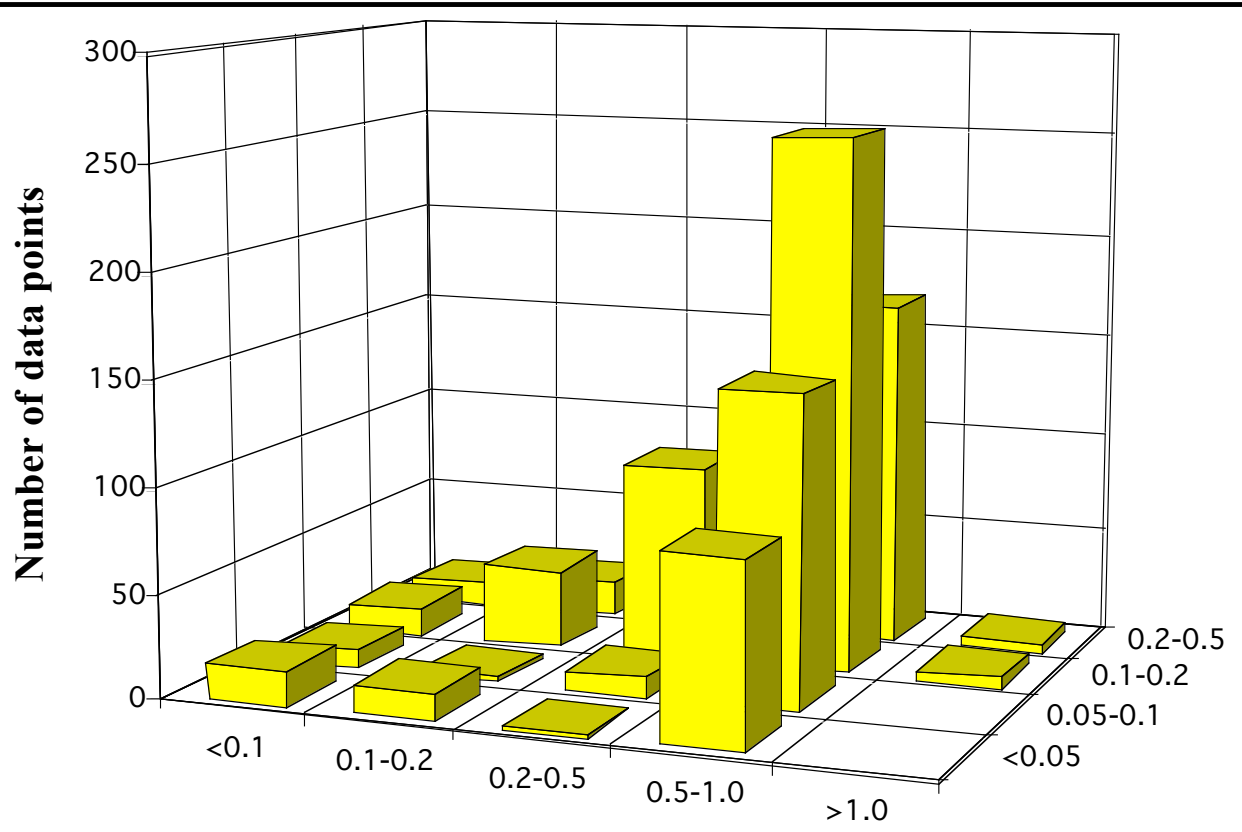

Copper content (wt \%) Nickel content (wt \%)

Figure 2: Distribution of power reactor Charpy data for copper and nickel content for base and weld materials. 


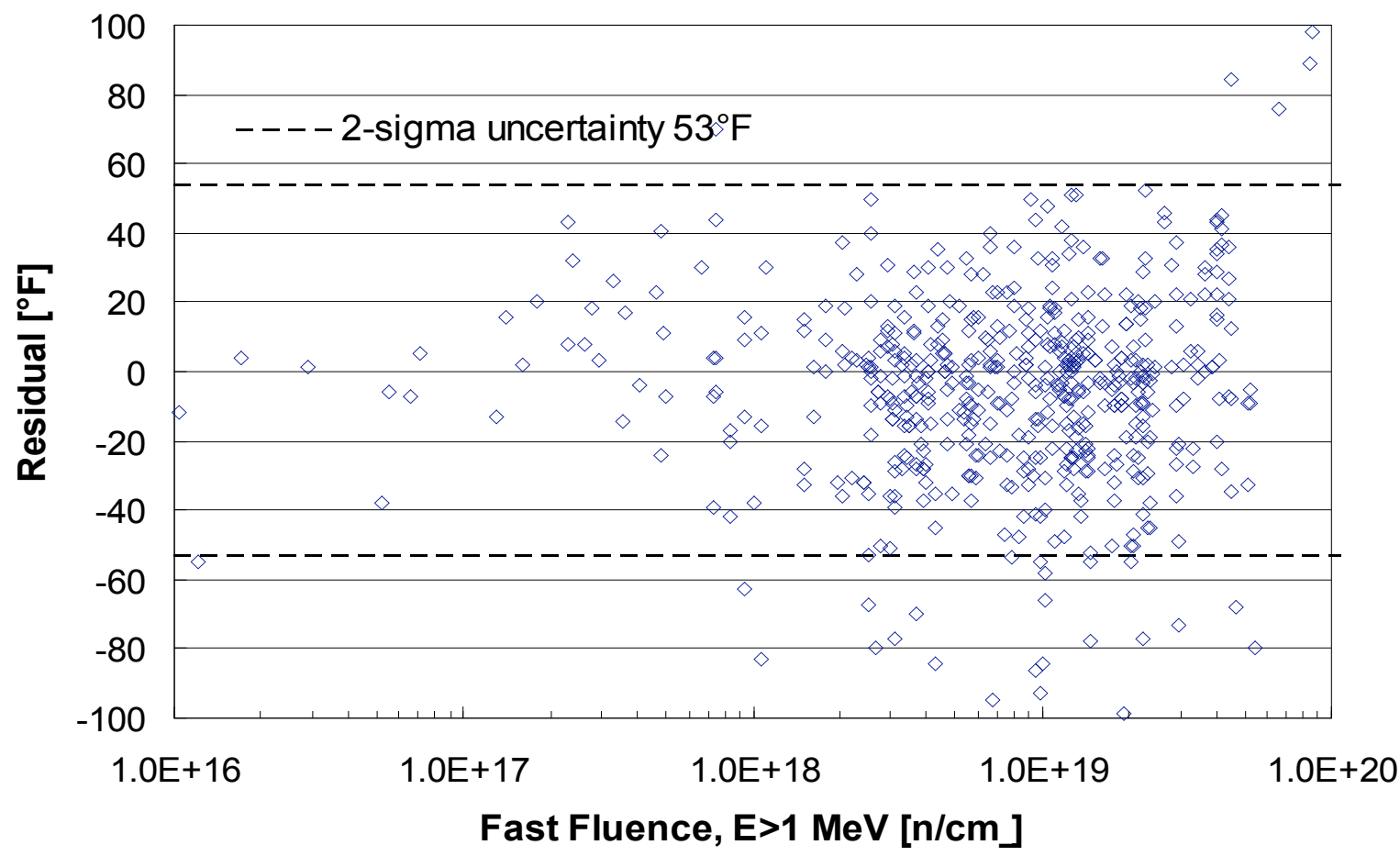

Figure 3: RG1.99/R2 residual for surveillance base materials.

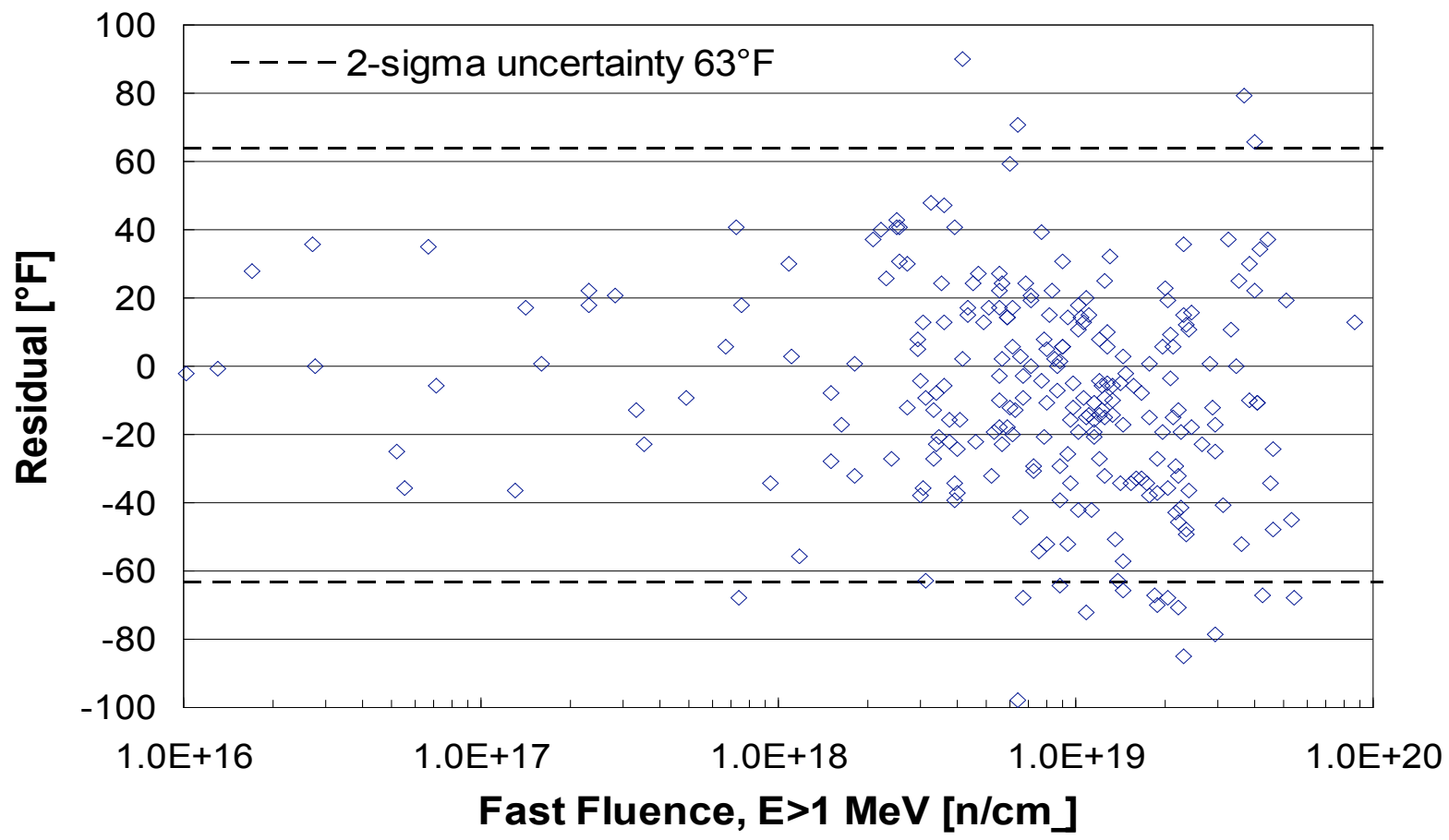

Figure 4: RG1.99/R2 residual for surveillance weld materials. 



\section{ARCHITECTURE}

\subsection{INTRODUCTION}

In dBASE, a collection of one or more tables store and classify information and related files such as indexes and memo files. A table consists of one or more records. A database that consists of only one table is called "flat," which is the format used for older collections, including the MPC database." This approach makes data retrieval easy, requiring no special software, but complicates data entry. For instance, chemical composition data common to a particular material must be repeated for every record that contains the same material. Also, more than one chemical composition determination may be made for the same material such that not only is the same chemical composition repeated over several records but each record must also provide room for several different chemical compositions. These requirements make a flat database unwieldy and error prone, which has led to the introduction of "relational" databases. In a relational database, information is split into several different tables (files), each of which contains only related data. Data from different files are connected (related) with each other by means of unique identifiers that are common to the tables. For instance, all chemical composition data are collected in a chemical composition file, where each chemical composition record contains a unique material identifier. The same material identifier is contained in each test record for that material so that test results can be combined with chemistry. In this way, duplication is avoided and it is possible to list any number of different chemical composition determinations for the same material. The downside to this structure is that several files must be linked together to extract the desired information and software support is necessary to do this effectively. Such software support is now widely available as is the use of relational databases for all but the simplest database applications.

The PR-EDB is a collection of many different data files, each of which closely resembles the data tables found in the original surveillance reports or other technical documents. For instance, most reports have tables containing transition temperatures and upper-shelf energies for Charpy specimens before and after irradiation and/or the shifts in these values during irradiation that are collected in the file "SHFT_PR.dbf." Data are collected as reported; that is, there are fields for unirradiated, irradiated, and shift values, depending on what is reported. Fields are added to accommodate units required by different reports [i.e., English units, the International System of Units (SI)]. Similarly, the file TEN_PR.dbf collects information about tensile tests, the file REAC_PR.dbf collects information about irradiation, such as capsule fluence and temperature, and so on. The linkage between different data files in the PR-EDB is provided by "key identifiers" that are common to these files. For instance, all files with data concerning a specific material, such as results of material property tests, material manufacture, heat treatment, and chemical composition, contain a field for the material identifier, HEAT_ID. Similarly, files with data concerning irradiations contain fields for the identifiers of reactor (PLANT_ID), and the capsule (CAPSULE). Section 0 provides a detailed description of the key identifiers. Care was exercised to assign the correct identifier to each record, ensuring that connections between data from different records are made correctly. Numerous cross checks ensure correct identifications, and also detect mistakes not caught by conventional proofreading. Section 0 provides a complete list of the data files in the PR-EDB. The relational database format has the following significant advantages for the PR-EDB:

1. The structure of the data files need not be predetermined; the data files are designed according to what is available in the original reports, and new data files can be added without disturbing the existing ones.

2. Because every record in a data file originates from a single report and, in most cases, from a single table in that report, a unique reference, including page number(s), can be given for each record. This feature allows the user to go back to the source of the data when questions arise. 
3. Multiple determinations of the same quantity are given in different records, each with its proper references. Such multiple determinations may occur, for example, if the chemical composition is determined by the manufacturer of the material and from broken specimens. Also, fluence determinations are frequently updated in subsequent reports using improved neutron physics calculations. Because different determinations are kept in the PR-EDB the user must decide which determination to use for a particular application or, perhaps, calculate averages from several applications. (For statistical evaluations and model fittings one value may be used for any given quantity; for these applications, "evaluated" data files need to be created which contain only unique data by averaging information from different reports or by related procedures.)

The process in the construction of relational databases by which data are distributed over different files is known in the database literature as "normalization." A relational database is considered normalized if no data except key identifiers are repeated. Full normalization is a desirable goal for aesthetic as well as practical reasons but may lead to unnatural separation of connected data. For example, results of Charpy tests for irradiated materials are usually not considered in isolation but are related to the same data for unirradiated material (baseline data) to determine the changes caused by radiation. On the other hand, baseline data are the same for all irradiations of the same material and should therefore be listed in a separate file to avoid duplications. However, the file SHFT_PR.dbf for evaluated Charpy tests contains both irradiated and baseline data in the same record as well as the differences (shifts) between the two, although shift values can be obtained by simple arithmetic. This simplifies the eventual use of the data, although strict normalization was not performed in this case. Additionally, fluences and irradiation temperatures are listed with each data set and collected in the file REAC_PR.dbf. (However, in this case fluences and temperatures are relative to the specimen or sets of specimens, which may be different from the values for the whole capsule that are listed in REAC_PR.dbf.)

All data in the PR-EDB are given in character format; that is, numerical data are represented internally in the dBASE files by the ASCII characters representing the numbers. This policy allows the data to be represented exactly as reported. For example, prefixes such as $>,<$, and $\sim$ can be included in the data fields. Blank fields represent missing data. The disadvantage of using character format is that special conversion procedures are necessary if comparisons or numerical manipulations are to be performed on the data. Such procedures are included in the EDB-Utilities program described in Appendix A. Additional structure files (identified with the extension .str) that identify the numerical (and date) fields in the PR-EDB files are required since this information is not contained in the regular dBASE structure files.

Data in the PR-EDB are given in the units used in the original reports. ASTM recommends using SI units as described in ASTM Standard E380-93 for Metric Practice. This standard also provides the guidance and constants for unit conversion. The basic units for this system are meter $(\mathrm{m})$ for length, seconds (s) for time, and kilogram ( $\mathrm{kg}$ ) for mass. Before the adoption of SI units, customary engineering practice used units of force instead of mass as the third basic unit. Pound (lb) as a unit of force, in addition to foot (ft) and inch (in.) for length, has been used in the United States and other English-speaking countries and is still found in many U.S. reports (identified as US Unit). Older European reports use kilogram $(\mathrm{kg})$ or kilopond $(\mathrm{kp})$ as the unit of force, as well as meter and second. Units used in the EDB and the English conversions or SI units are listed in Table 1.

Figure 5 provides an overview of the data flow in the EDB where "Evaluated data files" is proposed for future development. The source data are first transcribed as exactly as possible to "Raw Data Files" in dBASE format with complete references. The keyboard is used for data entry. Direct transfer will be used whenever computer-readable documents are available. Any deviation from the norm, which was either reported or noted during transcription (such as the correction of obvious typographical errors), is indicated in the NOTES field. Data from available reports are included except when the information in a later report is simply a duplication of earlier data. More than one 
record of the same quantities may be included in the files if different documents report different evaluations of the same data. The user must select or average the different values for the same quantity. Thus, the raw data needs to be streamlined and converted into an evaluated data file for further analysis.

Next, EDB Utilities or other user-supplied software converts the selected evaluated data files to processed files. Processed files will typically be in dBASE format, but ASCII-coded files can also be obtained from dBASE-compatible software for input into scientific software (e.g., numerical analysis programs written in FORTRAN), word processing, and spreadsheet software. Additional software may be used to create tables and graphs for the purpose of model fitting, model verification, and other applications.

Table 1: Units used in Embrittlement Database (EDB) files

\begin{tabular}{|c|c|c|c|c|c|c|}
\hline \multirow{2}{*}{ Description } & \multirow{2}{*}{$\begin{array}{l}\text { Symbol used } \\
\text { in the EDB }\end{array}$} & \multirow{2}{*}{ Type of unit } & \multicolumn{4}{|c|}{ Conversion factors } \\
\hline & & & \multicolumn{2}{|c|}{ to English units } & \multicolumn{2}{|c|}{ to SI units } \\
\hline Mil (1/1000 inch) & mil & Length & 0.001 & inch & 0.00254 & $\mathrm{~cm}$ \\
\hline Millimeter & $\mathrm{mm}$ & Length & 0.03937 & inch & 0.1 & $\mathrm{~cm}$ \\
\hline Centimeter & $\mathrm{cm}$ & Length & 0.3937 & inch & 1.0 & $\mathrm{~cm}$ \\
\hline Inch & in. & Length & 1.0 & inch & 2.54 & $\mathrm{~cm}$ \\
\hline Fahrenheit & $\mathrm{F}$ & Temperature & 1.0 & $\mathrm{~F}$ & $(F-32) / 1.8$ & $\mathrm{C}$ \\
\hline Centigrade & $\mathrm{C}$ & Temperature & $1.8 \mathrm{C}+32$ & $\mathrm{~F}$ & 1.0 & $\mathrm{C}$ \\
\hline Kelvin & $\mathrm{K}$ & Temperature & $1.8 \mathrm{~K}-460$ & $\mathrm{~F}$ & $1.0 \mathrm{~K}-273$ & $\mathrm{C}$ \\
\hline Foot-pounds & $\mathrm{ft}-\mathrm{lb}$ & Energy & 1.0 & $\mathrm{ft}-\mathrm{lb}$ & 1.3558 & joules \\
\hline Joules & $\mathrm{J}$ & Energy & 0.7376 & $\mathrm{ft}-\mathrm{lb}$ & 1.0 & joules \\
\hline Kilogram-meters & $\mathrm{kgm}$ & Energy & 7.2330 & $\mathrm{ft}-\mathrm{lb}$ & 9.8066 & joules \\
\hline $\mathrm{Mkp}^{a}$ & MKP & Energy & 7.2330 & $\mathrm{ft}-\mathrm{lb}$ & 9.8066 & joules \\
\hline $\mathrm{Mkp} / \mathrm{cm}^{2}{ }^{b}$ & $\mathrm{MK} / \mathrm{C} 2$ & Energy & 5.78 & $\mathrm{ft}-\mathrm{lb}$ & 7.92 & joules \\
\hline $\mathrm{KJ} / \mathrm{m}^{2}$ & $\mathrm{KJ} / \mathrm{m}^{2}$ & Energy & & & 1.0 & $\mathrm{KJ} / \mathrm{m}^{2}$ \\
\hline Kilogram $/ \mathrm{mm}^{2}$ & $\mathrm{~K} / \mathrm{MM}$ & Stress & 1.4223 & ksi & 9.8066 & $\mathrm{MPa}^{c}$ \\
\hline Kip/inch ${ }^{2}$ & KSI & Stress & 1.0 & ksi & 6.895 & $\mathrm{MPa}^{c}$ \\
\hline Pound/inch ${ }^{2}$ & PSI & Stress & 0.001 & ksi & 6.895 & $\mathrm{kPa}^{\mathrm{c}}$ \\
\hline Mega Pascal & MPa & Stress & 0.145 & $\mathrm{ksi}$ & 1.0 & $\mathrm{MPa}^{c}$ \\
\hline $\mathrm{MPa} \sqrt{m}$ & $\mathrm{MPa} \cdot \mathrm{m}^{\wedge}(1 / 2)$ & Stress & 0.910 & ksiVin & 1.0 & $\mathrm{MPa} \sqrt{\mathrm{m}}$ \\
\hline KsiVin & KSI $\cdot$ in $^{\wedge}(1 / 2)$ & Stress & 1.0 & ksiVin & 1.099 & $\mathrm{MPa} \sqrt{\mathrm{m}}$ \\
\hline Second & $\mathrm{S}$ & Time & 1.0 & $\mathrm{~s}$ & 1.0 & $\mathrm{~s}$ \\
\hline Hour & $\mathrm{H}$ & Time & 3,600 & $\mathrm{~s}$ & 3,600 & $\mathrm{~s}$ \\
\hline Day & $\mathrm{D}$ & Time & 86,400 & $\mathrm{~s}$ & 86,400 & $\mathrm{~s}$ \\
\hline Year (365 Days) & $\mathrm{Y}$ & Time & $31,536,000$ & $\mathrm{~s}$ & $31,536,000$ & $\mathrm{~s}$ \\
\hline \multicolumn{7}{|c|}{$\begin{array}{l}{ }^{a} \text { Same as kilogram-meters. } \\
{ }^{b} \text { Energy relative to the cross section of the Charpy minus notch }=0.80 \mathrm{~cm}^{2} \text { (reported for the Beznau } \\
\text { reactors). } \\
{ }^{c} \mathrm{kPA}=\text { kilo Pascal }=10^{3} \text { Pascal; } \mathrm{MPa}=\text { Mega Pascal }=10^{6} \text { Pascal. }\end{array}$} \\
\hline
\end{tabular}




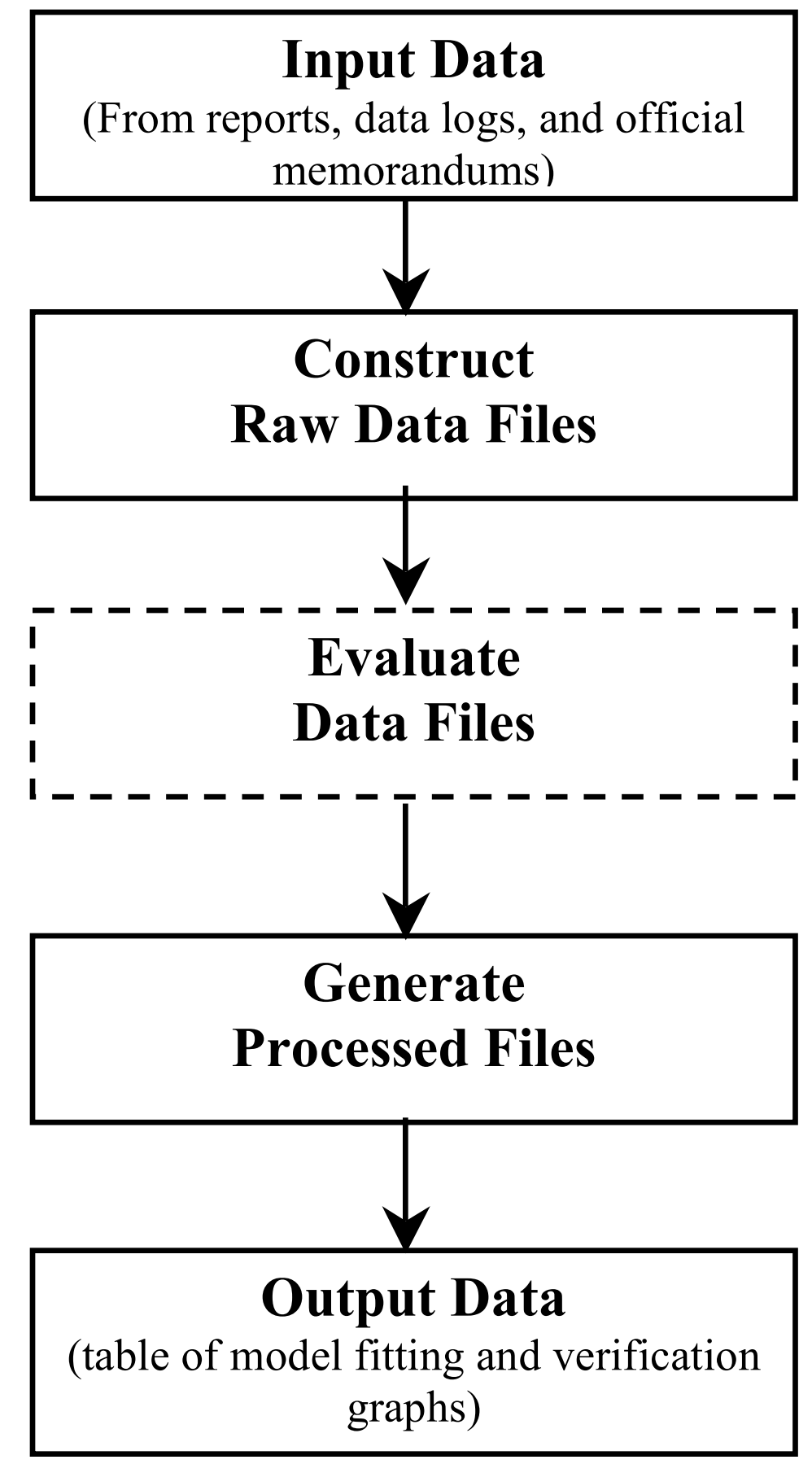

Figure 5. An overview of the data flow in the PR-EDB

\subsection{KEY IDENTIFIERS}

One or more fields in each data file are occupied by "key identifiers," which allow the combination of data from several files through "relations" that link the corresponding records in these files. The database manager assigns the key identifiers so that the same unique identifiers label the data among the various data tables that refer to the same experiments, materials, or source documents. Identifiers used in source reports do not always provide such unambiguous labeling. The current version of the EDB uses the following key identifiers: 


\section{PLANT_ID}

Up to six characters in PLANT_ID identify the reactor in which the irradiation was performed. Only the first three characters in PLANT_ID identify commercial power reactors. For commercial power reactor surveillance data, the reactor code in PLANT_ID is also used to identify the surveillance program as a source of data, even if these data do not refer specifically to irradiation (as in files about chemical composition or heat treatment; for details see Sect. 2.4). The files REAC_LST.dbf holds detailed information about the reactors identified by PLANT_ID.

\section{CAPSULE}

Up to six characters identify the irradiation capsule. In most cases the capsule identifications in the original reports were used. Sometimes specimens that come from different capsules with similar fluences are lumped together; in these cases, special identifiers are assigned for data sets from combined capsules.

\section{HEAT_ID}

The material identifier can have up to ten characters. A simple scheme was devised for the EDB which works as follows: The coding assigns the first letter to the material type, namely $\mathrm{P}_{-}$late, F_orging, W_eldment, H_eat-Affected-Zone material, or S_tandard R_eference $M_{-}$aterial (correlation monitor materials). The next three characters contain a general code related to the origin of the material (the first three characters of reactor identifier PLANT_ID are used here for commercial power reactor data) with two additional characters to distinguish between different materials of the same origin. Other identification letters are used, namely, SASTM for the A302B ASTM reference plate and SHSS02 for HSST plate 02, for standard reference materials that are not restricted to a particular experiment or a commercial surveillance program. The last four letters are reserved to distinguish between different parts of the same material (e.g., between surface and $1 / 2 \mathrm{~T}$ or between several sections of a plate) if different parts show markedly different material properties as documented in the reports. For instance, SASTM S1 and SASTM S2 denote pieces of the 6-in. ASTM A302B reference plate used in the Garigliano and Yankee Rowe reactors, respectively, the baseline properties of which vary considerably from the same material used in Westinghouse reactors, which is denoted simply by SASTM. The file HEAT_LST.dbf gives a complete list of identifiers used as HEAT_ID together with the corresponding identifiers in the referenced reports.

Using the identifiers given in the reports for HEAT_ID, a practice used in the MPC database, was initially considered; this proved to be impractical. Base material (plates or forgings) is usually characterized by the heat number (assigned to the ingot) or a manufacturer's number (assigned to the plate or forging after fabrication; see, for instance, BAW-1820), and only one of these numbers, or neither, is used in reports, frequently with different choices of identification in different reports. For welds, a weld code such as SA-1585 or WF-232 is sometimes used, but the same code may be applied to different welds of the same type (BAW-1820). Alternatively, the wire heat number is used for identification or just the heat numbers of the two plates joined by the weld. A distinct identification is rarely given for the HAZ material.

HEAT_ID provides the link between the material test data and the fabrication and chemical composition data. In many cases, chemical composition and fabrication data are available only for the "generic" material, which is for the plate or weldment as a whole and not for a particular section depth as identified by the last four characters in the HEAT_ID. Thus, linkage may be possible only by restricting it to the first six characters of HEAT_ID when no link exists for the full ten-character identifier. To find the chemical composition data for annealed material, it is necessary to go back to the parent material or, again, the first six characters of HEAT_ID. A 
similar situation exists for the HAZ materials; their chemical composition is rarely determined separately. Thus, the data from the parent (plate) material must be used. The file HAZ.dbf lists parent material for each HAZ.

\section{SPEC_ORI}

Different orientations of the material test specimens may lead to substantially different property test results. Thus, this necessary identifier correctly links the properties of irradiated specimens to the corresponding baseline values. Orientations are assigned in the now customary T-L-S system as described in ASTM Standard E399, where L is the primary rolling or forging direction, or for welds and HAZ, the direction of the weld seam; $\mathrm{T}$ is perpendicular to $\mathrm{L}$ and parallel to the plate surface; and $\mathrm{S}$ is perpendicular to the plate surface. The first letter describes the loading direction of the specimen (perpendicular to the crack surface, if any), and the second letter describes the direction of the crack propagation (perpendicular to the notch). The orientation for each specimen set was determined as accurately as possible, preferably from drawings, ensuring that the same orientations are assigned to corresponding specimen sets. SPEC_ORI is left blank if no information is available.

\section{REF_ID}

In most files, each record is assigned a reference that indicates the source of the data. This reference is a 20-character field REF_ID and is usually a report number or a similar code that links it uniquely to the complete bibliographic information (i.e., author, title, and date of publication) given in the file REF_TITL.dbf. If the source document is an article in a larger volume that contains other unrelated, material, the reference includes the initial page number of the article.

\subsection{Organization of EDB RaW Data FiLeS}

The architecture of the current version of PR-EDB is shown in 6. At the top center of the PREDB architecture is the file SPEC_LST.dbf (Table 2) containing a complete list of test specimen sets that are used in the commercial surveillance programs. The specimen sets can be uniquely identified by SPEC_TYPE and four key identifiers; PLANT_ID, CAPSULE, HEAT_ID, and SPEC_ORI. Specimen sets for testing the baseline properties of unirradiated materials are characterized by leaving the CAPSULE field blank.

Radiation embrittlement data are distributed over three major categories in PR-EDB: preirradiation material history, irradiation environment, and mechanical test results. The detailed architecture of the EDB data is illustrated in Figure 6 and descriptions of each major category of data follow:

- The first category (left-hand side of Figure 6) includes results of material mechanical property tests. Charpy, both individual tests and results of curve fittings, tensile are currently available (SHFT_PR.dbf, RAW_C_PR.dbf, and CV_RF_PR.dbf for Charpy data; TEN_PR.dbf for tensile; Tables 3-6 show the structures of these files). Each record in these files is uniquely characterized by the combination PLANT_ID, CAPSULE, HEAT_ID, and SPEC_ORI.

- $\quad$ The second category (middle of Figure 6) contains data describing the reactor and radiation environment for each surveillance capsule. The file REAC_PR.dbf (Table 7) contains a detailed description of the fluence, irradiation temperature and irradiation time for each irradiation capsule. This file links with the others via the key identifiers PLANT_ID, and CAPSULE. This linkage will not be needed in most cases because fluence and irradiation temperature are also given in the data files, such as SHFT_PR.dbf and TEN_PR.dbf. Note 
that the fluence values given in REAC_PR.dbf apply only for the capsule as a whole (i.e., average or capsule center), which is not necessarily the same as for the individual specimen or specimen group listed in the test data files. However, many details such as values for fluence $(\mathrm{E}>0.1 \mathrm{MeV})$ or dpa are listed, when available, in REAC_PR.dbf. The file REAC_LST.dbf (Table 8 is a list of irradiation facilities used in the experiments. The key identifier field in this file is PLANT_ID. The development team is considering the addition of more detailed files containing the irradiation history, the group fluence spectra, and dosimetry data to allow for fluence determination by independent investigators and more detailed investigation on the rate effect, spectrum effect, and residual defects to the embrittlement prediction models.

- The third category (right-hand side of Figure 1) contains information about the chemical composition and fabrication of materials used in RPV surveillance programs. HEAT_LST.dbf lists all HEAT_IDs with reported codes, and CHEM.dbf, HEAT.dbf, WELD.dbf, and HAZ.dbf list the actual chemical composition and fabrication data. HEAT_ID links these files to the rest of the PR-EDB files. These files are shown in Tables 9-13.

Most records in the PR-EDB files include a reference in the field REF_ID with one or more page numbers that permits verification of the data sources and points to additional information. Exceptions are given in the file REAC_LST.dbf, in which information comes from many different sources. References are not listed in RAW_C_PR.dbf because the associated file CV_RF_PR.dbf has the necessary references. A detailed list of all references with complete title, authors, and date of publication is given in the REF_TITL.dbf. REF_ID is the link to the other files.

PR-EDB files with the suffix _LST are somewhat different from the other data files in that they provide a sort of directory of the other files and their relations to key identifiers. SPEC_LST.dbf is a directory of capsules and baseline specimen sets. REAC_LST.dbf is a directory of power reactors. Finally, HEAT_LST.dbf is a directory of the materials contained in the PR-EDB files. Section 0 provides detailed descriptions of these data files. 


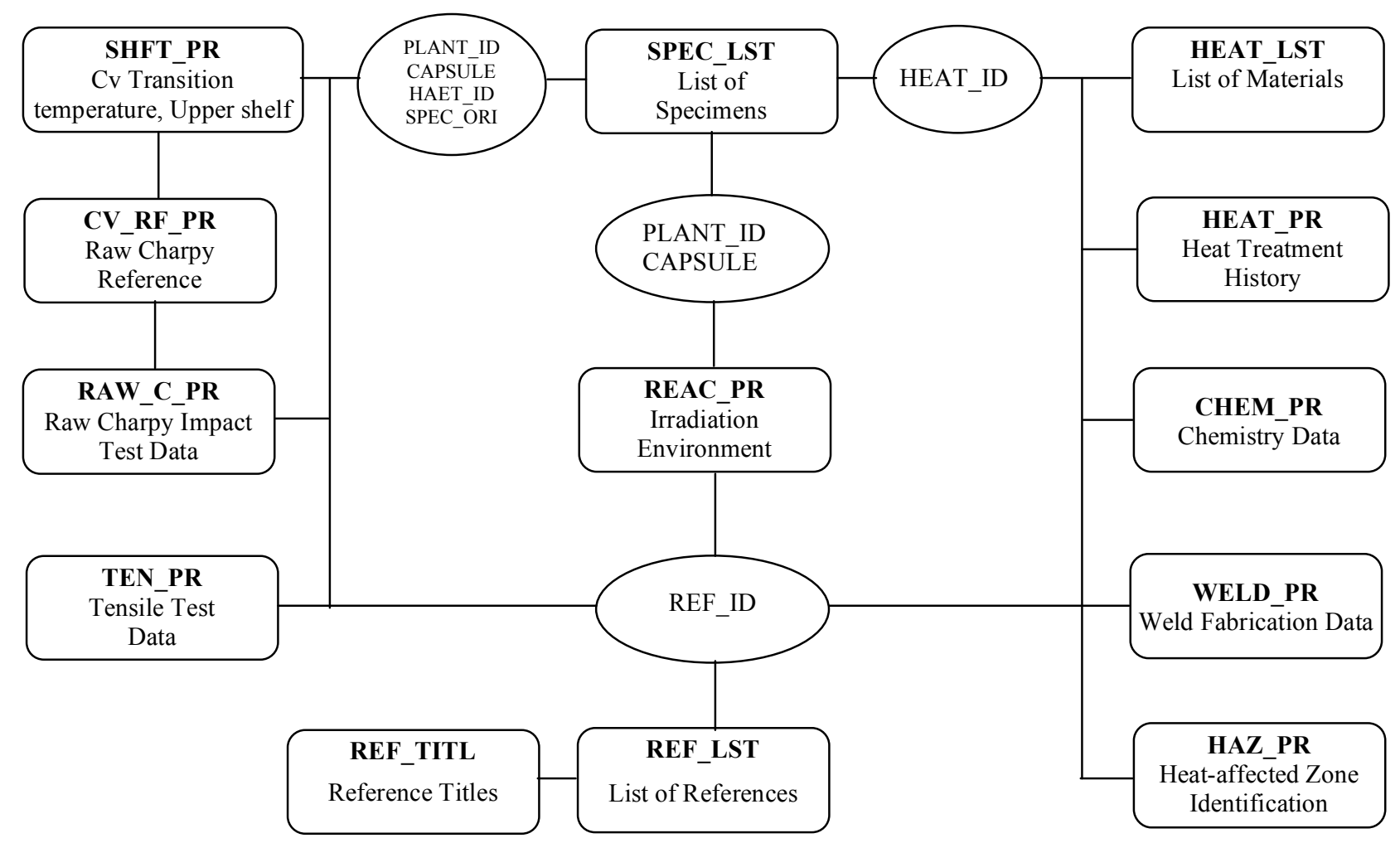

Figure 6: Architecture of PR-EDB.

\subsection{LIST OF EDB FILES}

\section{SPEC_LST.dbf}

SPEC_LST.dbf (Table 2) provides a complete list of all specimen sets of the test data contained in other PR-EDB files. A "set" is defined here as a group of test specimens that share the same combination of PLANT_ID, CAPSULE, HEAT_ID, and SPEC_ORI and are of the same specimen type, such as Charpy, tensile, etc. PLANT_ID + CAPSULE identify a particular experiment, and HEAT_ID + SPEC_ORI identifies a particular material. SPEC_TYPE indicates the type of specimen, and its size; for nonstandard specimens, specimen thickness can be added in front of specimen type. SPEC_POS indicates the layer(s) relative to the surface from which the specimens were cut. (This is $1 / 4 \mathrm{~T}$ in most cases; $1 / 4 \mathrm{~T}+3 / 4 \mathrm{~T}$ means that the set consists of a mixture of specimens cut from the 1/4T and 3/4T layers, and 1/4T - 3/4T means that the specimens are cut from the whole range between 1/4T and 3/4T.) If available the number of specimens in each set is listed. 
Table 2: Structure file for SPEC_LST.dbf Specimen Information

\begin{tabular}{clcl}
\hline Field & Field_Name & Width & Description \\
\hline 1 & TAG & 1 & Used for Internal Operation \\
2 & PLANT_ID & 6 & Reactor Identification \\
3 & CAPSULE & 6 & Surveillance or Experiment Capsule Identification \\
4 & HEAT_ID & 10 & Identification Code for Given Material \\
5 & SPEC_TYPE & 6 & Type of Specimen: S_tandard Charpy (CV), or M_initure CV, \\
& & & TEN_sile, \\
& & & 1T C_ompact T_ension, 1/2T WOL, etc., for Non-standard specimen, \\
& & & specimen thickness can be added in front of specimen type \\
6 & SPEC_ORI & 2 & Specimen Orientation: TL, LT, TS, etc. \\
7 & SPEC_POS & 10 & Specimen Position: 1/4T, 1/2T, 3/4T, etc. \\
8 & NO_OF_SPEC & 2 & Number of Specimens in Capsule or Experimental Set \\
9 & REPORT_TAG & 1 & Type of Reporting: R_aw data, A_verages, G_raphs, L_ine Drawings \\
10 & REF_ID & 20 & Reference Identifier \\
11 & PAGES & 20 & Page Number(s) \\
12 & NOTES & 30 & Pertinent Information Related to Data Entries, If Needed \\
\hline
\end{tabular}

\section{SHFT_PR.dbf}

SHFT_PR.dbf (Table 3) lists transition temperatures and upper-shelf energies as determined by the evaluator of the report. It lists $30 \mathrm{ft}-\mathrm{lb}, 50 \mathrm{ft}-\mathrm{lb}$, and 35-mil transition temperatures (irradiated and unirradiated) and shift (difference between the two) as shown in the report and similarly lists uppershelf energy with both absolute and relative shift values. Data describing irradiation as applied to the Charpy specimen set are also included. These data include fluences $(\mathrm{E}>1.0 \mathrm{MeV})$ and irradiation temperature at the location of the specimen, accounting for the differences within the capsule between different specimen sets. The transition temperature at $50 \%$ shear is not included since it is seldom reported and is difficult to determine reliably. It can also be readily reconstructed from the individual Charpy test data, whenever available. Also omitted are transition temperatures at other energy levels or lateral expansions such as $15 \mathrm{ft}-\mathrm{lb}$ or $3 \mathrm{kgm}$ (see Table 1 for units), which are sometimes listed in older reports. Shift values listed represent the actual differences between unirradiated and irradiated data; additional safety margins that are sometimes included in reports have been subtracted. Shift values are sometimes determined in separate graphs independent from the determination of unirradiated and irradiated test data and for this reason may be inconsistent with the latter. This is indicated in the notes. Fields added for temperature and energy units allow data in different units to be entered. 
Table 3: Structure file for SHFT_PR.dbf Charpy Transition Temperature and Upper-Shelf Energy

\begin{tabular}{clcl}
\hline Field & Field_Name & Width & Description \\
\hline 1 & TAG & 1 & Used for Internal Operation \\
2 & PLANT_ID & 6 & Reactor Identification \\
3 & CAPSULE & 6 & Surveillance or Experiment Capsule Identification \\
4 & HEAT_ID & 10 & Identification Code for Given Material \\
5 & PROD_ID & 3 & Material Type: P_late, F_orging, W_eld, HAZ, or S_tandard \\
& & & R_eference M_aterial (SRM) \\
6 & SPEC_ORI & 2 & Specimen Orientation: TL, LT, TS, etc. \\
7 & CSP_F1 & 10 & Fluence $>1$ MeV at Charpy Specimen Location (n/cm ${ }^{2}$ ) \\
8 & UTT30 & 5 & Charpy V-notch Transition Temperature (CVT) at 30 ft-lb, \\
& & & Unirradiated Charpy Specimen \\
8 & UTT50 & 5 & CVT at 50 ft-lb, Unirradiated Charpy Specimen \\
10 & ULE35 & 5 & CVT at Lateral Expansion = 35 mils, Unirradiated. Charpy Specimen. \\
11 & UUSE & 5 & Upper Shelf Energy, Unirradiated Charpy Specimen \\
12 & ITT30 & 5 & CVT at 30 ft-lb, Irradiated Charpy Specimen \\
13 & ITT50 & 5 & CVT at 50 ft-lb, Irradiated Charpy Specimen \\
14 & ILE35 & 5 & CVT at Lateral Expansion = 35 mils, Irradiated Charpy Specimen \\
15 & IUSE & 5 & Upper Shelf Energy, Irradiated Charpy Specimen \\
16 & DTT30 & 5 & CVT Shift at 30 ft-lb (ITT30 - UTT30) \\
17 & DTT50 & 5 & CVT Shift at 50 ft-lb (ITT50 - UTT50) \\
18 & DLE35 & 5 & CVT Shift at Lateral Expansion = 35 mils (ILE35 - ULE35) \\
19 & DUSE_ABS & 5 & Absolute Drop in Upper Shelf Energy (UUSE - IUSE) \\
20 & DUSE_REL & 5 & Percent Drop in Upper Shelf Energy \\
21 & TEMP_U & 1 & Unit used for Temperature Data \\
22 & USE_U & 5 & Unit used for Energy Data (in Upper Shelf Energy) \\
23 & REF_ID & 20 & Reference Identifier \\
24 & PAGES & 20 & Page Number(s) \\
25 & NOTES & 30 & Pertinent Information Related to Data Entries, If Needed \\
\hline & & &
\end{tabular}

\section{RAW_C_PR.dbf and CV_RF_PR.dbf}

RAW_C_PR.dbf (Table 4) gives a complete list of individual Charpy test results. In addition to the materials test results, the key identifiers link the raw data with the evaluations in SHFT_PR.dbf and related files. Fluence and irradiation temperature that may be different for each specimen are also included. Different sets in RAW_C_PR.dbf are contained in the associated file CV_RF_PR.dbf (Table 5). In addition to the key identifiers, CV_RF_PR.dbf includes the references for the raw Charpy data that are not included in RAW_C_PR.dbf to save space, since each specimen in the same set has the same reference. These combinations are also contained in the ASCII file RAW_C_PR.dat, used for the EDB fitting programs. 
Table 4. Structure file for RAW_C_PR.dbf Charpy Impact Test

\begin{tabular}{llll}
\hline Field & Field_Name & Width & Description \\
\hline 1 & TAG & 1 & Used for Internal Operation \\
2 & PLANT ID & 6 & Reactor Identification \\
3 & CAPSULE & 6 & Surveillance or Experiment Capsule Identification \\
4 & HEAT ID & 10 & Identification Code for Given Material \\
5 & PROD_ID & 3 & Material Type: P_late, F_orging, W_eld, HAZ, or S_tandard \\
& & & R_eference M_aterial (SRM) \\
6 & SPEC_ORI & 2 & Specimen Orientation: TL, LT, TS, etc. \\
7 & SPEC_ID & 8 & Specimen Identifier \\
8 & TST_TEMP & 4 & Test Temperature of Specimen \\
9 & TST_TEMP_U & 1 & Unit of Temperature used in TST_TEMP \\
10 & IMP_E & 6 & Impact Energy of Charpy Specimen \\
11 & IMP_E_U & 5 & Unit Associated with Impact Energy \\
12 & FRACT_APP & 3 & Fracture Appearance Value (\% shear) \\
13 & LAT_EXP & 4 & Lateral Expansion of Charpy Specimen \\
14 & LAT_EXP_U & 5 & Unit Associated with Lateral Expansion \\
15 & CSP_F1 & 10 & Fluence $>1$ MeV at Charpy Specimen Location $\left(\mathrm{n} / \mathrm{cm}^{2}\right)$ \\
16 & CSP_TEMP & 4 & Irradiation Temperature of Charpy Specimen \\
17 & CSP_TEMP_U & 1 & Unit of Temperature used in CSP TEMP \\
\hline
\end{tabular}

Table 5. Structure file for CV_RF_PR.dbf References for Charpy Data Sets

\begin{tabular}{clcl}
\hline Field & Field_Name & Width & Description \\
\hline 1 & TAG & 1 & Used for Internal Operation \\
2 & PLANT_ID & 6 & Reactor Identification \\
3 & CAPSULE & 6 & Surveillance or Experiment Capsule Identification \\
4 & HEAT_ID & 10 & Identification Code for Given Material \\
5 & PROD_ID & 3 & Material Type: P_late, F_orging, W_eld, HAZ, or SRM \\
6 & SPEC_ORI & 2 & Specimen Orientation: TL, LT, TS, etc. \\
7 & USE_U & 5 & Unit used for Energy Data (in Upper-Shelf Energy) \\
8 & REF_ID & 20 & Reference Identifier \\
9 & PAGES & 20 & Page Number(s) \\
10 & NOTES & 30 & Pertinent Information Related to Data Entries, If Needed \\
\hline
\end{tabular}

\section{TEN_PR.dbf}

TEN_PR.dbf (Table 6) lists the results of tensile tests with separate entries for each test. Averages from several experiments are included if no other information is available but are omitted if individual test data are given. Such cases are indicated in NOTES. Fluences and irradiation temperatures are included and may differ from specimen to specimen as in RAW_C_PR.dbf. Units from the original reports are used as specified in the unit fields. 
Table 6. Structure file for TEN_PR.dbf Tensile Test

\begin{tabular}{clcl}
\hline Field & Field_Name & Width & Description \\
\hline 1 & TAG & 1 & Used for Internal Operation \\
2 & PLANT_ID & 6 & Reactor Identification \\
3 & CAPSULE & 6 & Surveillance or Experiment Capsule Identification \\
4 & HEAT_ID & 10 & Identification Code for Given Material \\
5 & PROD_ID & 3 & Material Type: P_late, F_orging, W_eld, HAZ, or SRM \\
6 & SPEC_ORI & 2 & Specimen Orientation: TL, LT, TS, etc. \\
7 & TSP_F1 & 10 & Fluence $>1$ MeV at Tensile Specimen Location $\left(\mathrm{n} / \mathrm{cm}^{2}\right)$ \\
8 & TSP_TEMP & 4 & Irradiation Temperature of Tensile Specimen \\
9 & TSP_TEMP_U & 1 & Unit Associated with Temperature \\
10 & SPEC_ID & 8 & Specimen Identifier \\
11 & TST_TEMP & 4 & Test Temperature of Specimen \\
12 & TST_TEMP_U & 1 & Unit Associated with Temperature \\
13 & YLS & 5 & Material Yield Stress \\
14 & UTS & 5 & Ultimate Tensile Strength (UTS) \\
15 & ULG & 4 & Uniform Elongation of Tensile Specimen $(\%)$ \\
16 & TLG & 4 & Total Elongation of Tensile Specimen $(\%)$ \\
17 & RA & 4 & Reduction in Area of Tensile Specimen $(\%)$ \\
18 & REF_ID & 20 & Reference Identifier \\
19 & PAGES & 20 & Page Number(s) \\
20 & NOTES & 30 & Pertinent Information Related to Data Entries, If Needed \\
\hline
\end{tabular}

\section{REAC PR.dbf}

REAC_PR.dbf (Table 7) lists fluences for $\mathrm{E}>1.0 \mathrm{MeV}, \mathrm{E}>0.1 \mathrm{MeV}$, and dpa with uncertainties, as well as fluence rates at full power, full-power-equivalent irradiation times, and startup and removal dates of the surveillance capsules. In some cases, the capsules had been moved from one reactor to another or had been irradiated more than once and annealed in between. The different irradiations are listed in separate records with the same CAPSULE identification; the sequence of irradiations is indicated in the CONFIG field. Irradiation temperatures within the capsule are reported either as maxima and minima or as a nominal (target) value, sometimes with a temperature range. Included in the temperature data is a TEMP_TAG that indicates how the irradiation temperature was determined. Many uncertainties about capsule temperatures exist for commercial power reactors. Because these values are difficult to determine and there are some questions concerning the reported data, the Electric Power Research Institute (EPRI) has assigned seven categories that characterize the reported data and their suggested use. Category numbers are listed in the TEMP_TAG field and denote the following:

\begin{tabular}{c} 
Category \\
\hline 1 \\
2 \\
3 \\
4 \\
5 \\
6 \\
7
\end{tabular}

\section{Description}

Temperatures reflect the best-known capsule environment during irradiation Temperatures reflect the normal cycle operating range, applicable to the capsule during irradiation

Maximum temperature can be considered nominal capsule temperature

Minimum temperature can be considered nominal capsule temperature

Maximum temperature is not known or not reported

Minimum temperature is not known or not reported

No temperatures reported (listed temperatures, if any, are assumed on the basis of operating temperature or other capsules of the same reactor) 
Table 7. Structure file for REAC_PR.dbf Irradiation Environment

\begin{tabular}{clcl}
\hline Field Field_Name & Width Description \\
\hline 1 & TAG & 1 & Used for Internal Operation \\
2 & PLANT_ID & 6 & Reactor Identification \\
3 & CAPSULE & 6 & Surveillance or Experiment Capsule Identification \\
4 & START_DATE & 10 & Date at Start of Irradiation (MM/DD/YYYY) \\
5 & STOP_DATE & 10 & Date at End of Irradiation (MM/DD/YYYY) \\
6 & CONFIG & 6 & Indicator for Change in Irradiation Environment \\
7 & EFP_TIME & 10 & Effective Full-Power Time of Irradiation \\
8 & TIME_U & 1 & Unit of Time: S_econds, M_inutes, H_ours, D_ays, and Y_ears \\
9 & CAP_T_MIN & 4 & Minimum Irradiation Temperature at Capsule Center \\
10 & CAP_T_MAX & 4 & Maximum Irradiation Temperature at Capsule Center \\
11 & CAP_T_NOM & 4 & Nominal Irradiation Temperature for Capsule \\
12 & TEMP_RANGE & 4 & Temperature Variations within the Capsule \\
13 & TEMP_U & 1 & Unit used for Temperature Data \\
14 & TEMP_TAG & 1 & Irradiation Temperature Determination: C_alculated, T_hermocouples, \\
& & & M_elt wires; or Category 1 - 7 \\
15 & CAP_F1 & 10 & Fluence E $>1$ MeV at Capsule Center (n/cm $\left.{ }^{2}\right)$ \\
16 & F1_UNC & 3 & Uncertainty of Fluence E $>1.0$ MeV (Percentage of Standard \\
& & & Deviation) \\
17 & F1_RATE & 10 & Fluence Rate E $>1$ MeV at Capsule Center [n/(cm $\left.\left.{ }^{2} \cdot s\right)\right]$ \\
18 & CAP_FP1 & 10 & Fluence E $>0.1$ MeV at Capsule Center (n/cm $\left.{ }^{2}\right)$ \\
19 & CAP_DPA & 10 & Dpa of Iron at Capsule Center \\
20 & DPA_UNC & 3 & Uncertainty of Dpa $($ Percentage of Standard Deviation) \\
21 & REF_ID & 20 & Reference Identifier \\
22 & PAGES & 20 & Page Number(s) \\
23 & NOTES & 30 & Pertinent Information Related to Data Entries, If Needed \\
\hline & & &
\end{tabular}

\section{REAC_LST.dbf}

For each reactor code given in PLANT_ID, REAC_LST.dbf (Table 8) lists the full name of the reactor, utility, vendor, pressure vessel manufacturer, and the architect/engineer of the plant. No references are included since these data come from many different sources and are easily verifiable.

Table 8. Structure file for REAC_LST.dbf Reactor Identification

\begin{tabular}{clcl}
\hline Field & Field_Name & Width & Description \\
\hline 1 & TAG & 1 & Used for Internal Operation \\
2 & PLANT_ID & 6 & Reactor Identification \\
3 & REAC_TYPE & 5 & $\begin{array}{l}\text { Reactor Type: Pressurized-Water Reactor (PWR), Boiling Water } \\
\text { Reactor (BWR) }\end{array}$ \\
4 & REAC_NAME & 50 & Reactor Name \\
5 & LOCATION & 30 & Reactor Location \\
6 & PLANT_OP & 50 & Reactor Operator or Utility \\
7 & PLANT_DES & 25 & Reactor Designer or Vendor \\
8 & ARCH_ENG & 50 & Reactor Architect/Engineer \\
9 & VESSEL_MFG & 50 & Reactor Vessel Manufacturer \\
\hline
\end{tabular}




\section{HEAT LST.dbf}

HEAT_LST.dbf (Table 9) relates the material codes given in HEAT_ID to the descriptions and heat numbers given in the reports and the MPC database. It also includes the ASTM (or foreign standard) material classification, the supplier of the material, and the thickness. The SOURCE field gives specific information about the origin of the material (if available). SCR_ap indicates that the material was obtained from excess material during fabrication of a pressure vessel (this applies also to welds); CUTOUT, nozzle cutouts; SIM_ulated weld, if the material was not obtained from an actual weld seam but fabricated from excess plate material using the same filler and flux; and FABR_icated, the material was fabricated exclusively for irradiation experiments.

Table 9. Structure file for HEAT_LST.dbf List of Heat Identification

\begin{tabular}{clcl}
\hline Field & Field_Name & Width & Description \\
\hline 1 & TAG & 1 & Used for Internal Operation \\
2 & PLANT_ID & 6 & Reactor Identification \\
3 & HEAT_ID & 10 & Identification Code for Given Material \\
4 & RPT_ID & 20 & Identifier Used in Surveillance Reports \\
5 & HEAT_NO & 10 & Heat Number of Material Used by Supplier \\
6 & PROD_ID & 3 & Material Type: P_late, F_orging, W_eld, HAZ, or SRM \\
7 & MAT_ID & 10 & Material Classification: A302B, A5082, A533B1, etc. \\
8 & SUPPLIER & 20 & Supplier of Material \\
9 & THICKNESS & 10 & Thickness of Given Material \\
10 & LENGTH_U & 3 & Unit of Thickness \\
11 & SOURCE & 10 & Source of Material: FABR_icated, SCR_ap, SIM_ulated Weld, or \\
& & & CUTOUT \\
12 & REF_ID & 20 & Reference Identifier \\
13 & PAGES & 20 & Page Number(s) \\
14 & NOTES & 30 & Pertinent Information Related to Data Entries, If Needed \\
\hline
\end{tabular}

\section{CHEM_PR.dbf}

CHEM_PR.dbf (Table 10) lists the chemical compositions for the given materials together with information about the laboratory and method used, if reported, and whether it is derived from test specimens or represents generic values given by the supplier of the material. Generic values are identified in SPEC_ID as LADLE, CHECK, or HEAT, depending on what is revealed in the reports. The term WIRE is used if the chemical composition of the filler wire, rather than that of the actual weld material, has been reported. Other terms listed in SPEC_ID are identifiers of the test specimen, the chemical composition of which was determined. All different chemical composition determinations for the same material are listed as reported, but duplications are omitted.

\section{HEAT_PR.dbf}

HEAT_PR.dbf (Table 11) lists up to eight different steps of heat treatment with temperature ranges, duration, quench method, and an indication of whether the particular step was intended for normalizing, austenizing, tempering, or stress relief, as far as reported. The supplier of the material and the facility performing the heat treatment, plus the identification used for the ingot (HEAT_NO) and the code used for the finished material (SUPPL_ID), are also included. Field NOMTEMP_x is the nominal temperature of the treatment step, if no MAXTEMP_x and MINTEMP_ $\mathrm{x}$ is reported. RANGE, if reported, indicates the deviation from the nominal temperature (in both directions if \pm is attached). 
Table 10. Structure file for CHEM_PR.dbf Chemical Composition

\begin{tabular}{|c|c|c|c|}
\hline Field & Field_Name & Width & Description \\
\hline 1 & TAG & 1 & Used for Internal Operation \\
\hline 2 & PLANT_ID & 6 & Reactor Identification \\
\hline 3 & HEAT_ID & 10 & Identification Code for Given Material \\
\hline 4 & PROD_ID & 3 & Material Type: P_late, F_orging, W_eld, HAZ, or SRM \\
\hline 5 & MAT_ID & 10 & Material Classification: $\overline{\mathrm{A}} 302 \mathrm{~B}, \mathrm{~A} 50 \mathrm{0} 2 \mathrm{2}, \mathrm{A} 533 \mathrm{~B} 1$, etc. \\
\hline 6 & CHEM_LAB & 15 & Chemistry Laboratory or Procedure Identification \\
\hline 7 & METHOD & 30 & Method for Determining the Chemistry \\
\hline 8 & SPEC_ID & 8 & Specimen Identifier \\
\hline 9 & $\mathrm{C}$ & 5 & Carbon \\
\hline 10 & $\mathrm{MN}$ & 5 & Manganese Content (wt \%) \\
\hline 11 & $\mathrm{P}$ & 5 & Phosphorus Content (wt \%) \\
\hline 12 & S & 5 & Sulfur Content (wt \%) \\
\hline 13 & SI & 5 & Silicon Content (wt \%) \\
\hline 14 & NI & 5 & Nickel Content (wt \%) \\
\hline 15 & $\mathrm{CR}$ & 5 & Chromium Content (wt \%) \\
\hline 16 & MO & 5 & Molybdenum Content (wt \%) \\
\hline 17 & $\mathrm{CU}$ & 5 & Copper Content (wt \%) \\
\hline 18 & $\mathrm{~V}$ & 5 & Vanadium Content (wt \%) \\
\hline 19 & $\mathrm{~B}$ & 5 & Boron Content (wt \%) \\
\hline 20 & $\mathrm{CS}$ & 5 & Cesium Content (wt \%) \\
\hline 21 & $\mathrm{TI}$ & 5 & Titanium Content (wt \%) \\
\hline 22 & $\mathrm{CO}$ & 5 & Cobalt Content (wt \%) \\
\hline 23 & $\mathrm{~N}$ & 5 & Nitrogen Content (wt \%) \\
\hline 24 & $\mathrm{O}$ & 5 & Oxygen Content (wt \%) \\
\hline 25 & SB & 5 & Antimony Content (wt \%) \\
\hline 26 & AS & 5 & Arsenic Content (wt \%) \\
\hline 27 & ZR & 5 & Zirconium Content (wt \%) \\
\hline 28 & $\mathrm{AL}$ & 5 & Aluminum Content (wt \%) \\
\hline 29 & PB & 5 & Lead Content (wt \%) \\
\hline 30 & $\mathrm{~W}$ & 5 & Tungsten Content (wt \%) \\
\hline 31 & $\mathrm{SN}$ & 5 & Tin Content (wt \%) \\
\hline 32 & $\mathrm{ZN}$ & 5 & Zinc Content (wt \%) \\
\hline 33 & TA & 5 & Tantalum Content (wt \%) \\
\hline 34 & $\mathrm{H}$ & 5 & Hydrogen Content (wt \%) \\
\hline 35 & NB & 5 & Niobium Content (wt \%) \\
\hline 36 & REF_ID & 20 & Reference Identifier \\
\hline 37 & PAGES & 20 & Page Number(s) \\
\hline 38 & NOTES & 30 & Pertinent Information Related to Data Entries, If Needed \\
\hline
\end{tabular}


Table 11. Structure file for HEAT_PR.dbf Heat Treatment Information

\begin{tabular}{|c|c|c|c|}
\hline Field & FIeld_Name & Width & Description \\
\hline 1 & TAG & 1 & Used for Internal Operation \\
\hline 2 & PLANT_ID & 6 & Reactor Identification \\
\hline 3 & HEAT_ID & 10 & Identification Code for Given Material \\
\hline 4 & PROD_ID & 3 & Material Type: P_late, F_orging, W_eld, HAZ, or SRM \\
\hline 5 & SUPPLIER & 15 & Supplier of Material \\
\hline 6 & HEAT_TREAT & 15 & Facility Performing Heat Treatment \\
\hline 7 & HEAT_NO & 10 & Heat Number of Material Used by Supplier \\
\hline 8 & SUPPL_ID & 10 & Identifier Used by Supplier \\
\hline 9 & MINTEMP_1 & 4 & Heat Treatment Minimum Temperature, Run 1 \\
\hline 10 & MAXTEMP_1 & 4 & Heat Treatment Maximum Temperature, Run 1 \\
\hline 11 & NOMTEMP_1 & 4 & Nominal Temperature, Run 1 \\
\hline 12 & RANGE_1 & 3 & Heat Treatment Temperature Range, Run 1 \\
\hline 13 & HOURS_1 & 6 & Heat Treatment Duration, Run 1 (h) \\
\hline 14 & QCHM_1 & 2 & Quench Method, Run 1 \\
\hline 15 & ID_1 & 1 & N_ormalizing, A_ustenizing, T_empering, and Stress R_elief, Run 1 \\
\hline 16 & MINTEMP_2 & 4 & Heat Treatment Minimum Temperature, Run 2 \\
\hline 17 & MAXTEMP_2 & 4 & Heat Treatment Maximum Temperature, Run 2 \\
\hline 18 & NOMTEMP_2 & 4 & Nominal Temperature, Run 2 \\
\hline 19 & RANGE_2 & 3 & Heat Treatment Temperature Range, Run 2 \\
\hline 20 & HOURS_2 & 6 & Heat Treatment Duration, Run 2 (h) \\
\hline 21 & QCHM_z & 2 & Quench Method, Run 2 \\
\hline 22 & ID_2 & 1 & N_ormalizing, A_ustenizing, T_empering, and Stress R_elief, Run 2 \\
\hline 23 & MINTEMP_3 & 4 & Heat Treatment Minimum Temperature, Run 3 \\
\hline 24 & MAXTEMP_3 & 4 & Heat Treatment Maximum Temperature, Run 3 \\
\hline 25 & NOMTEMP_3 & 4 & Nominal Temperature, Run 3 \\
\hline 26 & RANGE_3 & 3 & Heat Treatment Temperature Range, Run 3 \\
\hline 27 & HOURS_3 & 6 & Heat Treatment Duration, Run 3 (h) \\
\hline 28 & QCHM_ 3 & 2 & Quench Method, Run 3 \\
\hline 29 & ID_3 & 1 & N_ormalizing, A_ustenizing, T_empering, and Stress R_elief, Run 3 \\
\hline 30 & MINTEMP_4 & 4 & Heat Treatment Minimum Temperature, Run 4 \\
\hline 31 & MAXTEMP__ 4 & 4 & Heat Treatment Maximum Temperature, Run 4 \\
\hline 32 & NOMTEMP_4 & 4 & Nominal Temperature, Run 4 \\
\hline 33 & RANGE_4 & 3 & Heat Treatment Temperature Range, Run 4 \\
\hline 34 & HOURS_4 & 6 & Heat Treatment Duration, Run 4 (h) \\
\hline 35 & QCHM_- 4 & 2 & Quench Method, Run 4 \\
\hline 36 & ID_4 & 1 & N_ormalizing, A_ustenizing, T_empering, and Stress R_elief, Run 4 \\
\hline 37 & MINTTEMP_5 & 4 & Heat Treatment Minimum Temperature, Run 5 \\
\hline 38 & MAXTEMP_ 5 & 4 & Heat Treatment Maximum Temperature, Run 5 \\
\hline 39 & NOMTEMP_5 & 4 & Nominal Temperature, Run 5 \\
\hline 40 & RANGE_5 & 3 & Heat Treatment Temperature Range, Run 5 \\
\hline 41 & HOURS_5 & 6 & Heat Treatment Duration, Run 5 (h) \\
\hline
\end{tabular}


Table 11 (continued)

\begin{tabular}{clcl}
\hline Field & FIeld_Name & Width & Description \\
\hline 42 & QCHM_5 & 2 & Quench Method, Run 5 \\
43 & ID_5 & 1 & N_ormalizing, A_ustenizing, T_empering, and Stress R_elief, Run 5 \\
44 & MINTEMP_6 & 4 & Heat Treatment Minimum Temperature, Run 6 \\
45 & MAXTEMP_6 & 4 & Heat Treatment Maximum Temperature, Run 6 \\
46 & NOMTEMP_6 & 4 & Nominal Temperature, Run 6 \\
47 & RANGE_6 & 3 & Heat Treatment Temperature Range, Run 6 \\
48 & HOURS_6 & 6 & Heat Treatment Duration, Run 6 (h) \\
49 & QCHM_6 & 2 & Quench Method, Run 6 \\
50 & ID_6 & 1 & N_ormalizing, A_ustenizing, T_empering, and Stress R_elief, Run 6 \\
51 & MINTEMP_7 & 4 & Heat Treatment Minimum Temperature, Run 7 \\
52 & MAXTEMP_7 & 4 & Heat Treatment Maximum Temperature, Run 7 \\
53 & NOMTEMP_7 & 4 & Nominal Temperature, Run 7 \\
54 & RANGE_7 & 3 & Heat Treatment Temperature Range, Run 7 \\
55 & HOURS_7 & 6 & Heat Treatment Duration, Run 7 (h) \\
56 & QCHM_7 & 2 & Quench Method, Run 7 \\
57 & ID_7 & 1 & N_ormalizing, A_ustenizing, T_empering, and Stress R_elief, Run 7 \\
58 & MINTEMP_8 & 4 & Heat Treatment Minimum Temperature, Run 8 \\
59 & MAXTEMP_8 & 4 & Heat Treatment Maximum Temperature, Run 8 \\
60 & NOMTEMP_8 & 4 & Nominal Temperature, Run 8 \\
61 & NOMTEMP_1 & 4 & Nominal Temperature, Run 1 \\
62 & RANGE_8 & 3 & Heat Treatment Temperature Range, Run 8 \\
63 & HOURS_8 & 6 & Heat Treatment Duration, Run 8 (h) \\
64 & QCHM_8 & 2 & Quench Method, Run 8 \\
65 & ID_8 & 1 & N_ormalizing, A_ustenizing, T_empering, and Stress R_elief, Run 8 \\
66 & TEMP_U & 1 & Unit used for Temperature Data \\
67 & REF_ID & 20 & Reference Identifier \\
68 & PAGES & 20 & Page Number(s) \\
69 & NOTES & 30 & Pertinent Information Related to Data Entries, If Needed \\
\hline & & &
\end{tabular}




\section{WELD_PR.dbf}

WELD_PR.dbf (Table 12) gives additional information for weldments such as weld method, type and heat number of the filler material, and type and lot number of the flux used. The weld code and the supplier of the weld are also listed.

Table 12. Structure file for WELD_PR.dbf Weldment Information

\begin{tabular}{clcl}
\hline Field & Field_Name & Width & Description \\
\hline 1 & TAG & 1 & Used for Internal Operation \\
2 & PLANT_ID & 6 & Reactor Identification \\
3 & HEAT_ID & 10 & Identification Code for Given Material \\
4 & WLD_TYPE & 3 & Weld Type \\
5 & WLD_CODE & 10 & Identification Code used by Weld Manufacturer \\
6 & HEAT_1 & 10 & HEAT_ID of Plate on one side of Weld \\
7 & HEAT_2 & 10 & HEAT_ID of Plate on other side of Weld \\
8 & WELD_SUPLY & 15 & Supplier of Weld Material \\
9 & WIRE_TYPE & 10 & Type of Weld Wire \\
10 & WIRE_HEAT & 10 & Weld Wire Heat Identifier \\
11 & FLUX_TYPE & 10 & Type of Flux \\
12 & FLUX_LOT & 10 & Weld Flux Lot Identifier \\
13 & REF_ID & 20 & Reference Identifier \\
14 & PAGES & 20 & Page Number(s) \\
15 & NOTES & 30 & Pertinent Information Related to Data Entries, If Needed \\
\hline
\end{tabular}

\section{HAZ_PR.dbf}

HAZ_PR.dbf (Table 13) identifies the base material and weldments used to prepare the HAZ specimens.

Table 13. Structure file for HAZ_PR.dbf Identification of Heat-Affected-Zone Materials

\begin{tabular}{clcl}
\hline Field & Field_Name & Width & Description \\
\hline 1 & TAG & 1 & Used for Internal Operation \\
2 & PLANT_ID & 6 & Reactor Identification \\
3 & HEAT_ID & 10 & Identification Code for Given Material \\
4 & HEAT_B & 10 & HEAT_ID of the Base Material \\
5 & HEAT_W & 10 & HEAT_ID of Weld Material Connected to HAZ \\
6 & REF_ID & 20 & Reference Identifier \\
7 & PAGES & 20 & Page Number(s) \\
8 & NOTES & 30 & Pertinent Information Related to Data Entries, If Needed \\
\hline
\end{tabular}

\section{REF_TITL.dbf}

All PR-EDB files, with the exception of RAW_C_PR.dbf and REAC_LST.dbf, contain a reference in the REF_ID field, plus page numbers for each record. The complete bibliographic listing, including author, title, report number, and date of publication, is located in REF_TITL.dbf (Table 14). Each listing may extend to more than one record because of the limited length the title field REF_TITLE may occupy in the current version of dBASE. A set of linked records is characterized by the same REF_ID and a sequence of numbers in the CONT field $(1,2$, etc.). The list of authors and experiments described in the reference may also extend to more than one record. 
Table 14. Structure file for REF_TITL.dbf Reference Information

\begin{tabular}{clcl}
\hline Field & Field_Name & Width & Description \\
\hline 1 & TAG & 1 & Used for Internal Operation \\
2 & REF_ID & 20 & Reference Identifier \\
3 & CONT & 2 & Continuation Tag for References Occupying More than One Record \\
4 & REF_TITLE & 80 & Bibliographic Reference \\
\hline
\end{tabular}

\section{REF_LST.dbf}

The file REF_LST.dbf (Table 15) lists all references used in the PR-EDB arranged according to the reactors for which the reports were written. The references are given as REF_ID; detailed information can be found in the file REF_TITL.dbf. The first few references describe the A302B ASTM and the A533B1 HSST-1 and HSST-02 standard reference materials, respectively.

Table 15. Structure file for REF_LST.dbf Reference List

\begin{tabular}{clcl}
\hline Field & Field_Name & Width & Description \\
\hline 1 & TAG & 1 & Used for Internal Operation \\
2 & PLANT_ID & 6 & Reactor Identification \\
3 & REF_ID & 20 & Reference Identifier \\
\hline
\end{tabular}





\section{REFERENCES}

1. G. R. Odette, P. M. Lombrozo, and R. A. Wullaert, "Relationship Between Irradiation Hardening and Embrittlement of Pressure Vessel Steels," pp. 840-860 in Effects of Radiation on Materials, Twelfth International Symposium, ASTM STP 870, eds. Garner, F. A. and Perrin, J. S., American Society for Testing and Materials, Philadelphia, 1985.

2. G. E. Lucas, et al., "Effects of Composition, Microstructure, and Temperature on Irradiation Hardening of Pressure Vessel Steels," pp. 900-930 in Effects of Radiation on Materials, Twelfth International Symposium, ASTM STP 870, eds. Garner, F. A. and Perrin, J. S., American Society for Testing and Materials, Philadelphia, 1985.

3. V. N. Shah, et al., "Residual Life Assessment of Light Water Reactor Pressure Vessels," Effects of Radiation on Materials, ASTM STP 1011, American Society for Testing and Materials, Philadelphia, 1989, pp. 161-175.

4. F. W. Stallmann, et al., PR-EDB: Power Reactor Embrittlement Database, Version 2, NUREG/CR4816, U.S. Nuclear Regulatory Commission, 1994.

5. M. Prager, Final Report Evaluation, Analysis and Transfer of Materials Property Data, The Materials Properties Council, Inc., New York, New York, 1985.

6. H. Wiedersich, "Effects of the Primary Recoil Spectrum on Long-Range Migration of Defects," Radiation Effects and Defects in Solids, 113 (1990) pp. 97-107.

7. C. A. English, "Recoil Effects in Radiation Damage," Radiation Effects and Defects in Solids, 113 (1990) pp. 15-28.

8. L. E. Rehn, P. R.Okamoto, and R. S. Averback, "Relative Efficiencies of Different Ions for Producing Freely Migrating Defects,” Physical Review B 30 (1984) p. 3073.

9. L. K. Mansur, and K. Farrell, "On Mechanisms By Which a Soft Neutron May Induce Accelerated Embrittlement," J. Nuclear Material 170 (1990) pp. 236-245.

10. H. L. Heinsich, "Correlation of Mechanical Property Changes in Neutron Irradiated Pressure Vessel Steels on The Basis of Spectral Effects," Fusion Reactor Quarterly Progress Report, DOE/ERD0313/6, 1990.

11. R. E. Stoller, and L. R. Greenwood, "An Evaluation of Neutron Energy Spectrum Effects in Iron Based on Molecular Dynamics Displacement Cascade Simulations," ASTM 1366, pp. 548-559, American Society for Testing and Materials, 2000.

12. R. E. Stoller and G. R. Odette, "Recommendations on Damage Exposure Units for Ferritic Steel Embrittlement Correlations," J. Nucl. Mater. 186, (1992) pp. 203-205. 



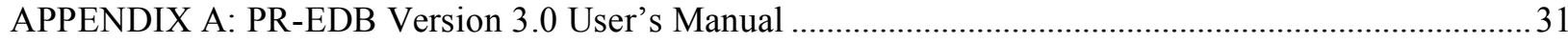

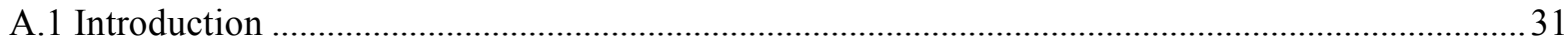

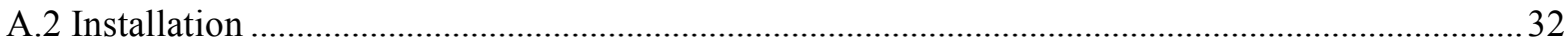

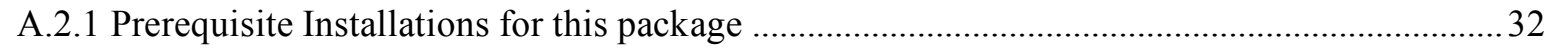

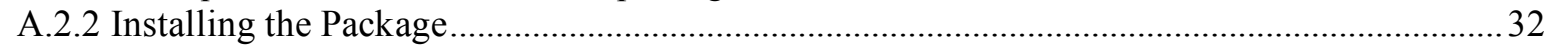

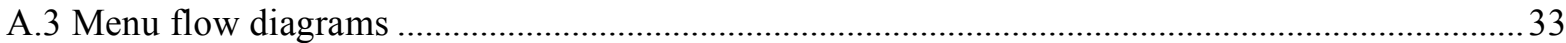

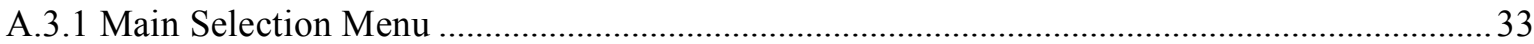

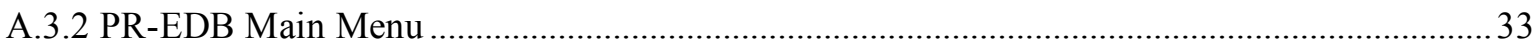

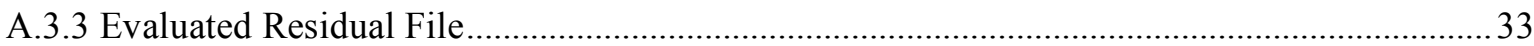

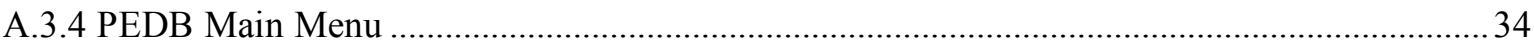

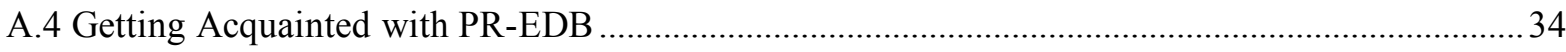

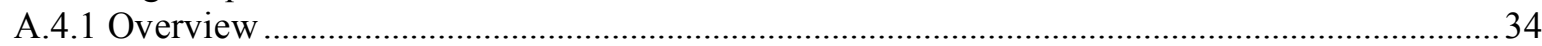

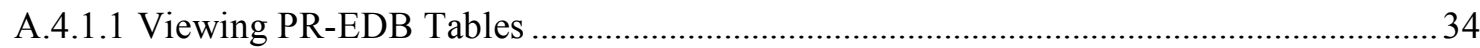

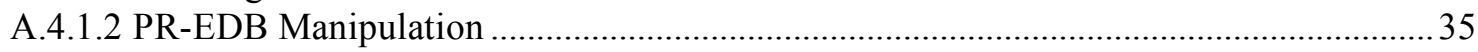

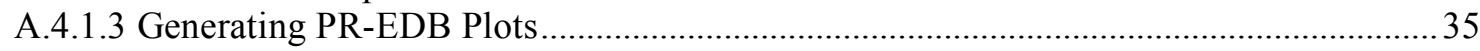

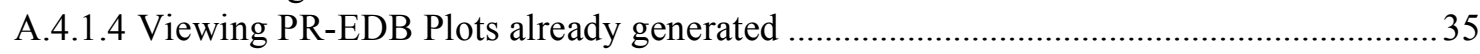

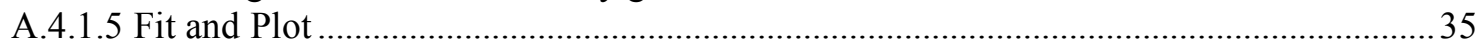

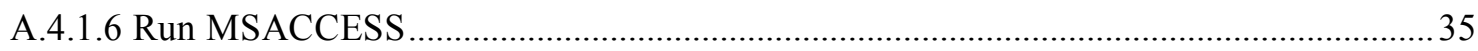

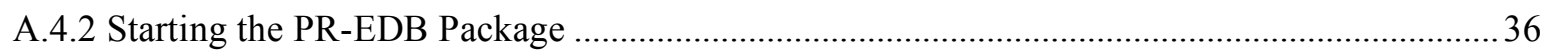

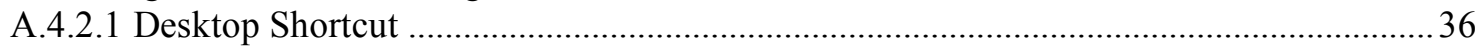

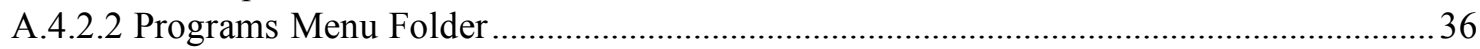

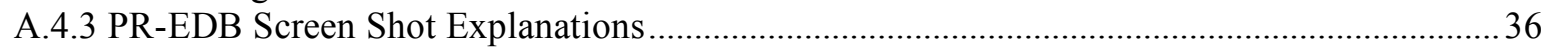

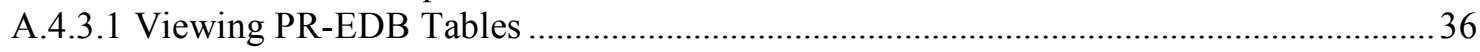

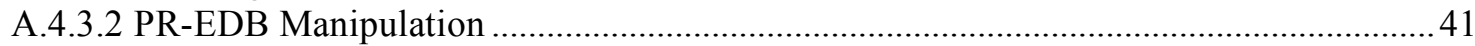

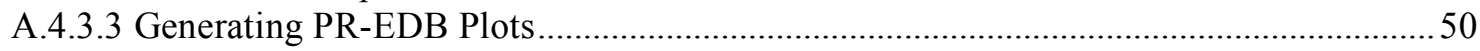

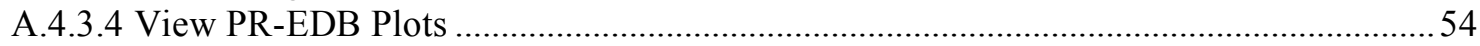

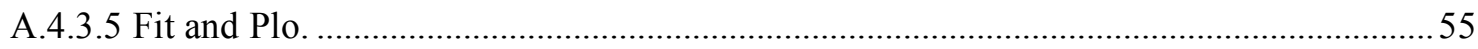

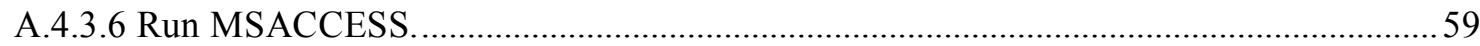

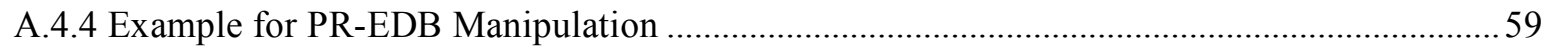

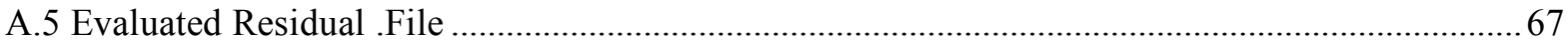

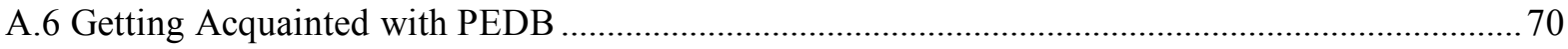

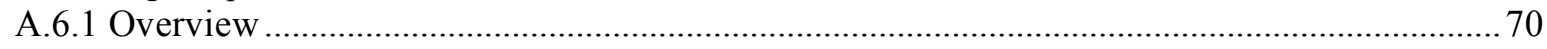

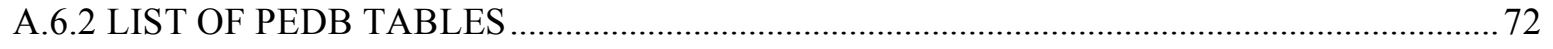

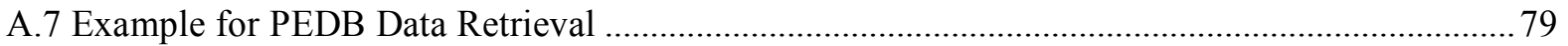

APPENDIX B Publication Lists

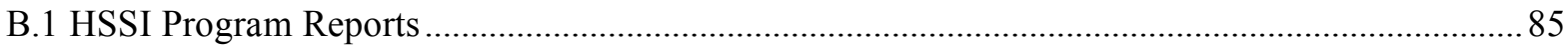

B.2 Reports Related to Irradiation Effects in Pressure Vessel Materials Used in the HSSI and HSST Programs. 



\section{APPENDIX A: PR-EDB VERSION 3.0 USER'S MANUAL A.1 INTRODUCTION}

This document is a User's manual for the PR-EDB Version 3.0 (Beta), Evaluated Residual File (Beta), and the PEDB Version 1.0 (Demo), containing the Software Package Tour which include explanation about the package features, screen shot explanations and examples.

The Current Version of PR-EDB is an Upgrade to the Version 2.0 and the PEDB is a demonstration version released for evaluation purposes. They have been developed using the .NET framework and use Microsoft Access (2000 or higher) for backend data storage, Microsoft Excel (2000 or higher) for plotting of graphs.

This Software Package is Windows (98 or higher) compatible and has been built with a highly versatile User Interface. PR-EDB Version 3.0 provides the user with tools to process the Raw Embrittlement data and create a variety of tables, view them over a spread sheet like grid, generate fits and graphs for reports and verification of irradiation embrittlement predictions.

Evaluated Residual File is a utility that can be used to streamline the PR-EDB raw data files to produce one to one relationship data for the specific key identifiers. For examples, in this beta version, the processed data files for shft_pr.dbf, reac_pr.dbf, and chem._pr.dbf files were generated. These three processed data files can be used directly by the researchers to investigate the associated issues related to the radiation embrittlement of reactor pressure vessel steels.

PEDB Version 1.0 provides a demonstration of how processed EDB data from different tables can be combined to form a User defined composite file. The PEDB combination of data from different tables is based on the underlying concept of Relational Databases. PEDB is far from complete and is only an evaluation version and on approval it could be merged with the Manipulation module to provide the user with ability to generate User specific data and further manipulating them to narrow down to generate processed data suiting his needs.

The program package provides the means for a number of file-manipulation tasks, including the display of data on the screen over a grid form and printing a hardcopy of the data on a printer. The package uses Microsoft excel for plotting and interoperates between the underlying Microsoft Access data storage and Excel to transfer data from the storage into useful graphs which aide in data analysis. This method has made void the need for generating ASCII files of the data needed earlier for plotting.

But Version 3.0 has the fitting modules that have not been altered and is another set of task that needs to be done in the future to make the package completely User friendly. In the current version data is being converted to ASCII file only for use with the fitting module. More specifically only the table RAW_C_PR can be converted into ASCII file and would be saved as RAW_C_PR.dat which can be used by the fitting procedures to generate fits and graphs. RAW_C_PR has not been generated by default and is available in table format from which the user can generate the dat file. 


\section{A.2 INSTALLATION}

Users who have read the readme.doc from the root of the installation CD and have followed the instructions can avoid reading this section. For others who have not yet read the readme.doc found below are the step by step instructions to install the PR-EDB Version 3.0(Beta) \& PEDB Version 1.0 (Demo) package.

\section{A.2.1 PREREQUiSITE INSTALLATIONS FOR THIS PACKAGE}

This package needs Microsoft Data Access Components (MDAC 2.8 or higher) and Microsoft Office 2000 or higher to be pre-installed for proper startup and functioning.

1. Install Microsoft Data Access Components 2.8 or higher ( MDAC 2.8 has been shipped along with this package $\&$ can be found at the root of the installation $C D$ )

Or as an alternative

Install MDAC 2.8 from the Microsoft Website

http://www.microsoft.com/downloads/details.aspx?FamilyID=6c050fe3-c795-4b7d-b037$\underline{185 \mathrm{~d} 0506396 \mathrm{c} \& \text { displaylang=en }}$

2. Install Microsoft Office 2000 or higher

\section{A.2.2 Installing the Package}

Insert the Installation CD labeled PREBD

Autorun starts Setup.exe. If Autorun is disabled, run Setup.exe from the root of the installation $\mathrm{CD}$.

The Installation would first check to see if the .NET framework has been installed on the computer, if so would continue with installation of the PR-EDB Version 3.0 (Beta) Package, else would first install the .NET framework which has been packaged along with the installation and then proceed to install the PR-EDB Version 3.0 (Beta) Package. 


\section{A.3 MENU FLOW DIAGRAMS}

\section{A.3.1 Main Selection Menu}

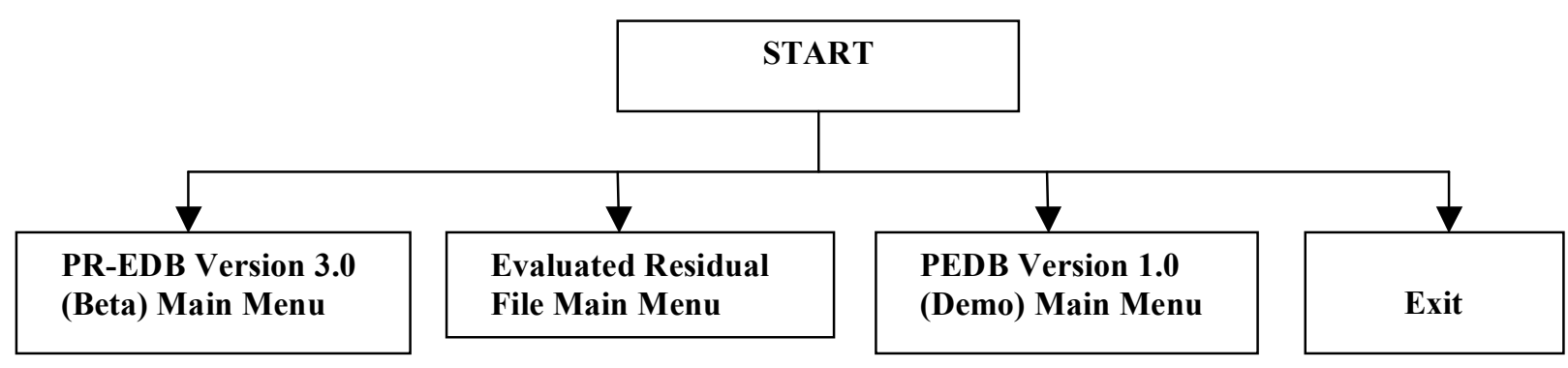

\section{A.3.2 PR-EDB MAIN MENU}

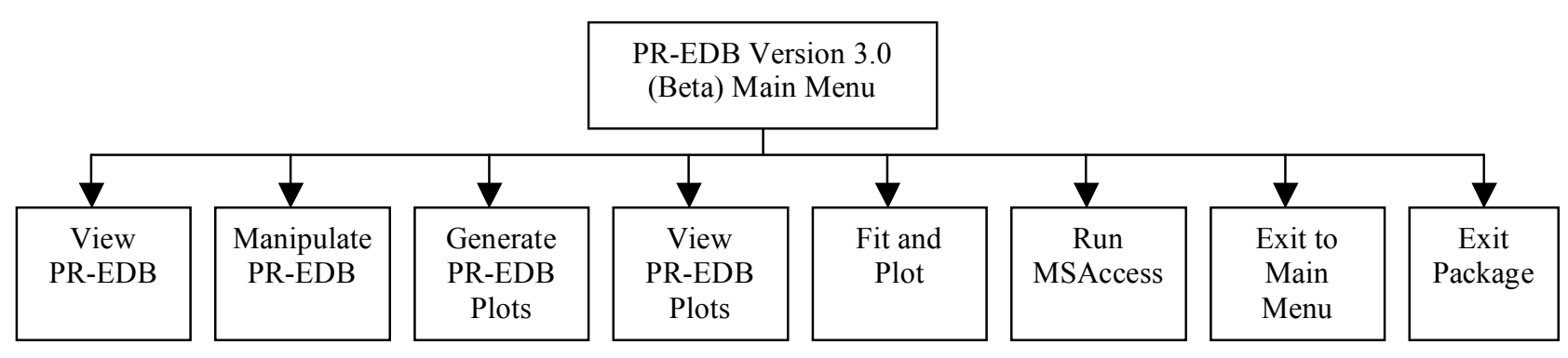

\section{A.3.3 Evaluated Residual File}

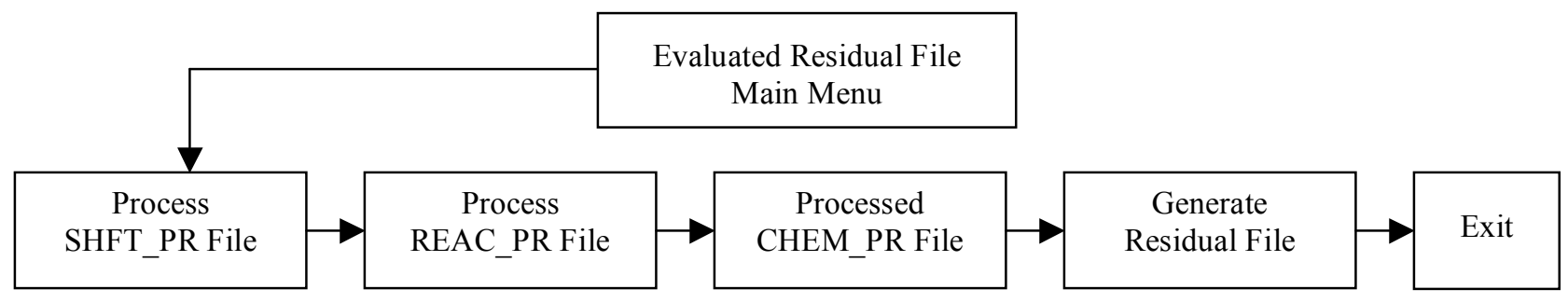




\section{A.3.4 PEDB MaIn MenU}

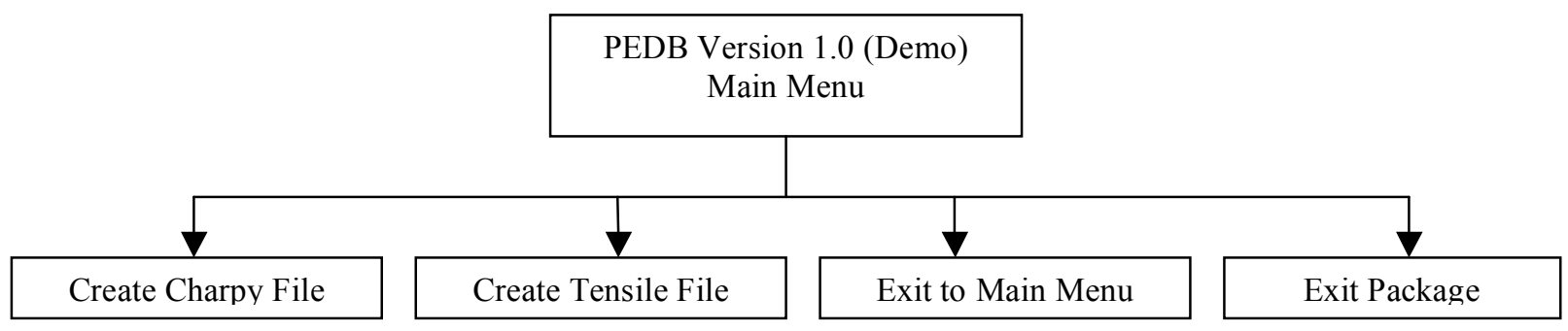

\section{A.4 GETTING ACQUAINTED WITH PR-EDB}

\section{A.4.1 OVERVIEW}

The PR-EDB Consists of a number of data files in MSACCESS format. Each File can be considered as a table of data; the columns are called Data Fields and the rows, Records.

The main purpose of this PR-EDB package is to provide a Friendly User Interface to View, Manipulate and use these tables to generate plots. This Package is the first WINDOWS version of the PR-EDB.

All data in this Proprietary Database has been stored as TEXT Type Fields for archiving purposes. However during Manipulation these Fields are converted into appropriate Types internally for making plotting and calculating easier. This Type conversions are based on information provided by the manufacturer in a Metadata file called the 'structure table'.

The 'structure table' can be imagined as a global control of all the fields in the PR-EDB that contains all needed details about the fields like Field Name, Storage Type, Original Type, Length, Description and a list of tables the Fields is present in. Reading this single table a complete profile can be obtained about a particular Field in the database and can be used to provide information as needed.

The tables after manipulation will be saved into an MSACCESS table with data types specified by the manufacturer in the 'structure table' rather than TEXT Type archive Fields, in order to make further manipulation, plotting easier.

The PR-EDB section of the package has different options to choose from and the choice can be made by clicking the buttons found on the left side of the screen which would toggle between the different frames (i.e different operation) on the right side of the screen from which the user the perform the function. The six major functions from which the user can choose are as follows.

\section{A.4.1.1 Viewing PR-EDB Tables}

This section provides a grid like view for the PR-EDB tables. Using this function the user can view the data available in the proprietary and user generated tables; get a print preview of how the data will be printed onto a printer and to print the data onto a printer.

Another important feature of this Data View section is that the Fields can be optionally hidden from view providing a select view of data.

(Note: The hiding of Fields does not delete it from the table under manipulation and can be brought back into view anytime by just selecting view all fields. 


\section{A.4.1.2 PR-EDB Manipulation}

This section allows the proprietary tables to be customized to suit the user's needs. The seven major manipulation operations that can be performed thro this section are as follows:

1. Adding User Defined Fields to the table.

2. Deleting Existing Fields from the table.

3. Adding Records to the Existing table.

4. Deleting Records from the Existing table.

5. Calculating User Fields.

6. Sorting Records.

7. Saving manipulations and generating plot tables.

\section{A.4.1.3 Generating PR-EDB Plots}

This section uses the plot table generated by the manipulation section to move data onto an Excel spread sheet and generate a graph, plotting all the necessary data and curves. The three types of curve plotting available are as follows:

1. Reg Guide 1.99, Rev 2 with uncertainties.

2. $\quad(\mathrm{X}=\mathrm{Y})$ Diagonal lines.

3. $\quad(\mathrm{Y}=0)$ And/Or $(\mathrm{Y}= \pm 2 \sigma)$ for Residuals.

\section{A.4.1.4 Viewing PR-EDB Plots Already Generated}

This section provides means to view the Excel plots generated earlier by just choosing the file and viewing directly from the package rather than having to locate the Excel file.

\section{A.4.1.5 Fit and Plot}

This section is a DOS program from the earlier PR-EDB Version 2.0 which has been bundled along with the Version 3.0 to provide means for fitting and plotting. This section has not been recreated in Windows environment and is pending transformation.

Raw Charpy Impact data from the table RAW_C_PR can be used by this module for fitting to a hyperbolic tangent curve and the results plotted once the table has been converted into an ASCII file. This conversion of data from the table to ASCII file is done by the manipulation module about which we will learn later in this Guide.

A Monte Carlo uncertainty analysis program is included which determines the uncertainties in the fitting parameters given the uncertainties in impact energy and test temperature of the original data. The following options are provided:
a. Single-Curve fitting and plotting.
b. Multiple-Curve fitting and plotting.
c. Monte Carlo uncertainty analysis.
d. Extracting selected Charpy sets.

\section{A.4.1.6 Run MSACCESS}

This section allows the user to run the MSACCESS program.

Without exiting PR-EDB package, provided Microsoft office 2000 or higher has been installed. The user can, in this manner easily switch between different options and edit or perform operations that are needed to be done on the PR-EDB for customization but had not been included in the package.

(Note: All proprietary tables contain data stored in TEXT data type format and all user generated tables contain data in their original format specified by the manufacturer in the global control table called the structure table "STR_ALL".) 


\section{A.4.2 Starting The PR-EDB Packag}

The PR-EDB package can be installed very easily following the instructions found in the Root of the Installation $\mathrm{CD}$ or the one found earlier in this Guide. On installation the package provides a Desktop shortcut and a Programs Menu folder shortcut by default, which can be used to start the package.

\section{A.4.2.1 Desktop Shortcut}

To start the package using the Desktop shortcut, see through your present desktop and find the shortcut which specifies PR-EDB 3.0 and click that Icon. The package will then be loaded to show a package emblem momentarily (till the package starts up) and will be followed by the Disclaimer statement screen. On moving further from this screen by clicking the OK button at the bottom the Main choice menu is brought up which Switches back and forth between the PR-EDB and PEDB. To move into PR-EDB section click the button which says 'PR-EDB Version 3.0 (Beta)'.

\section{A.4.2.2 Programs Menu Folder}

As an alternate approach the package can be started using the shortcut provided in the Programs Menu Folder. To find this shortcut, first click on the START button on the leftmost side of the Windows toolbar. Once the button is clicked a menu pops with many items, click on Programs and it would open a complete list of Installed programs on your computer. Find and click the one that says PR-EDB, further it would open up into a shortcut saying PR-EDB 3.0. Click on this shortcut to start the package.

The package will then be loaded to show a package emblem momentarily (till the package starts up) and will be followed by the Disclaimer statement screen. On moving further from this screen by clicking the OK button at the bottom the Main choice menu is brought up which Switches back and forth between the PR-EDB and PEDB. To move into PR-EDB section click the button which says 'PR-EDB Version 3.0 (Beta)'.

\section{Note: Users are strongly advised to read the Disclaimer statement.}

\section{A.4.3 PR-EDB SCREEN SHOT EXPLANATIONS}

\section{A.4.3.1 Viewing PR-EDB Tables}

This option is used to provide a Data view of the proprietary and user generated tables on a Grid. This option has been provided to enable users to only view the data and not modify any data.

In order to view data from the tables, click on the View PR-EDB button on the left side of the screen or the View PR-EDB item from the Drop down Menu 'File'. The package by default when loading would display this section, but when the user had toggled to some other section, he could always bring back the View PR-EDB section using the above said instructions. 


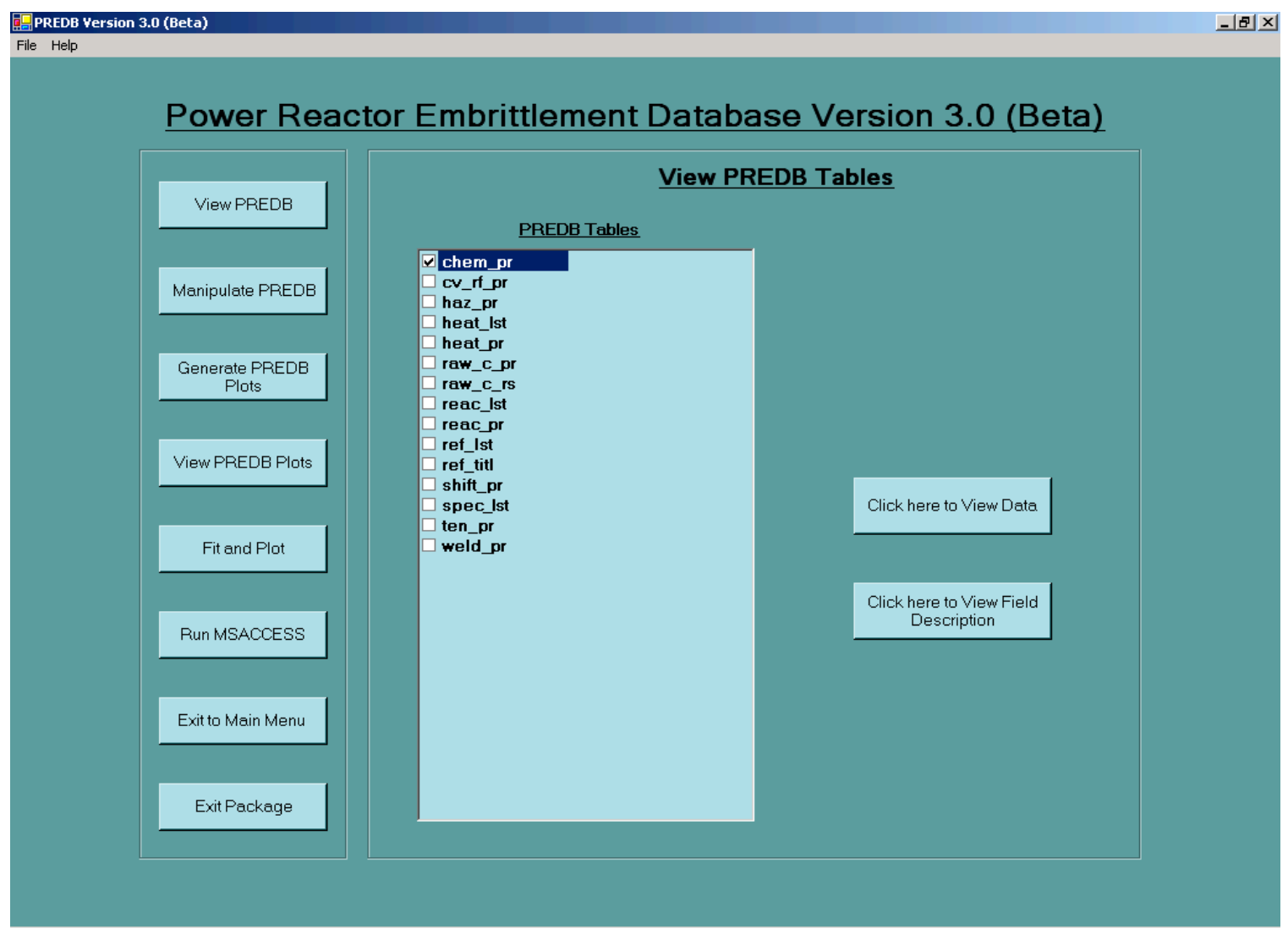

Now select the file to be viewed from the list of PR-EDB tables (Note: only one PR-EDB table can be viewed at a time), and then click the button which says 'Click here to view Data' in order to view the table content.

Table descriptions (Field Names and Field Descriptions) can be obtained for Proprietary tables by selecting the table from the list and clicking the button which says 'Click here to View Field Description' however this option would not hold good for User generated tables.

\section{A.4.3.1.1 Viewing Data from Tables}

When the button 'Click here to View Data' has been clicked after choosing the table, it will bring up the screen found below which shows a grid containing data from the table. 


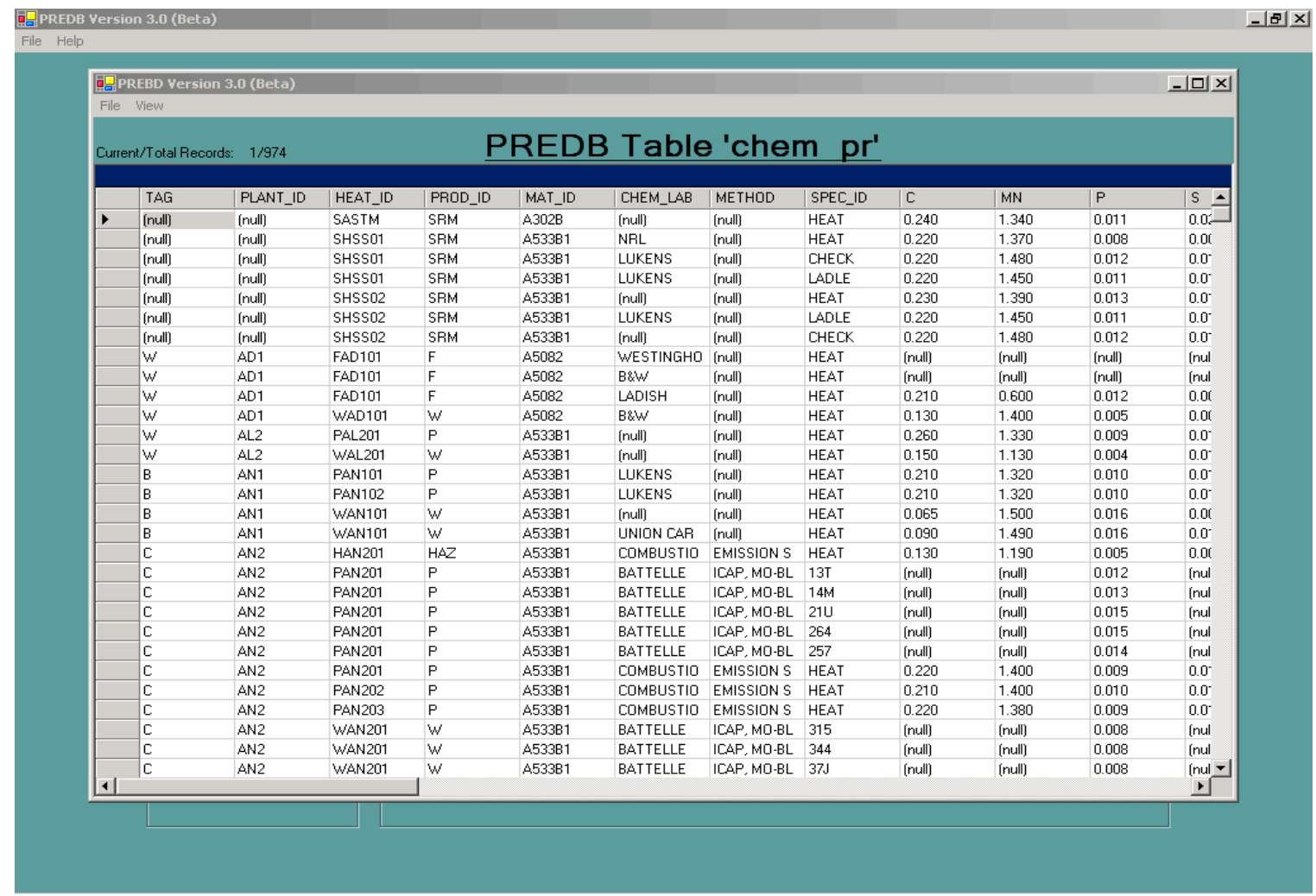

The Data can be viewed by scrolling up and down using a mouse or the keyboard Up/Down keys. The hidden fields can be viewed by moving the scrollbars. The total number of rows and current row number are displayed on the top left corner for reference. The current row numbers get updated as and when the user changes the cursor position by clicking on a different row using a mouse or the Up/Down keys from the keyboard.

Another major functionality of this Data Preview section is the provision of selected view of data. Thereby Fields can be hidden from View without having to delete from the table. Such Fields can be brought back to View any time by just clicking a menu item.

In order to view Select Fields, click on the Drop down menu which says 'View' and it will pull down Menu items 'all Fields' \& 'Selected Fields'. Choose and click the item 'Selected Fields'. This item when clicked will hide the present screen which is showing the Data on the Grid and will bring up a screen shown below. 


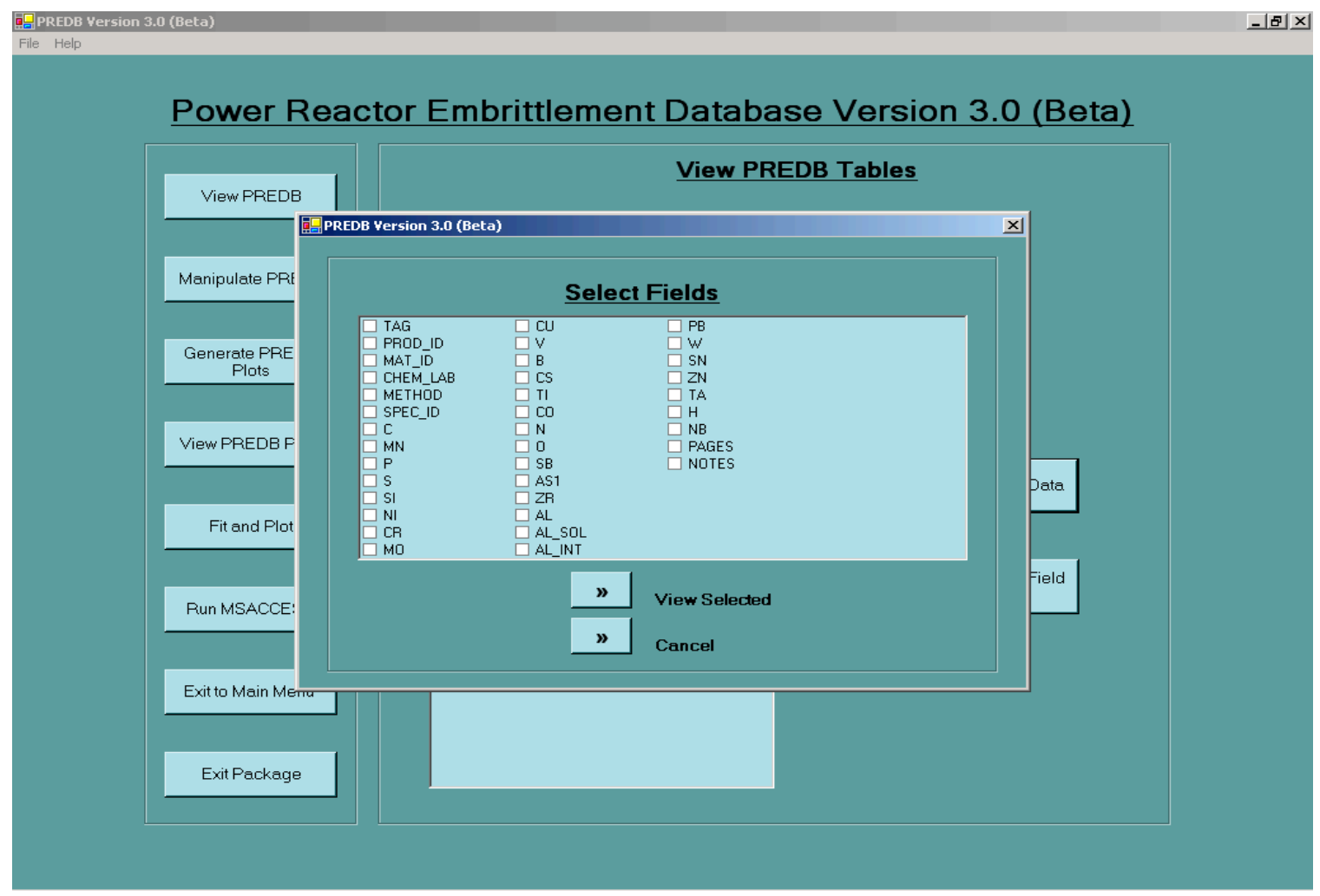

Now this screen can be used to Select fields needed for view and can be brought to view by clicking the button which says 'View Selected'. All other Fields than the selected are hidden from view but are not deleted from the table. (Note: However this option of hiding Fields does not work for the KEY FIELDS and are shown on the view by default. They cannot be hidden and also are not available on the Select Field list.)

In case moving to this screen was a mistake or is not required, the user can toggle back to the Grid Screen by clicking the button which says 'Cancel'. The Select Field page is hidden and the Grid Screen is brought back with the selection of Fields that was made last (it could be All Fields if that was the state it was left at, or a Select Field View if that was chosen earlier.)

A key feature included in this Preview section is the Print Preview and Print options. Select these options from the Drop down menu which says 'File'.

Click on the Menu item 'Print Preview' which will bring up the screen shown below displaying how the table will be printed on the paper. 


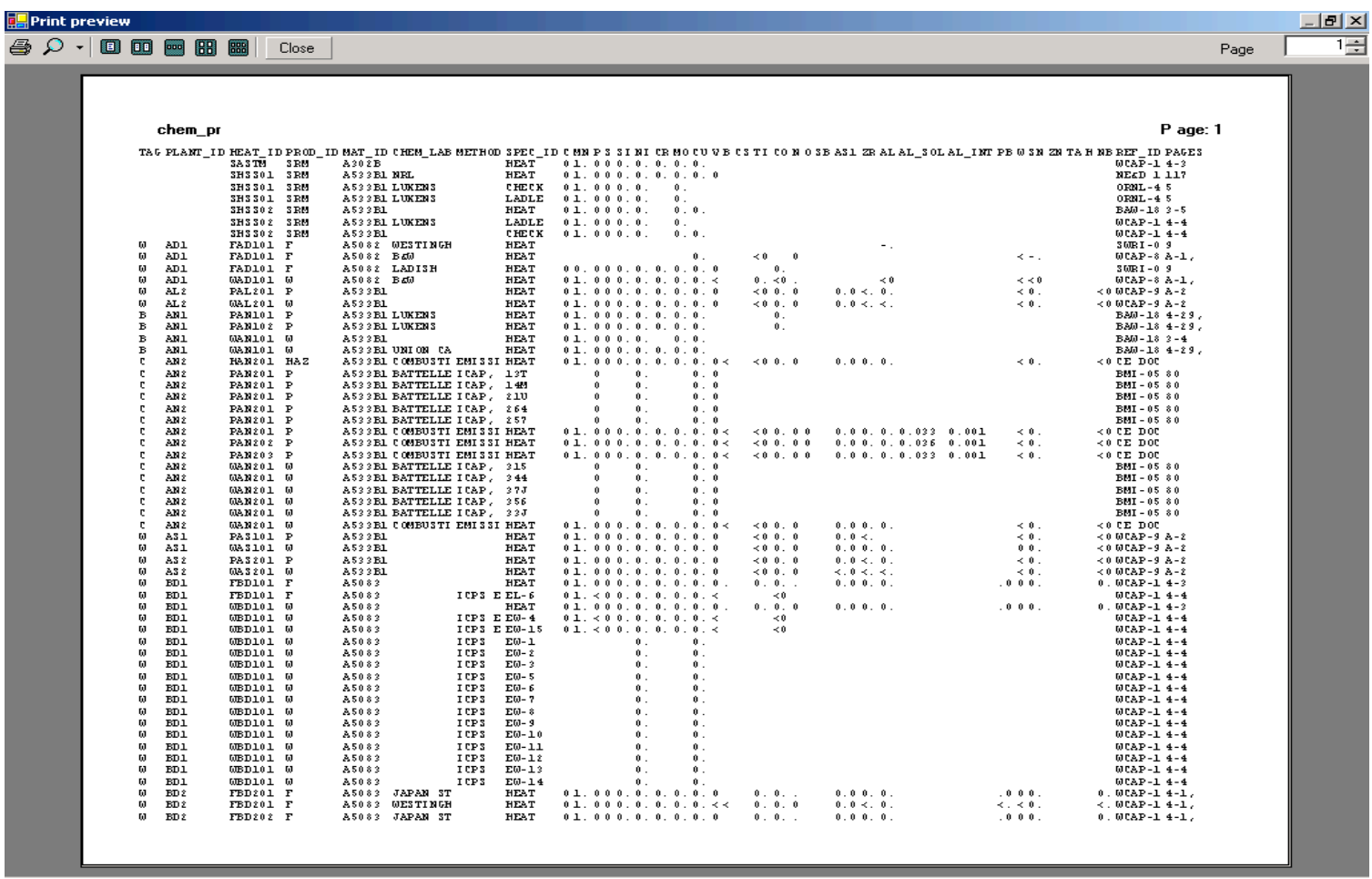

This screen has options to view single/two/three/four/six pages on the screen, Zoom into a single page and to print the pages onto a default printer.

As an alternative to print the data on a printer, the user can select the Drop down menu 'File' and click the item 'Print'. A confirmation is asked from the user to print data onto the printer after which the data is sent to a printer for printing. A confirmation has been provided at this point to stop the misprinting of lengthy tables in case of wrong selection.

\section{A.4.3.1.2 Viewing Table Description}

This option has been provided to view the table description of the proprietary tables available in this package. Choose the proprietary table and click the button 'Click here to view Table Description' which will bring up the Grid showing Field Name and Field Description like the one shown below. 


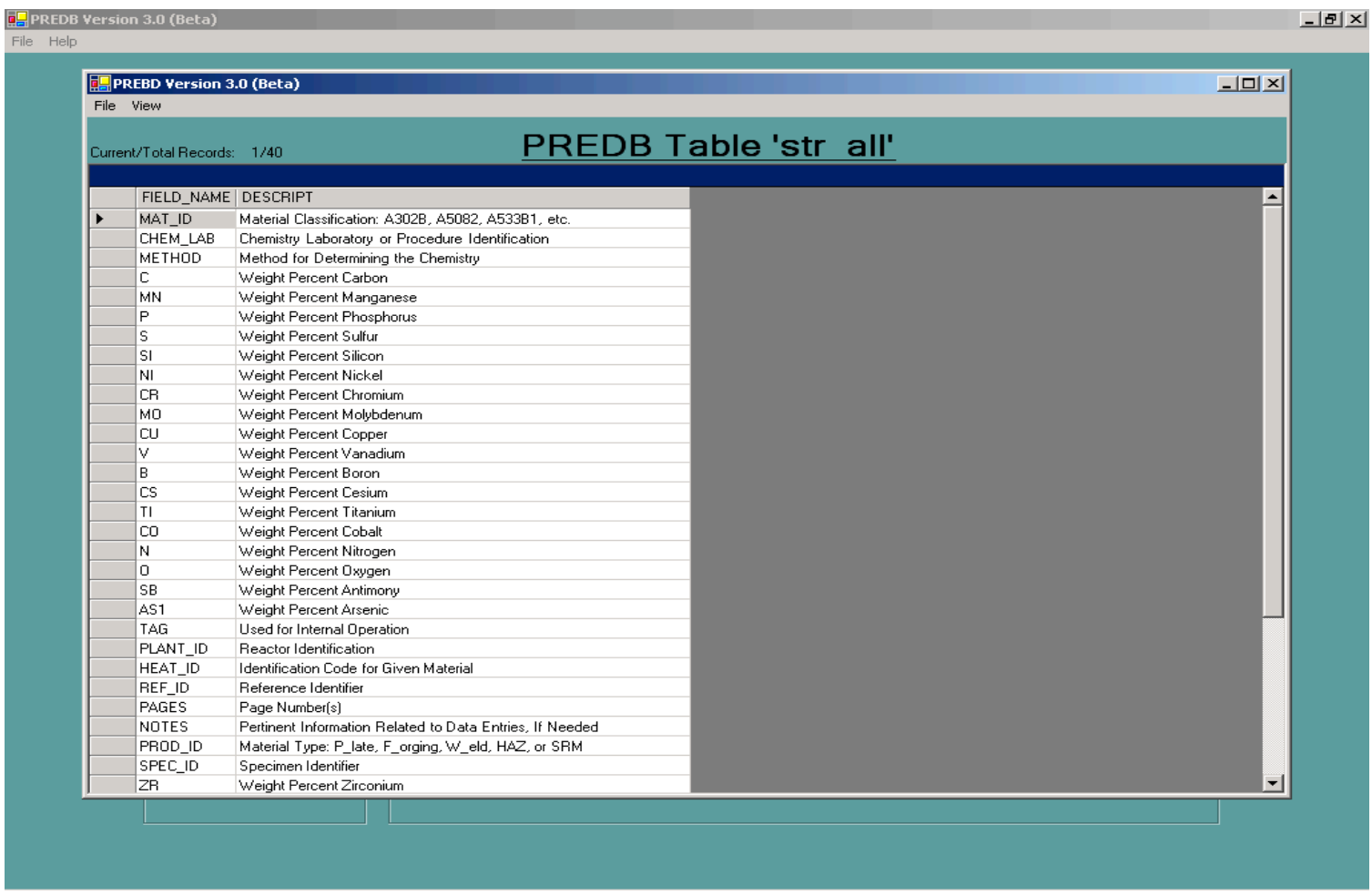

The total row numbers at the top left corner indicate the number of Fields in the table and the current row indicates the Field on which the cursor is pointed to. The hidden Fields can be browsed by scrolling with a mouse or using the Up/Down keys of a keyboard. Print Preview and Print options can be used to generate a paper print of the table descriptions similar to getting Data printed.

\section{A.4.3.2 PR-EDB Manipulation}

This section allows the proprietary tables to be customized to suit the user's needs. All manipulation procedures are never performed on the original proprietary table, rather a copy of the table structure is made with the name provided by the user and the data is fetch into memory from source. After manipulation data is saved onto the empty structure to generate a User customized table. The package will never allow overwriting of the proprietary tables provided by the manufacturer. The manipulations have to be saved back to the database to be accessible later else would result in a blank structure being stored in the table.

To bring a table into manipulation first click on the button 'Manipulate PR-EDB' on the left side of the screen or the Menu item 'Manipulate PR-EDB' from the Drop down menu 'File'. This will toggle the right side of the screen from other functionality blocks to the PR-EDB Manipulation block wherein a list of PR-EDB tables and options to enter a destination table name are found.

Select the proprietary table needed to be manipulated and enter a destination table name in the Text box provided after which the user has to click the button 'Click here to Manipulate'. This action will bring up the screen found below. 


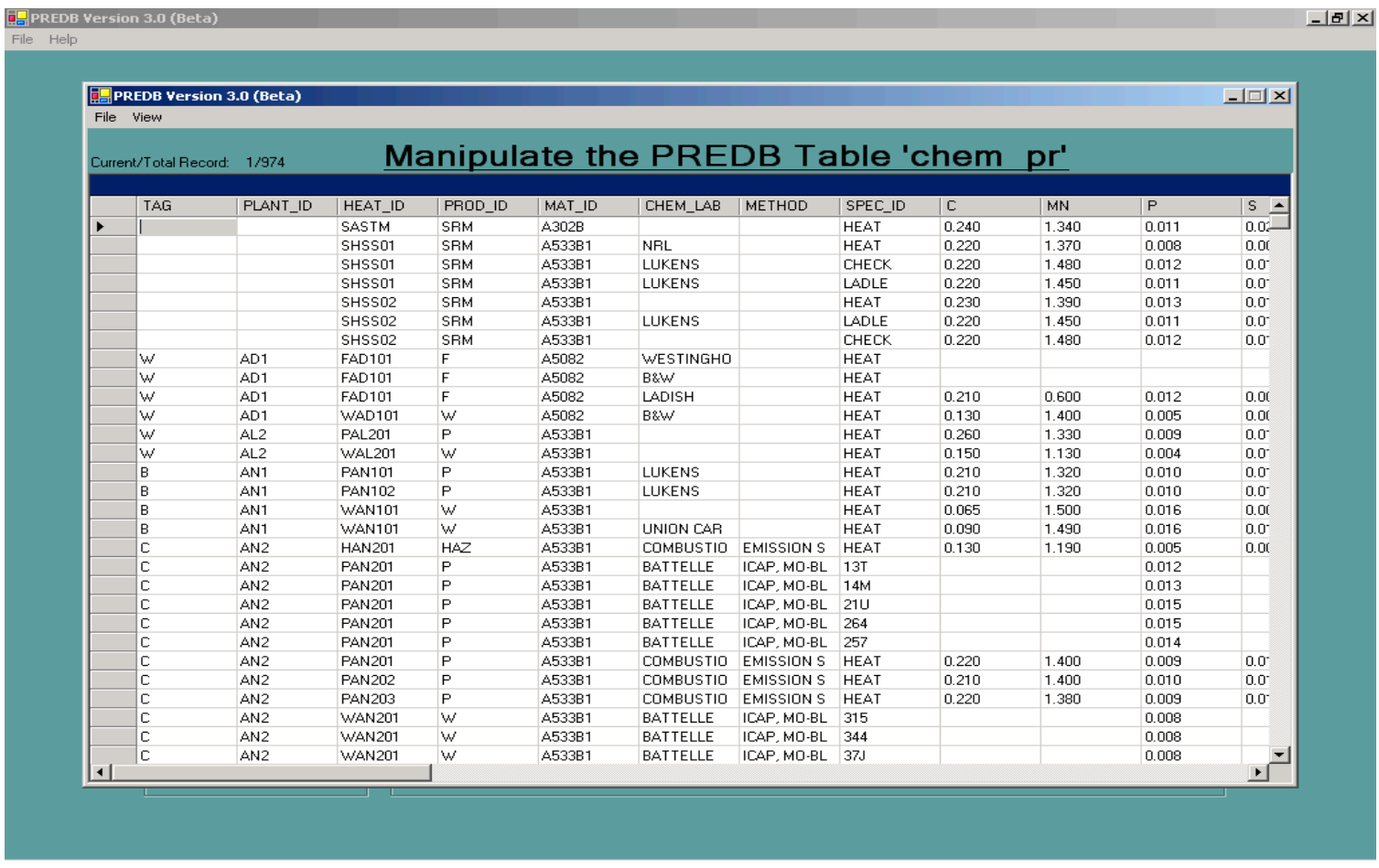

This screen is similar to the Grid screen that we saw earlier in this guide under View PR-EDB table section and has all the functions said above. In addition manipulation procedures are provided to customize the table. Manipulation functions can be executed by clicking the menu items from the Drop down menu 'File'.

\section{A.4.3.2.1 Add User Field}

Fields can be added to the working file for storing the results of calculations, and only these fields can be used for this purpose. However, fields added in a previous run to a table that was subsequently saved cannot be used during a later retrieval of the table.

In order to add a Field to the table choose the Menu item 'Add User Field' from the Drop down menu 'file', bringing up the following screen.

Fields added to the table are of Scientific Type by default. To add a Field to the table the user has to provide a Name to the field and a Field Description. On clicking of the button 'Add Field' a confirmation is asked from the user if he wants to add the field to the table, once permission is granted the Field addition is confirmed. The user can also skip adding the Field at the time of confirmation by just saying 'NO'. If this screen was brought on by mistake or if the user decided not to add the Field he can skip this section by clicking 'Cancel'. After adding the Field this screen closes and the Grid display screen is brought back into view. The added new Field is found at the end of the list of Fields which could be seen on scrolling the scrollbar towards the right. 


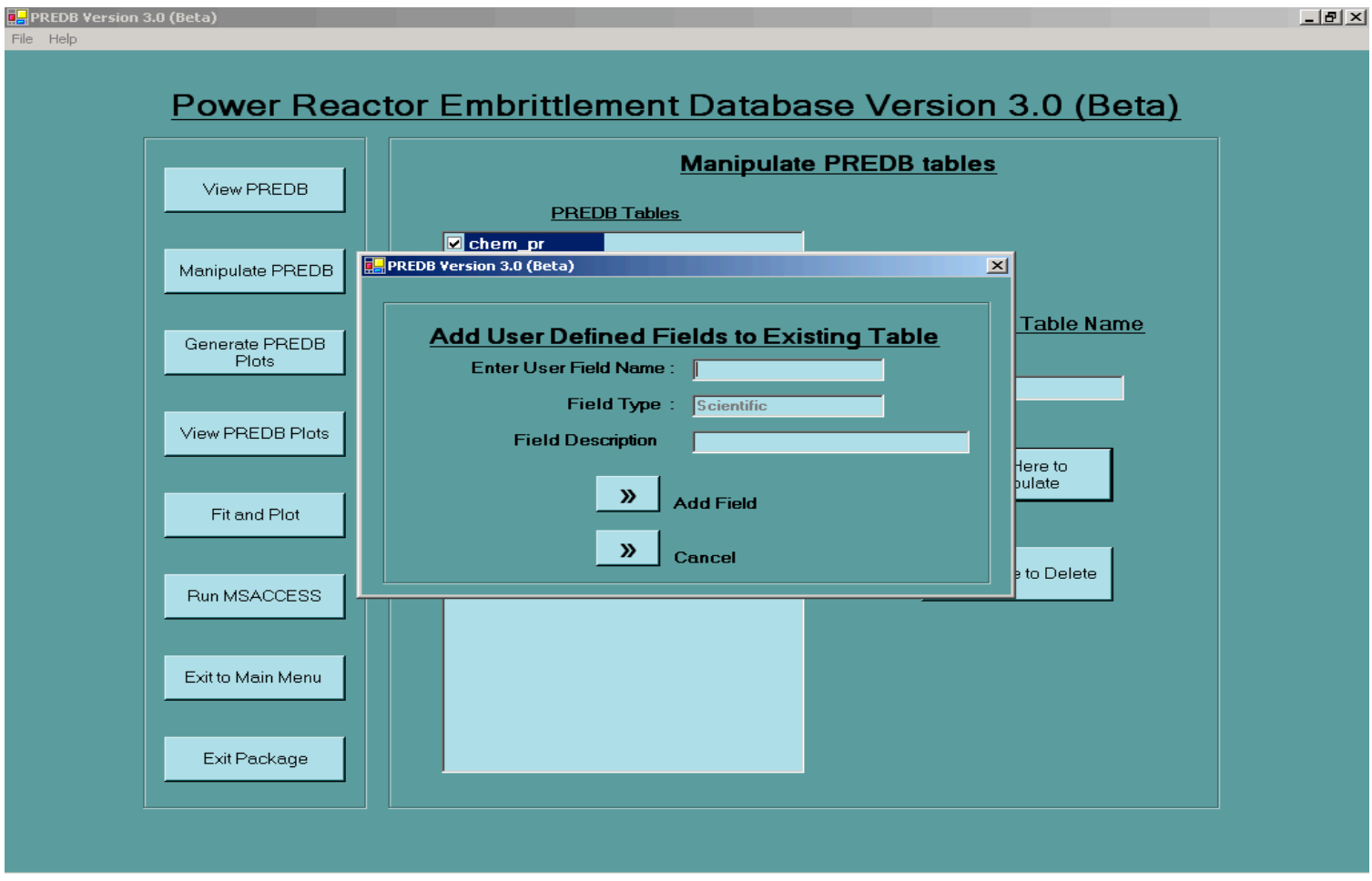

(Note: When Selective Field View is turned on the Added New Field is not shown in the view and can be brought into view by redefining the Fields to view.)

\section{A.4.3.2.2 Delete Existing Field}

Existing Fields from the table can be deleted to provide customization or to reduce the Data set. Any of the Existing Fields can be deleted from the table, which means the User defined Fields added on an earlier occasion can also be deleted if not needed. To delete a Field choose and click the Menu item 'Delete Existing Fields' from the Drop down menu 'File'. The screen found below is brought into view on such action.

Choose the Field to delete from the drop down box and click the button 'Delete Field' to delete the Field from the table. On clicking of the button 'Delete Field' a confirmation is asked from the user if he wants to delete the field from the table, once permission is granted the Field Deletion is confirmed. The user can also skip deleting the Field at the time of confirmation by just saying 'NO'. In case this screen was brought in as a mistake or if the user decided not to add the Field he can skip this section by clicking 'Cancel'.

After deleting the Field this screen closes and the Grid display screen is brought back into view. The deleted Fields is removed from the view and also physically from the table. 


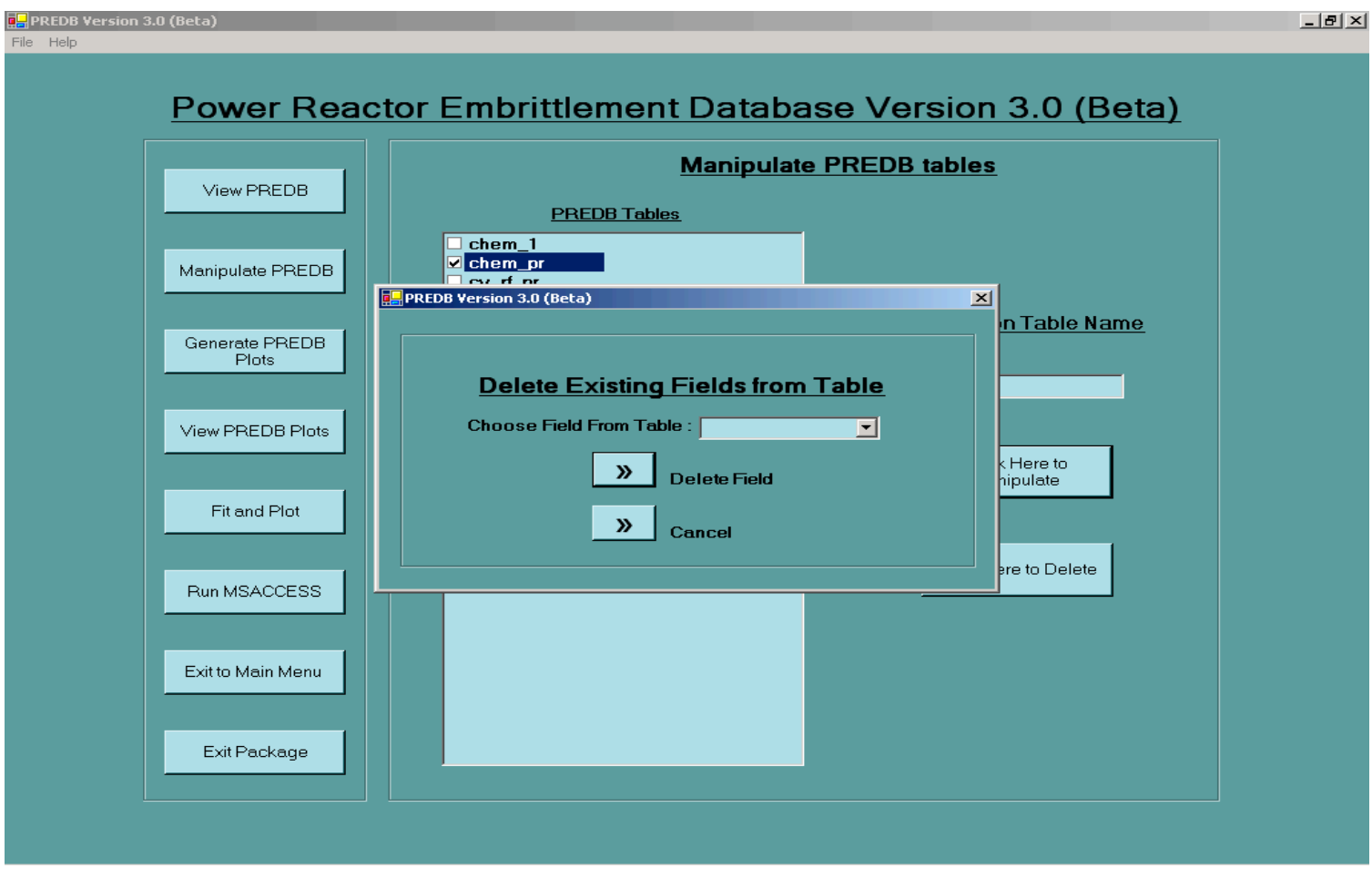

\section{A.4.3.2.3 Add Records to Existing Table}

Records can be added to the Existing table under manipulation from structurally similar tables inside PR-EDB. This function has been provided with the aim of merging two tables with similar structure to form a new table.

(Note: To perform this function, both the tables SHOULD have same structure i.e same order of the Fields with no additional/missing Fields on either of them.)

To add records to the Existing table choose and click the item 'Add Records to Existing Table' from the Drop down menu. The screen found below is brought into view on such action.

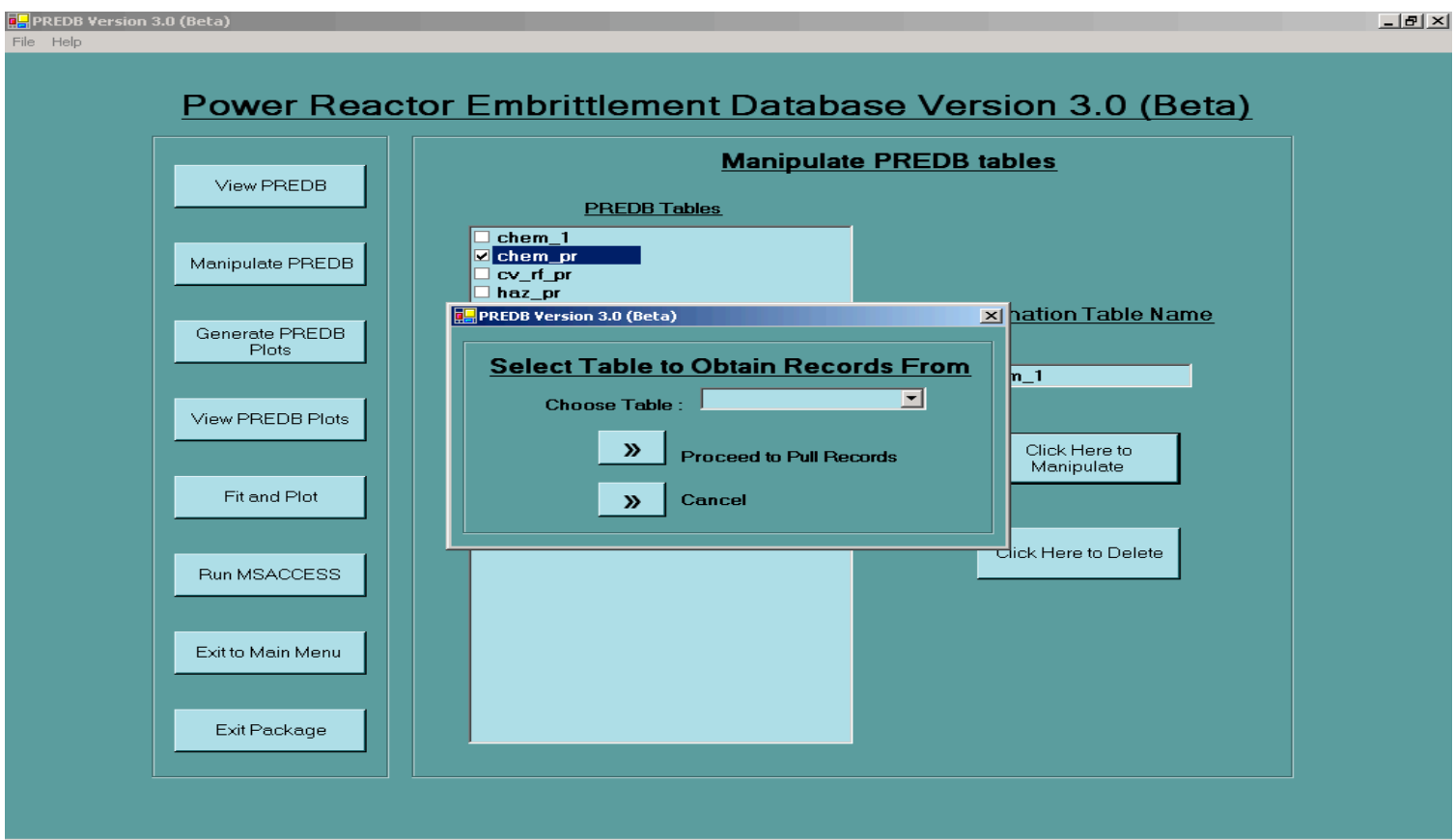


Choose the table from the Drop down box (one that has same structure of the table under manipulation) and click 'Proceed to Pull Records'. On clicking the package loads records from the external table and displays the 'Merge confirm' screen found below. In case this screen was brought in as a mistake or if the user decided not to add records to the table he can skip this section by clicking 'Cancel'.

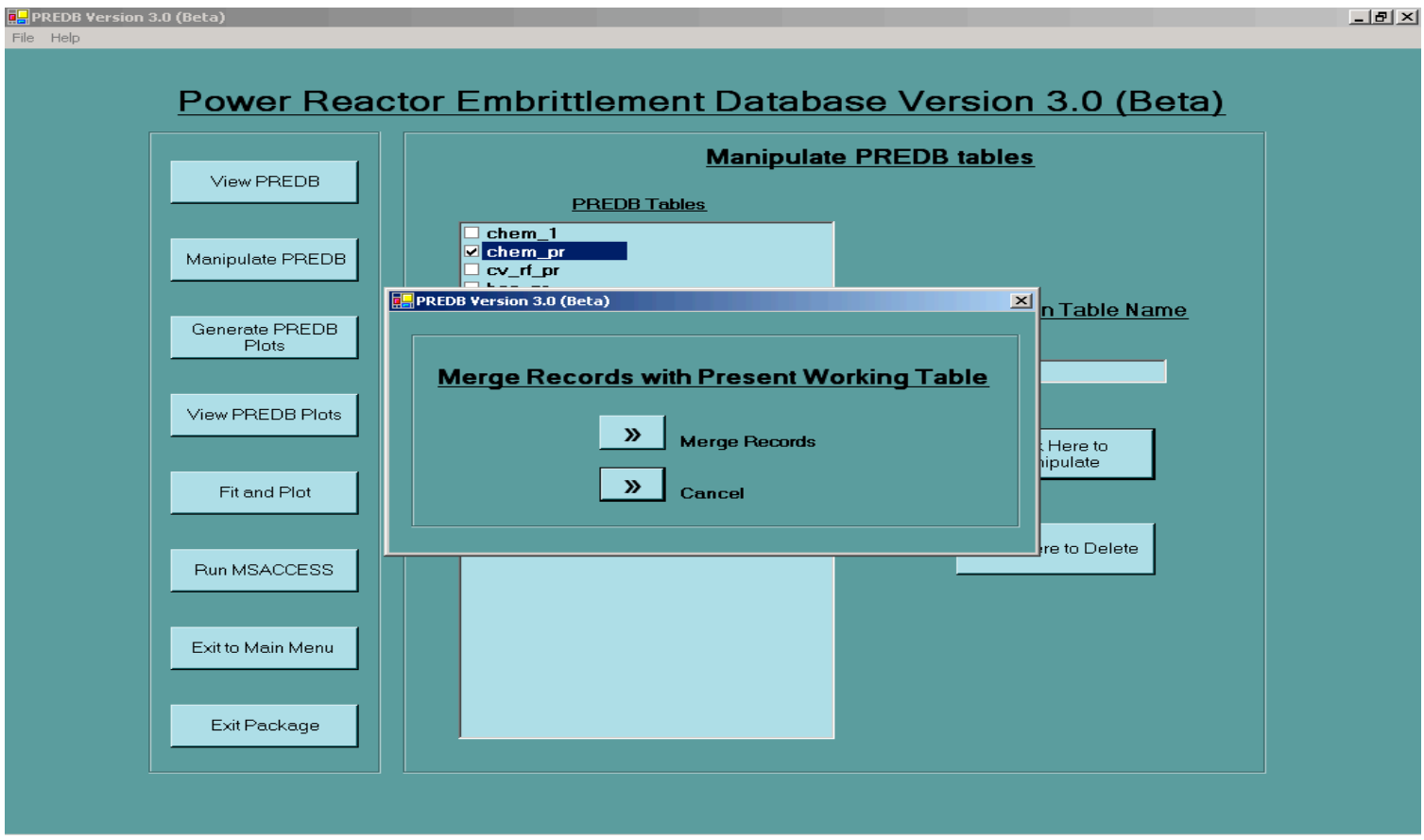

At this point the user has to confirm the merging of records to the present working table. He can do so by clicking the 'Merge'. If the table structures are the same the records are appended to the end of the present working table and a count of the number of records is displayed to let the user know how many records were added. If the table structures are different an 'Error' message is displayed indicating the tables are different.

\section{A.4.3.2.4 Delete Records from Existing Table}

Records can be deleted from the existing table to provide a smaller dataset from the present large one. Records are searched using certain user specified criteria and marked for deletion. Once all these markings are complete the deletion is confirmed and the records are removed from the table. So the deletion of records is a two step process, of which first is Marking records for deletion and second is confirming/rejecting deletions.

To delete records from the table choose and click the menu item 'Delete records from Existing table' from the Drop down menu 'File', after which the following screen is brought into view. 


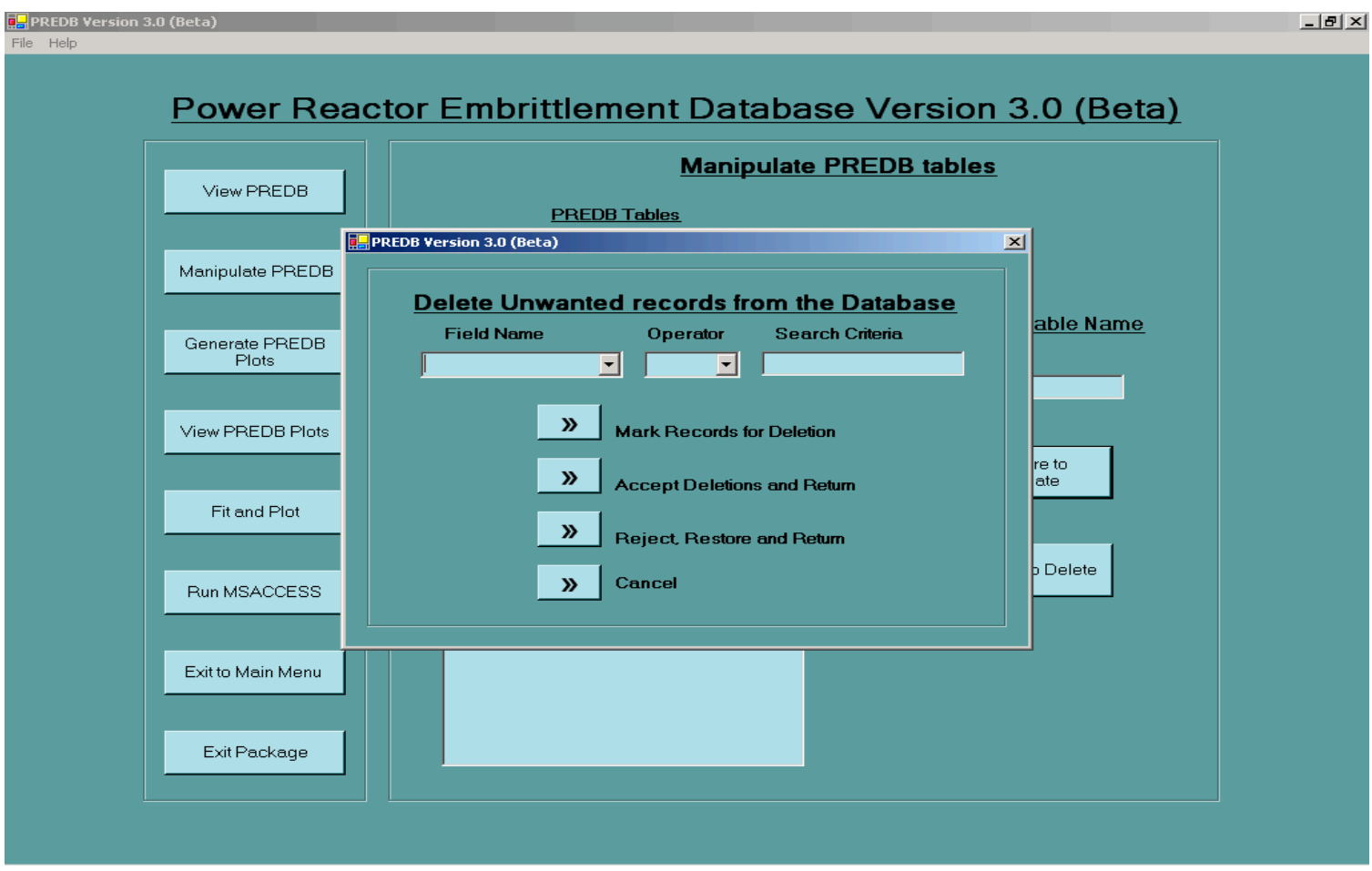

From this screen choose Field on which the Deletions are based on, Deletion operator like $<,>,=,<>$ etc, and also an appropriate deletion search criteria. After selection click 'Mark Records for Deletion' and the number of records matching the criteria is displayed on marking. Like wise the deletion marking can be done for many search criteria and finally after the markings are complete the records have to be removed physically from the present table.

To remove the records from the table after marking click 'Accept Deletions and Return'. When this button is clicked the records are physically removed from the table and the change is confirmed. If the user wants to revert back the deletions he can click 'Reject, Restore and Return' where the records that have been marked for deletion are unmarked and deletion section is skipped.

Deletion marking can be performed on many Fields and finally the deletions can be committed in one sweep. Search criteria have to be specified appropriately depending on whether the field is Numeric or String. Errors messages are displayed on using Inappropriate search criteria (i.e Using String Search criteria for Numeric Fields). The operators available for String Fields are ' $=$ ' and ' $<>$ '.

(Note: Once the deletions are confirmed the records cannot be retrieved back to the table.)

\section{A.4.3.2.5 Calculate User Fields}

A Variety of numerical operations can be performed on fields of numerical or scientific type data, with the results stored into the User-Defined scientific fields. Only one operation at a time can be performed, namely addition, subtraction, multiplication, division, exponentiation plus exponential function and logarithm. More complicated formulas can be calculated in a properly chosen sequence of operations using, perhaps, some auxiliary fields for temporary storage. Division by zero operation produces a result of " $1 . \mathrm{E}+100$ " to be stored indicating that there was a division by zero at that point. A blank is also stored in the User field after operation to indicate that either of the operated fields contained a blank. There is an option to perform operations with a 'Constant', which can be enabled by choosing the field to be operated from 'Source Field 1' and from the 'Source Field 2' obtain the first item in the list 'CONSTANT'. When this item is enabled a text box appears at the bottom, wherein the user enters the Constant. (Note: Care should be taken to enter proper Numeric CONSTANT in this box. String Constants are not allowed for entry in this box). 
To perform calculation on the Fields choose and click the menu item 'Calculate User Fields' from the Drop down menu 'File'. The screen found below is brought into view on such action.

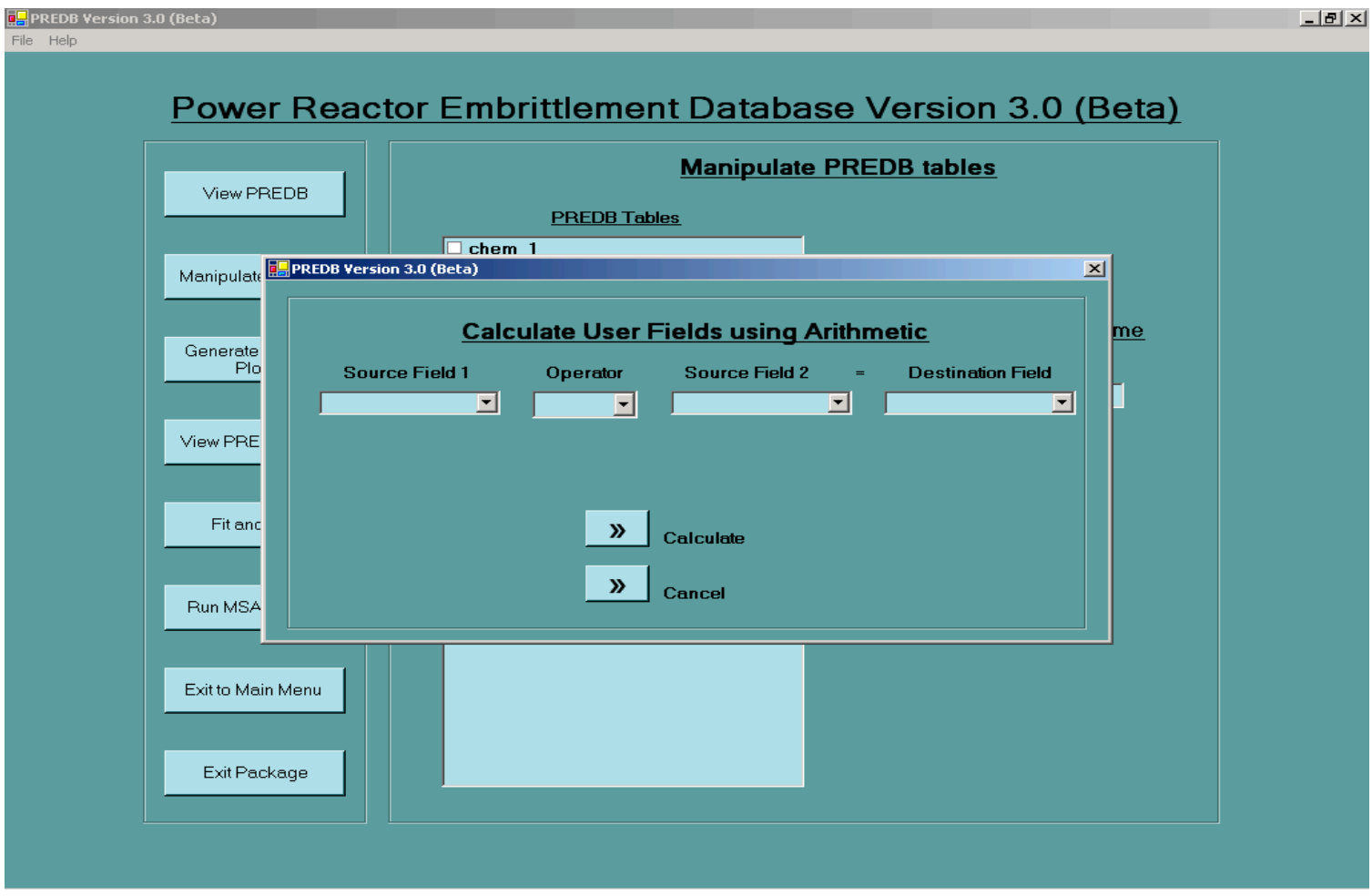

The screen found above is used to perform calculations on two different fields in the table whereas the screen found below is used to perform operation on a field with a constant. It can be noted that only on selection of the 'CONSTANT' from the 'Source Field 2' the constant entry box is shown and otherwise not.

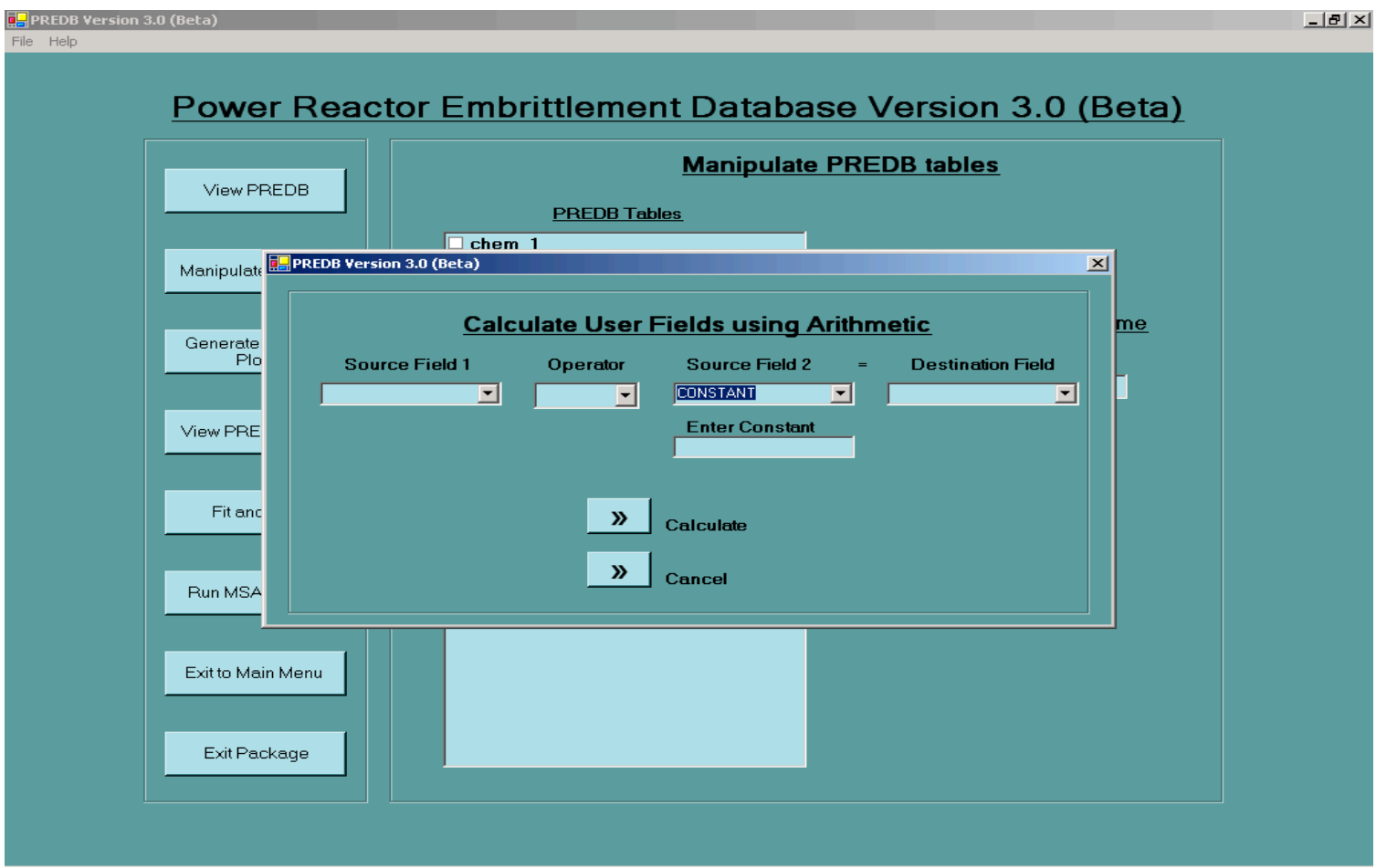


To perform operations between two Fields, select the first field from the 'Source Field 1' drop down box, second field from 'Source Field 2', operator from the 'Operator' drop down box and the destination field from the list of User- Defined fields in the drop down box 'Destination Field' and click 'Calculate'.

To perform operation with a Source Field and a CONSTANT, select the field from the 'Source Field 1' drop down box and from the 'Source Field 2' drop down box select the entry 'CONSTANT'. Just then a Text box appears at the bottom indicating the entry of the constant. Enter constant value in the box and click 'Calculate'.

If this screen was brought on by mistake or the user chooses to skip calculating of Fields he can do so by clicking 'Cancel'.

(Note: Calculations can be performed only on Numeric or Scientific type fields. When String Fields are operated by mistake an 'Error' message is displayed and the operation is cancelled.)

\section{A.4.3.2.6 Sorting Records}

Records of the working table can be sorted in a User-Specified order, which a five level priority. When records are sorted they cannot be brought back to the original order in a single reject command as it involves multiple level sorting. In order to bring back the order to how it was earlier the user can specify the reverse of how the sort was done, but in the same priority order specified earlier.

To sort records choose and click the menu item 'Sort Records' from the Drop down menu 'File' which will bring into view the following screen. In that screen choose the Fields needed to be sorted. User can choose a minimum of one Fields and a maximum of Five Fields. If the Sort order is not specified the order is by default 'ASCENDING'. Alternatively the user can specify if the sort order is 'ASCENDING' or DESCENDING' from the drop down box 'Sort Order'. After entering all the sort details click 'Sort Table and Return' to sort the table in the order specified.

If this screen was brought on by mistake or the user chooses to skip calculating of Fields he can do so by clicking 'Cancel'.

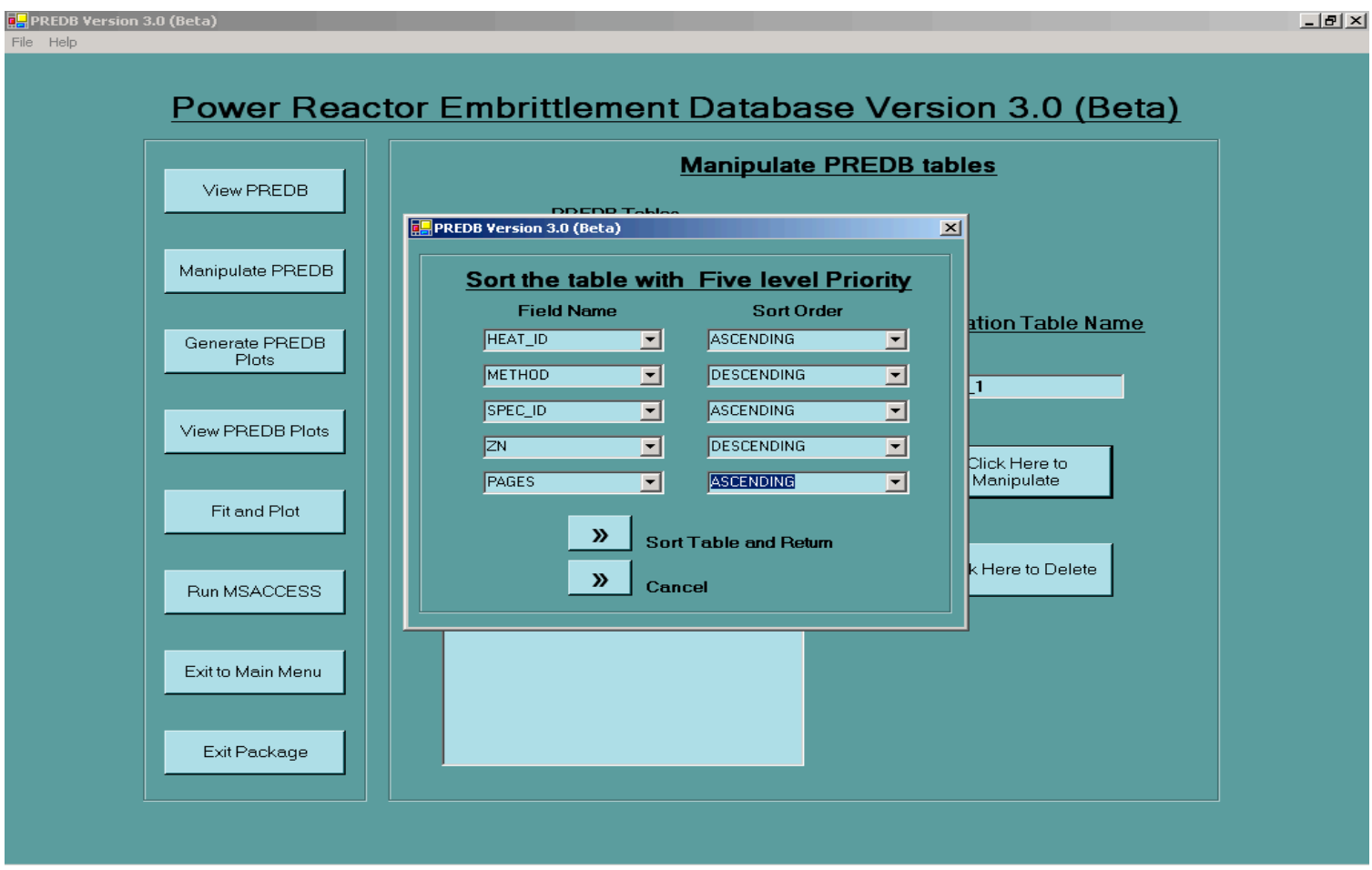




\section{A.4.3.2.7 Save Working Table}

After all manipulations have been completed on the working table, the data which is now present in memory has to be copied into the blank structure. The blank structure which had been created, when the table was fetched for manipulation first under goes changes all along as the Fields get added/deleted, so that it synchronizes with the final dataset obtained after manipulations.

This save section performs various functions, which would be saving data back to blank structure, creating a Plot data table, creating an ASCII file for fitting from Raw Charpy data.

To save data onto the table structure choose and click the menu item 'Save Working Tables' from the Drop down menu 'File'. On clicking that menu item the screen found below is brought into view.

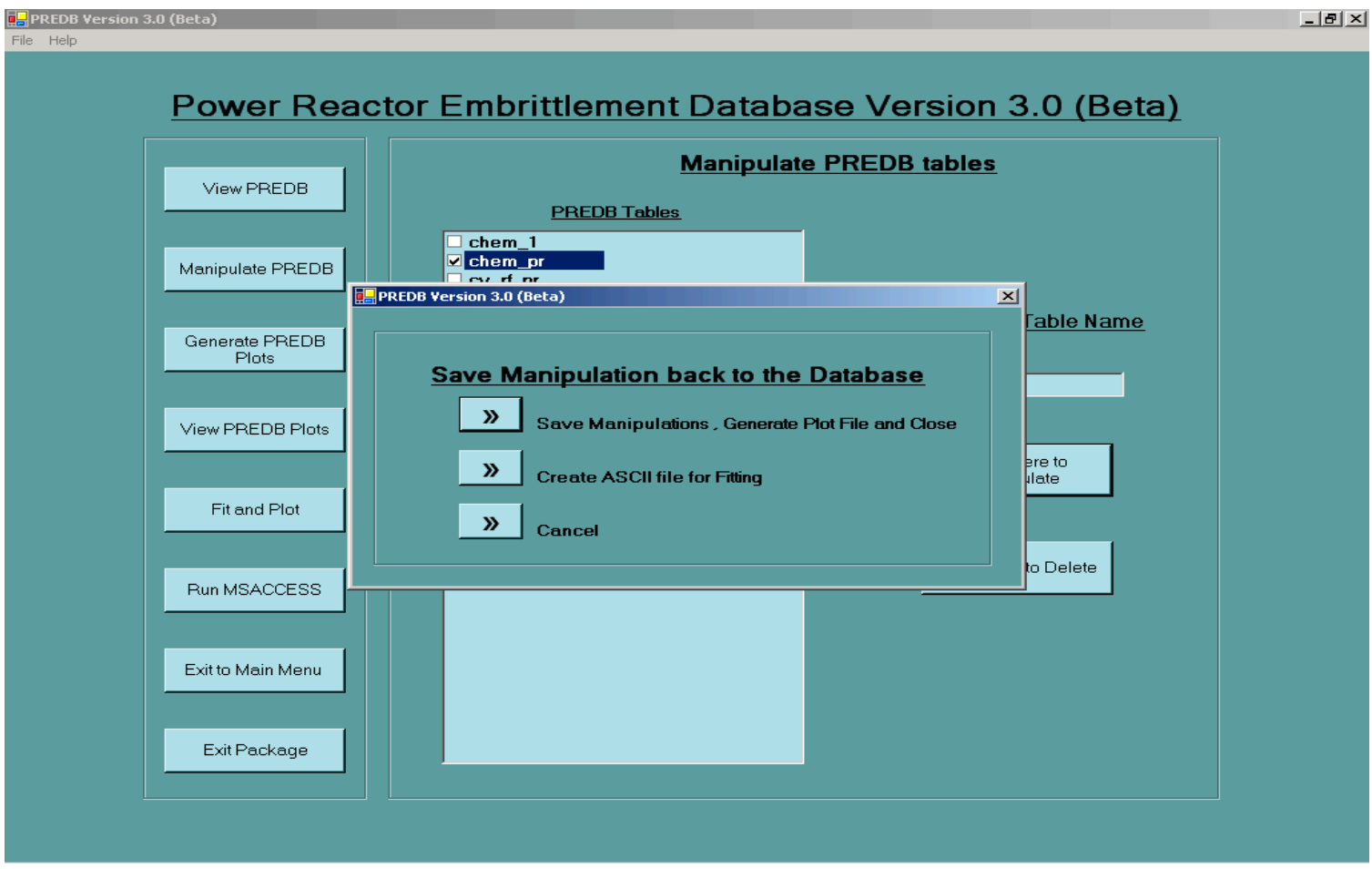

\section{A.4.3.2.7.1.1.1.1 Saving data onto a table and generating a Plot Table}

The data is first stored into a table from the memory and is then followed by a Plot table generation (Plot Tables are exact copies of the tables generated after manipulation, with an extension of _plt).

This extra step of first generating the manipulation table is being done as we are dealing with inmemory data as compared to the data that was present and was operated upon from 'files' itself in PR-EDB 2.0.

To perform this step click the button 'Save Manipulations, Generate Plot File and Close', just then all the will be stored into the blank table structure and a message is displayed asking the user choice if he wants to generate a Plot Table. When the user says 'Yes' to the message, a copy of the table is stored into a plot file with the same name with an addition of plt. Such plot tables can be viewed in a list by clicking the button 'Generate Plots' found on the left side.

\section{A.4.3.2.7.1.1.1.2 Saving data onto a table and skip generating a Plot Table}

The process of saving the data onto the blank table structure without generating a Plot Table is very much similar to the one said above in section 4.3.2.7.1, with the exception that an answer to the Confirmation message displayed should be a 'NO'. After which the table is filled with manipulated data and manipulation screen quits. 


\section{A.4.3.2.7.1.1.1.3 Create ASCII File for Fitting}

Fitting procedures available with Version 3.0 are the ones that were developed for the Version 2.0 and are pending revamp. Thus from the Version 3.0 an ASCII file is being generated to streamline the fitting procedures. This function works only for the PR-EDB table 'RAW_C_PR'.

To generate an ASCII file for fitting the user has to load the PR-EDB table 'RAW_C_PR' for manipulation and choose, click the menu item 'Save Working Table' from the Drop down menu 'File'. After which the RAW charpy file will be generated in the program directory and is ready to be used by the fitting procedures.

\section{A.4.3.1.1 Delete User Generated PR-EDB Tables}

User Generated PR-EDB tables can be deleted from the PR-EDB table list. However this package does not allow deletion of proprietary tables provided by the manufacturer. To delete User generated tables from the list, first toggle to the Manipulate PR-EDB section by clicking the button 'Manipulate PR-EDB', then select the User generated table to be deleted and click 'Click here to Delete'. A confirmation is asked for deletion from the user and on approval the table is deleted from the Database.

\section{A.4.3.3 Generating PR-EDB Plots}

The data input for the PR-EDB plotting section is prepared by the PR-EDB manipulation procedures in the form of a 'PLOT TABLE'. These Plot tables are nothing but tables similar to the ones generated in the manipulation process with an exception that they bear a name with addition of ' plt' to original table name indicating that it is a Plot Table.

Plots are generated in Microsoft Excel workbook format. The data from the table is first selectively moved into an Excel workbook and a corresponding graph is generated in the same work book on a different sheet. The entire workbook which contains the plot data on different sheets (from different datasets) along with the graphs is stored in an Excel file with extension '.xls'.

Number of datasets that can be plotted onto a graphs vary between a minimum of one to a maximum of ten. Each of these datasets has to be created as Plot tables using the process said above in section 4.3.2.7.1.

Another important point to be noted is the selection of datasets of similar structure. Plots are generated with the notion that all the selected datasets contain the values for $\mathrm{X}$ and $\mathrm{Y}$ axes chosen for plotting. When datasets with different structure are being fetched for plotting an 'Error' message is displayed and the plot will not continue.

To generate a plot first toggle to the plotting section using the button 'Generate PR-EDB plots'. Then select from the list of plot tables, the datasets that need to be plotted and click the button 'Click here to Generate Plot'. The screen found below is brought into view. 


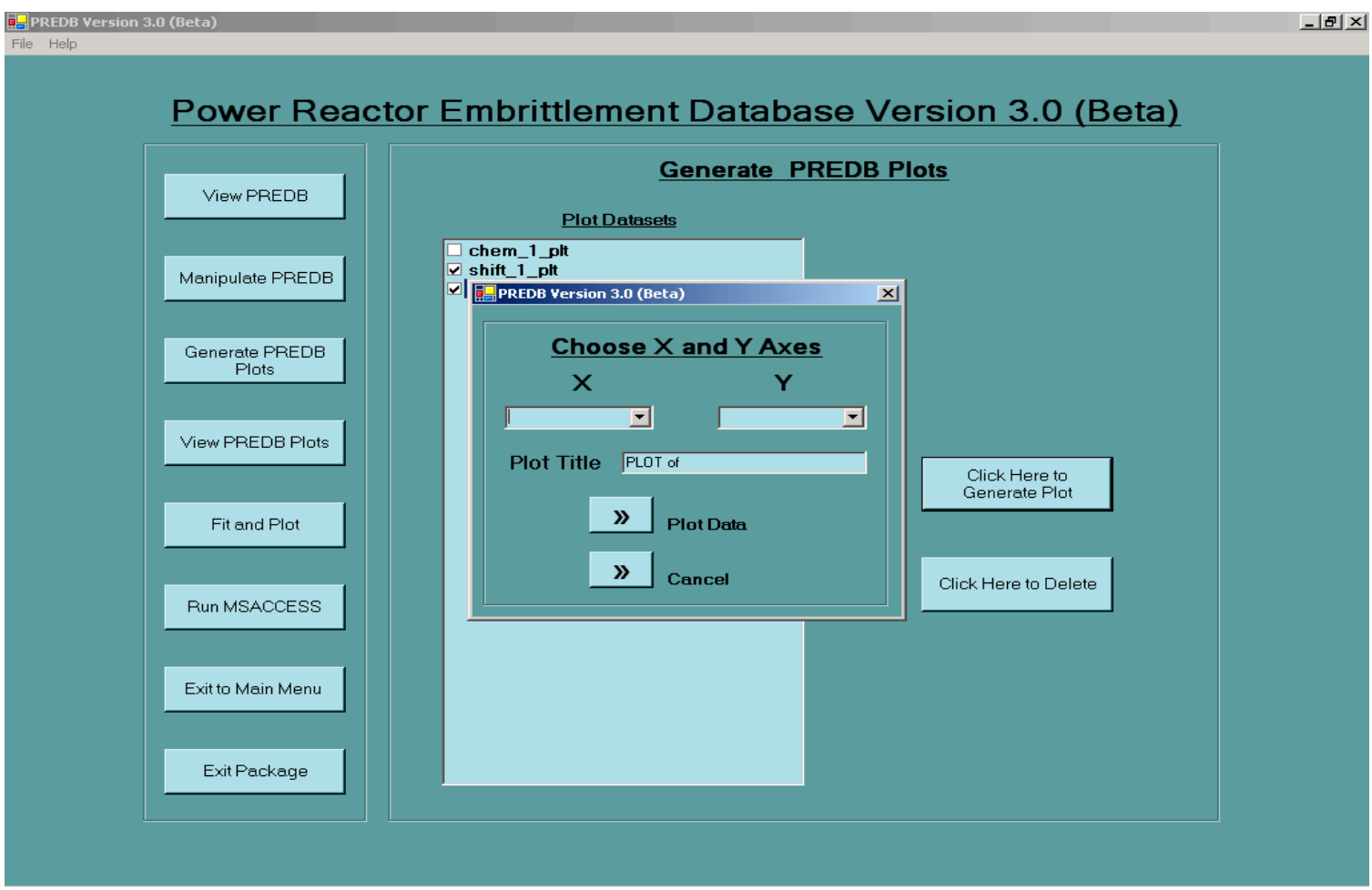

At this point choose the $\mathbf{X}$ and $\mathbf{Y}$ axes from the list of fields, enter the plot Title and click the button 'Plot Data'. The package first checks to see if the chosen $\mathrm{X}$ and $\mathrm{Y}$ axes are available in all the datasets selected, meaning it's a common dataset and the plotting continues further. If the chosen $\mathrm{X}$ and $\mathrm{Y}$ axes is not available in at least one plot table an 'Error' message is displayed mentioning that the datasets chosen are different. The user then has to click 'Cancel' to exit the plot screen and has to reselect a different set of Plot tables and then click the button 'Click here to Generate Plots'.

The package now moves data from the MSACCESS plot tables into an Excel workbook and generates a graph on a separate Excel work sheet. (Microsoft Excel manages all color \& shapes assignment to different datasets). After completing this process at the background the package displays a message asking the user if any curve generation needs to be done on the presently generated graph and depending on the user's request an appropriate curve is plotted on the same work sheet containing plotted data.

Three types of curve generation is available with this package namely.

\section{A.4.3.3.1 Reg Guide 1.99, Rev 2 with Uncertainties}

This curve is generated for a graph of CVT Shift at $30 \mathrm{ft}-\mathrm{lb}$ VS Fluence $>1 \mathrm{Mev}$ at Charpy Specimen location $\left[\mathrm{n} / \mathrm{cm}^{2}\right]$. This curve is specific to the PR-EDB table 'SHIFT_PR'. Reg Guide curves are generated for X axes chosen to be the Field 'CSPF1' and the Y axes Field 'DTT30'. On choosing the Fields 'CSPF1' and 'DTT30' the package will give on option of generating the reg guide curve. At this point the user has to choose the Reg Guide curve from the drop down box and click the button 'Define Curves'. On clicking this button the screen found below is displayed. 


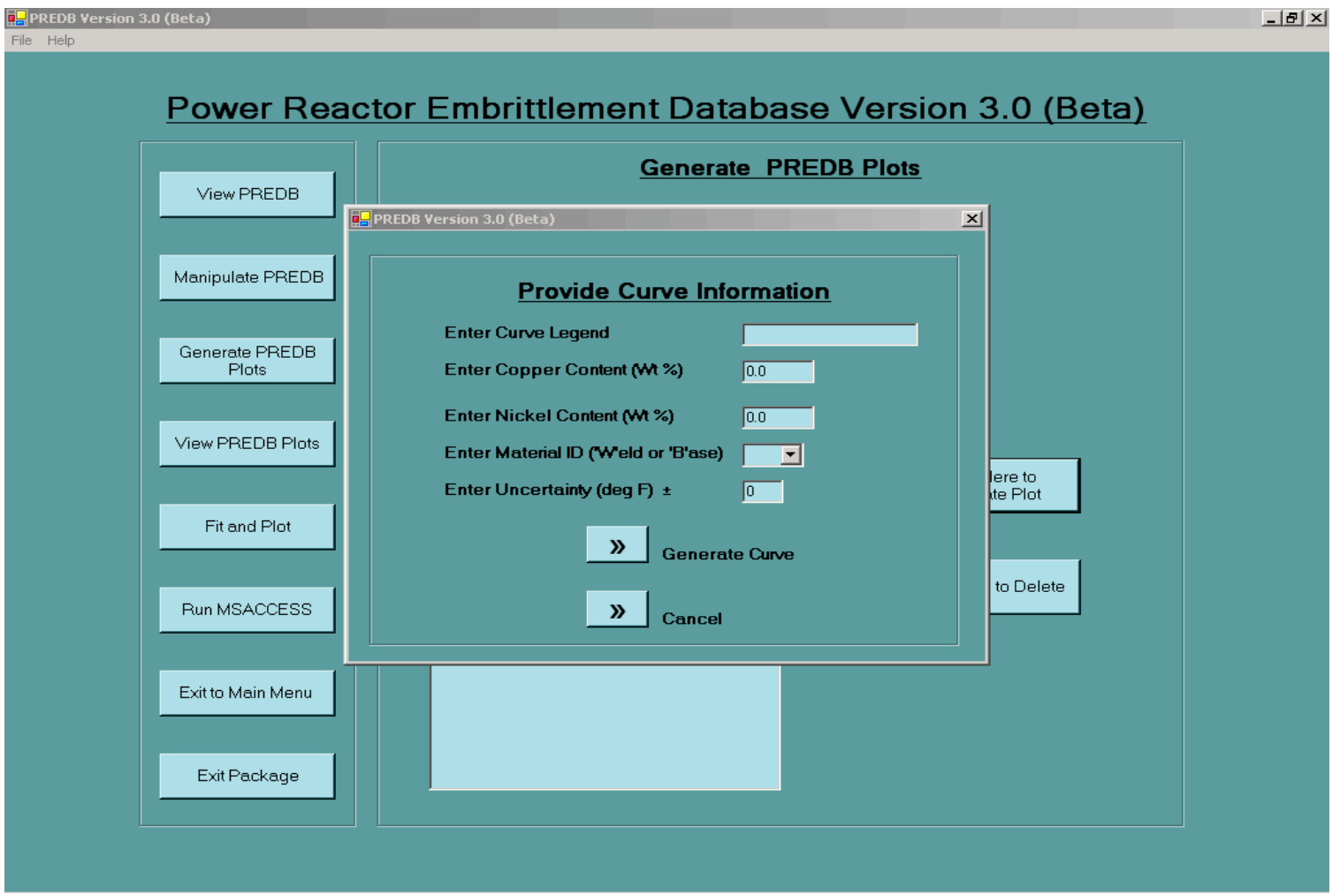

At this point the user has to provide all the parameters of the Reg guide curve he wants to generate namely the curve name, the copper content in weight $\%$, the nickel content in weight $\%$, the material (Weld or Base) and finally the uncertainty level. After entering all the values click the button 'Generate Curves'. The curve is then generated and user is asked if he wants to generate any more curves. If the user wants to generate more curves he could do so until the number of curve reach ten, after which reg guide curve generation quits automatically. The user can at any point of time quit curve generation by selecting 'Cancel' or saying a 'No' to the question asked for generating more curves.

\section{A.4.3.3.2 $(X=Y)$ Diagonal Lines}

This curve can be generated for all chosen Fields of $\mathrm{X}$ and $\mathrm{Y}$ Axes. After the user chooses his $\mathrm{X}$ and $\mathrm{Y}$ axes the data is first plotted onto an excel sheet and a curve selection screen is provided to the user. At this point the user has to select the option ' $(\mathrm{X}=\mathrm{Y})$ Diagonal Lines' On selection a Curve name entry screen is brought into view like the one found below. 


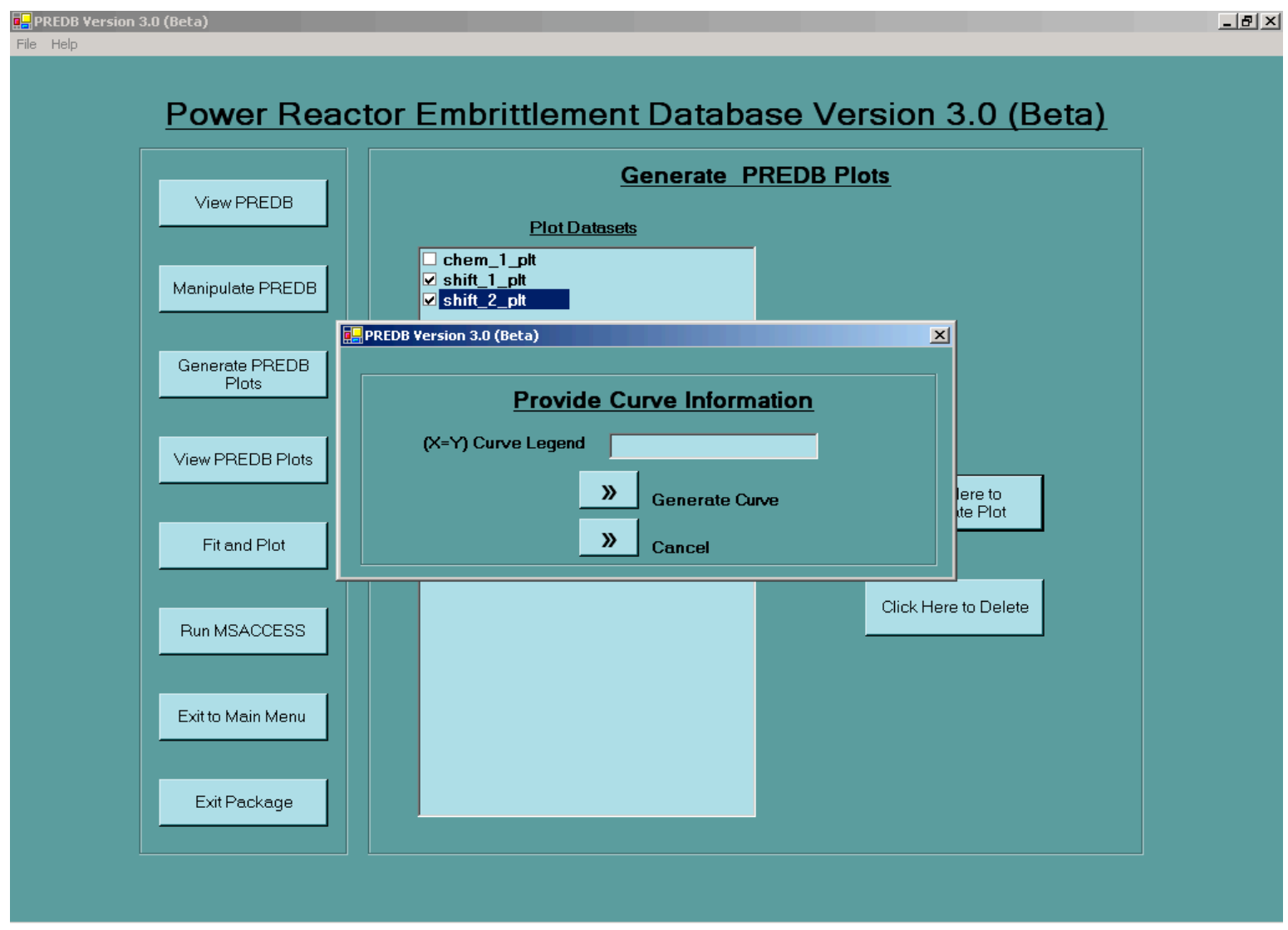

The user has to enter the curve name and then click 'Generate Curve'. A diagonal curve is generated on the graph where all the data from the table was plotted.

The user can at any point of time quit curve generation by selecting 'Cancel'.

\section{A.4.3.3.3 ( $Y=0)$ or $(Y= \pm 2 \sigma)$ for Residuals}

This curve can be generated for all chosen Fields of X and Y Axes. After the user chooses his X and $\mathrm{Y}$ axes the data is first plotted onto an excel sheet and a curve selection screen is provided to the user. At this point the user has to select the option ' $\mathrm{Y}=0$ or $\mathrm{Y}= \pm 2 \sigma$ for residuals' On selection a Curve name entry screen is brought into view like the one found below. 


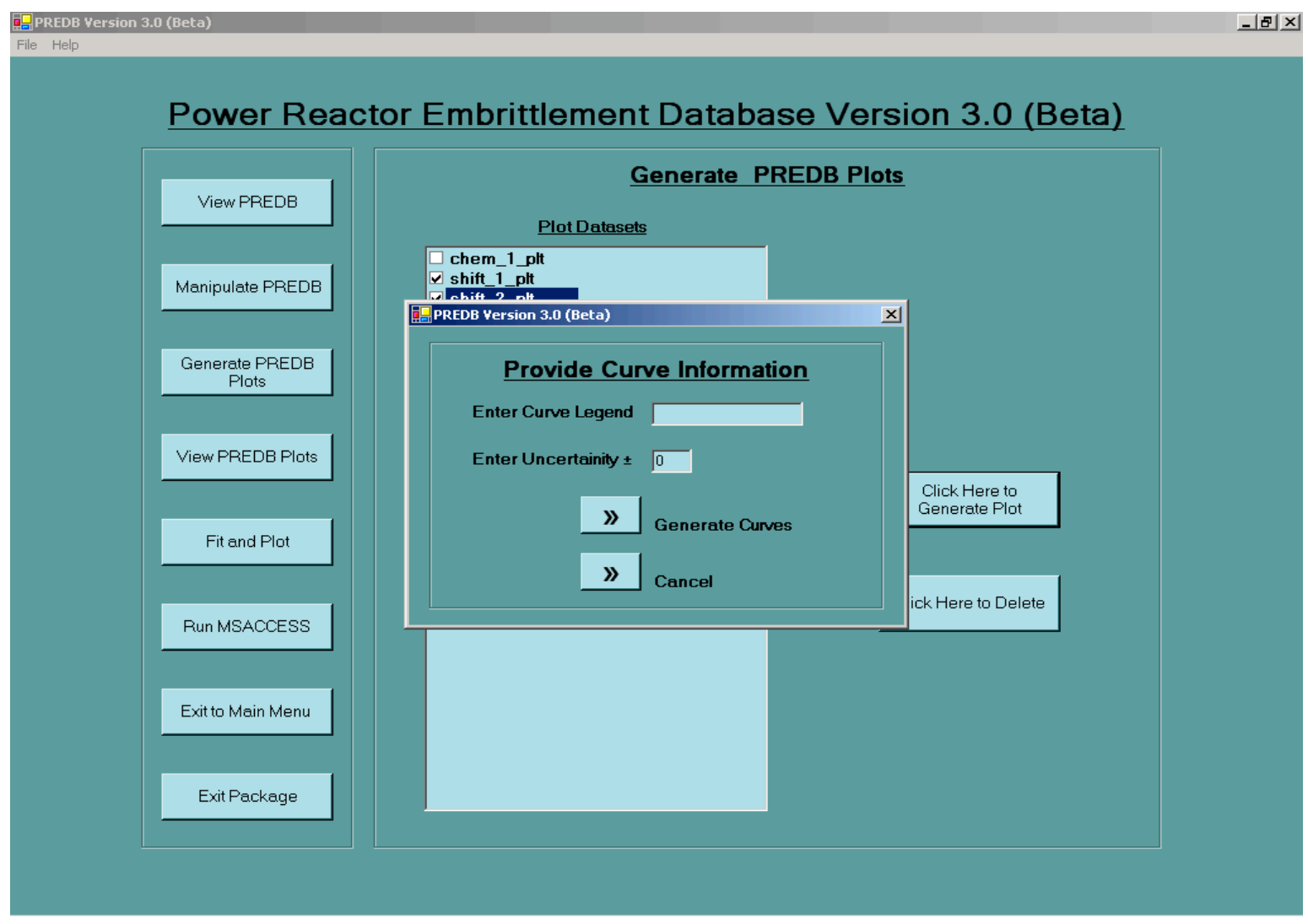

At this point the user has to provide Curve parameters namely the curve name and the uncertainty level. After entering all the values click the button 'Generate Curves'. The curve is then generated and user is asked if he wants to generate any more curves. If the user wants to generate more curves he could do so until the number of curve reach ten, after which curve generation quits automatically. The user can at any point of time quit curve generation by selecting 'Cancel' or saying a 'No' to the question asked for generating more curves.

\section{A.4.3.4 View PR-EDB Plots}

Plots generated by this package are stored in a sub-directory within the Package Installation directory. In order to enable the user to view these generated plots with ease a linking facility has been provided from the User Interface of the package. Users can toggle to this section by clicking 'View PR-EDB Plots' so switch from other sections to this section. After which the screen found below is brought into view.

At this point the user can select the Excel plot file from the list of plot files generated before and click the button 'Click here to View' in order to view the plots. The package uses the Microsoft Excel to open this plot file generated (It is assumed that Microsoft Excel 2000 or higher has been installed for this section to work.). 


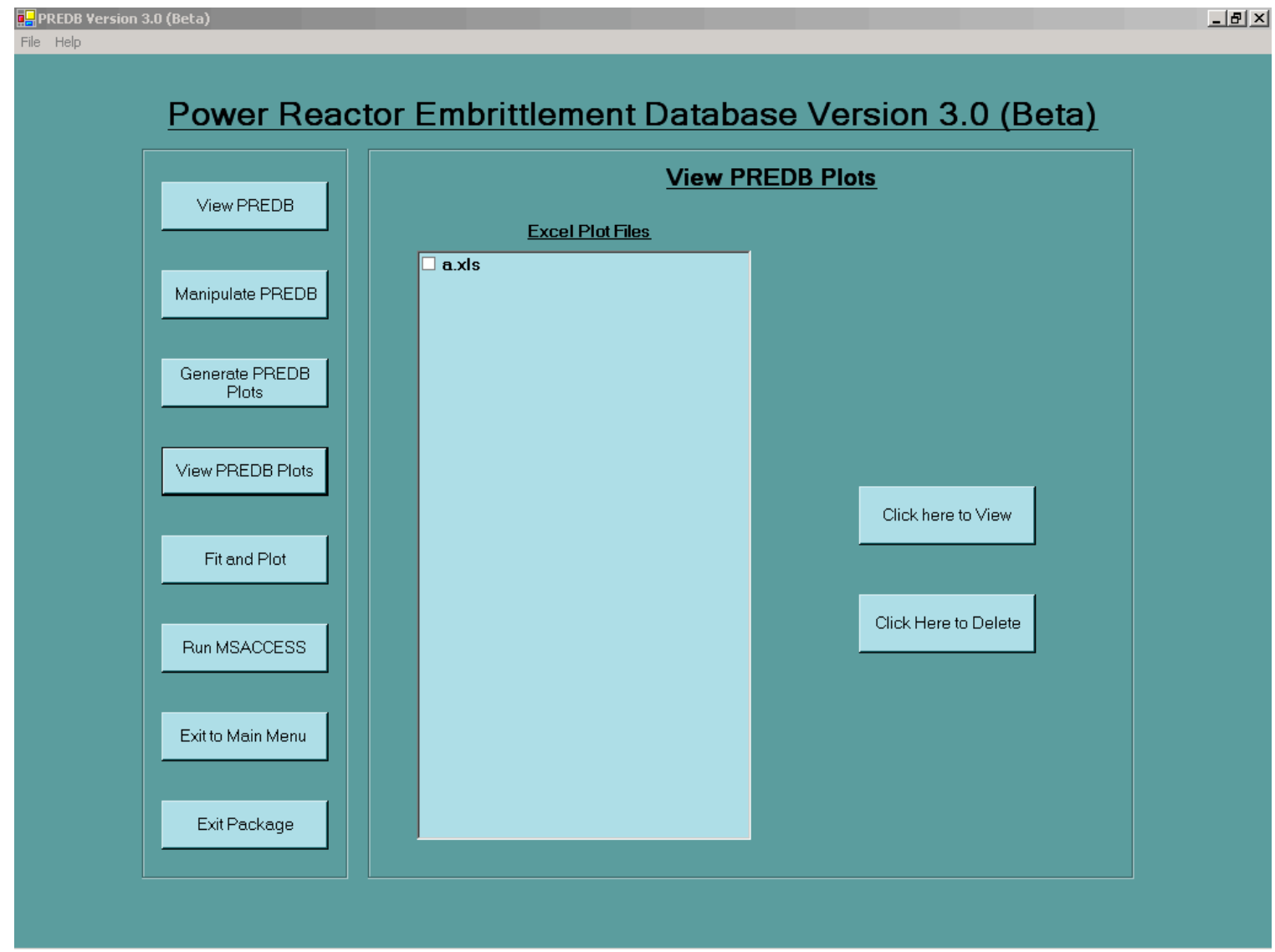

The user can also delete the Excel plot files without having to locate the file from the directory to delete them. The user has to select the file and click the button "Click here to Delete'. A confirmation is asked for deletion and on approval the file is deleted.

\section{A.4.3.5 Fit and Plot}

Procedures for fitting and plotting of raw Charpy data are shown schematically in Figure A.4.3.5.1. 


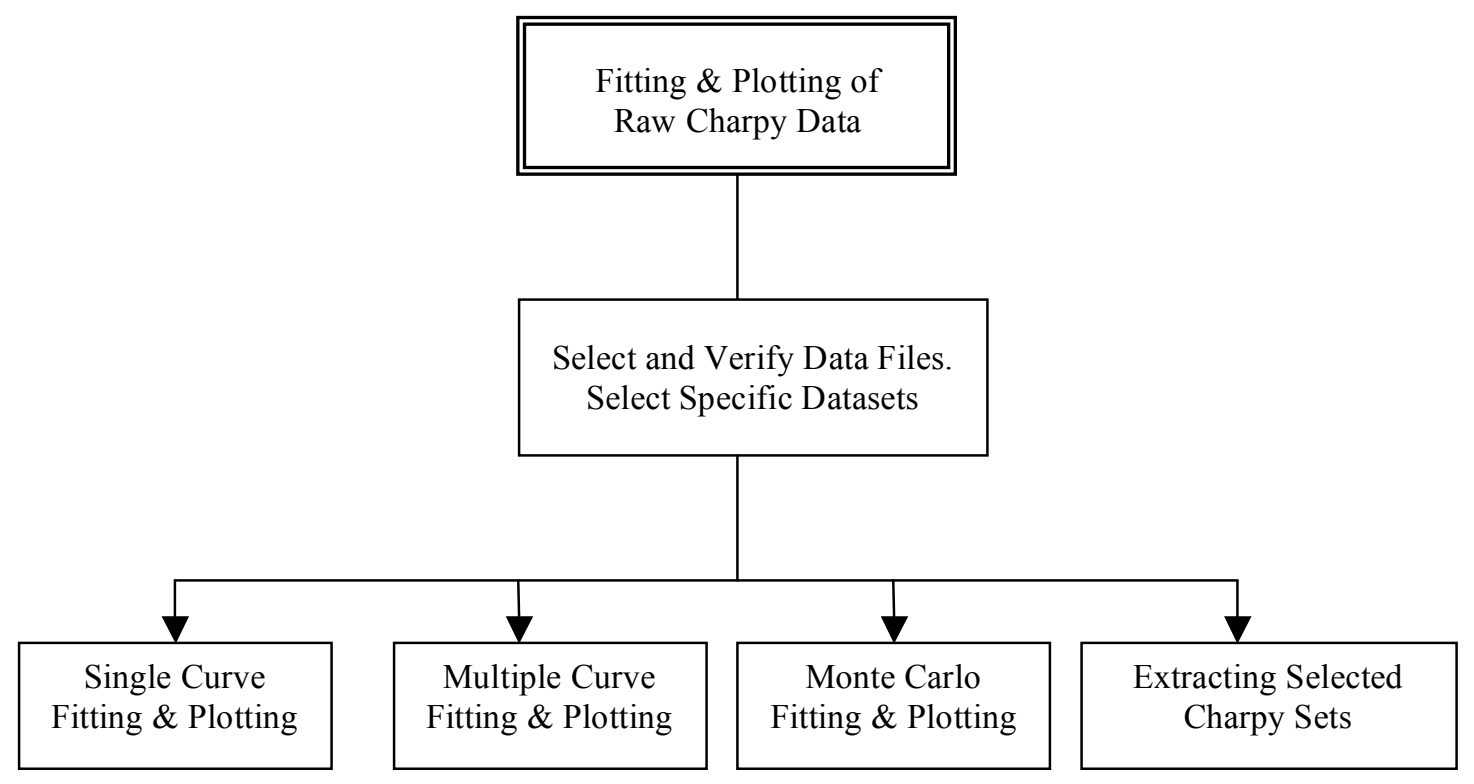

Figure A.4.3.5.1. Procedures for fitting and plotting raw Charpy data.

\section{A.4.3.5.1 General Considerations}

The EDB-Utilities software allows the creation of fits and plots for any given set of raw Charpy data using the hyperbolic tangent function. Each set of raw Charpy data is uniquely identified by the keys PLANT_ID + CAPSULE + HEAT_ID + SPEC_ORI, and all data points having the same combination of these four identifiers are combined into the same set, unless the sequence of data records is interrupted by a record that contains different key identifiers. The program requires an input file in ASCII format, RAW_C_PR.dat that was created from the PR-EDB table 'RAW_C_PR'. All data are converted to U.S. units, the unit fields are removed, and a one-character field is added in front of SPEC_ID. If this field contains an asterisk, the record will be excluded from processing; this feature is useful for removing outliers. No outliers are tagged in this way in the attached files. The modified file was then converted to ASCII format using the

Text file generation module of the PR-EDB Version 3.0 package.

\section{A.4.3.5.1.1.1.1.1 Generation of the .dat file 'RAW_C_PR.dat.'}

To generate this ASCII format Raw Charpy data file load the PR-EDB table into the manipulation module as said in the section A.4.3.2 of this guide. After loading the file choose and click the menu item 'Save Working Table' from the Drop down menu 'File'. A screen for saving the table back would appear as shown below 


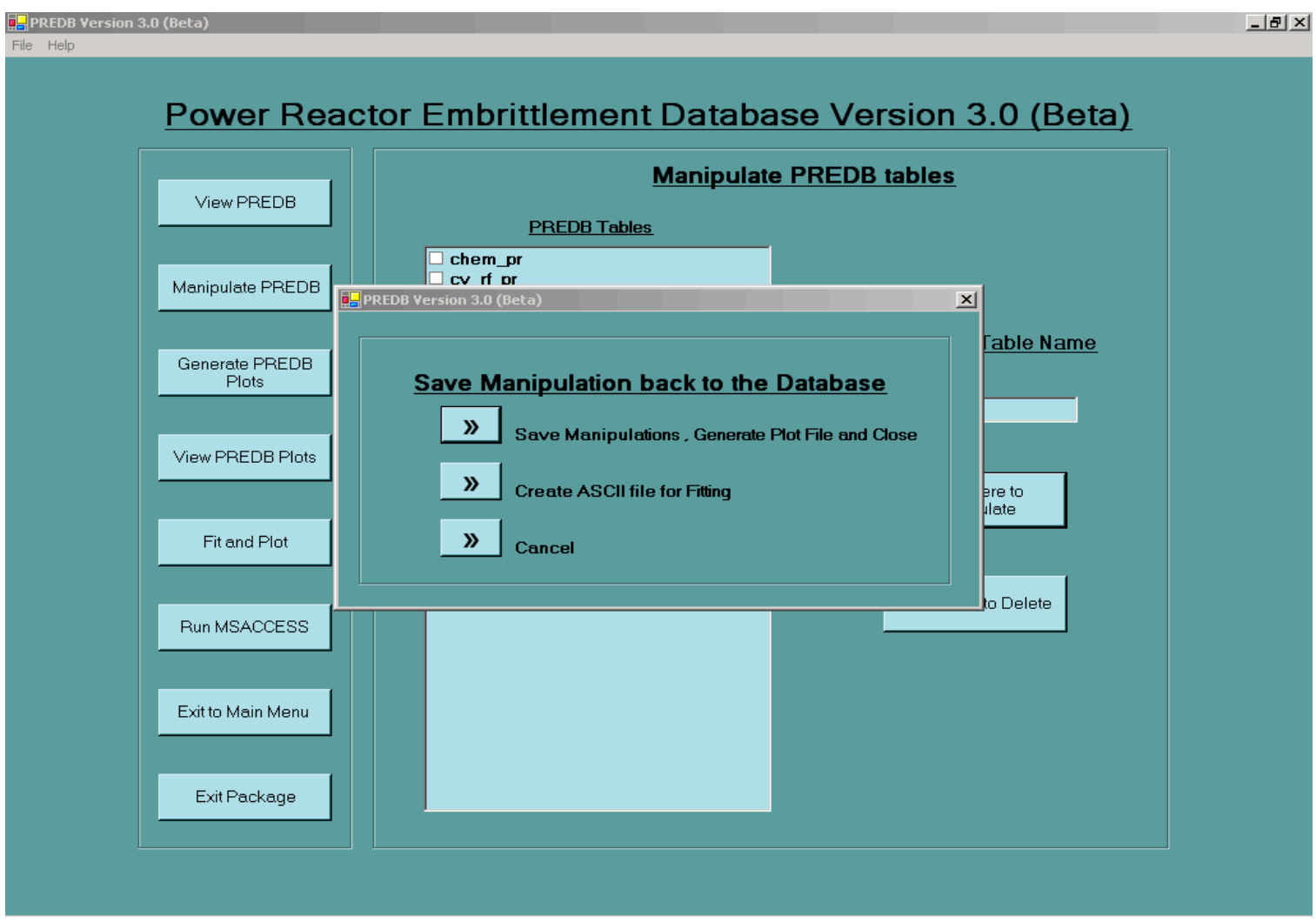

At this point the user has to just click the button 'Create ASCII file for Fitting'. On clicking the ASCII file is generated and on completion a Message is displayed confirming the file generation. After this step the user can continue with Fitting and plotting by selecting the option from the PREDB main screen.

To start the fitting module click on the button 'Fit and Plot' found on the left side of the screen.

The fitting procedure is completely automated. Upper and lower shelf values are restricted by adding a penalty proportional to the deviation from initial estimates to avoid unphysical fits. A first inspection of the points is made to obtain a rough estimate for the initial values of the curve parameters. A nonlinear least-squares fitting program ZSSQ from the IMSL library is used to determine the best fit, which is then plotted and appears on the screen, including data points with automatic scaling and labeling of the axes in both U.S. and international units. The plots can be sent to the printer, including a summary of transition temperatures and upper shelf data (in international units). All internal calculations are done in international units, centigrade and joule. Currently, no options are available to fit and plot lateral expansion or fracture appearance versus test temperature data. A detailed report of the fitting and uncertainty analysis will be available in the near future.

\section{A.4.3.5.2 Single-Curve Fitting and Plotting}

In this option, the selected data sets are fitted and plotted, one at a time, with optional printing of the results. Titles and subtitles for the plots can be either given individually or at the start of the procedure, with the key identifiers serving as subtitles. The user has the option to skip any data set and to terminate the procedure without reading the whole input file.

\section{A.4.3.5.3 Multiple-Curve Fitting and Plotting}

With this option, up to ten different fits can be placed into one plot which is useful for comparing data before and after irradiation. The user enters the overall title and legends for the individual fits. 
Default legends can be used which contain the name of the capsule and the total fluence $(>1.0 \mathrm{MeV})$. Legends can be placed by the user at a suitable free spot in the plot.

\section{A.4.3.5.4 Monte Carlo Uncertainty Analysis}

Uncertainties for the fitting parameters are needed to determine accuracy and credibility of the transition temperature and upper shelf data. A covariance matrix of the fitting parameters is part of any least-squares procedure, but these covariance are not used for uncertainty analysis in the EDBUtilities. The unavoidable linearization used for determining the covariance's disregards secondorder effects, and there is no possibility to account for uncertainties in test temperature. A more reliable procedure is the use of random variations of the input data (Monte Carlo procedure); such variations can be applied to both impact energy and test temperature, and the results reflect more accurately the influences of nonlinearities. The necessary computing time is, of course, increased by a large factor but remains manageable for today's computers. Because this option is completely automated, including printing the plots, a fairly large amount of data sets can be processed overnight or over a weekend. Nonphysical results and results that deviate substantially from the mean are eliminated from the sampling. This has the added advantage that fits can be obtained even after some tries have failed initially.

The user enters the (one-standard deviation) uncertainties for the impact energy and test temperature and the number of iterations. Unsuccessful iterations (i.e., the ones rejected by the program as nonphysical or inconsistent with the rest) are not counted; however, the total number of tries may not exceed five times the specified iteration number. Also needed is the number of sets to be skipped at the beginning of the input data file and the number to be processed. Processing is done, one set at a time, in sequence, starting after the specified numbers of sets have been skipped. A more specific selection can be obtained by using, as the input data file, the one created by the selection procedure (Sect. 5.5). Continuous plotting and printing can be chosen as an option, with the user providing the common title and the key identifiers as a subtitle.

Three output files are created by the procedure, the names of which are either entered by the user or assigned by default. The "Summary Output File" (default name FORT15; the 15 in FORT15 is the unit number of the FORTRAN output file) is a list which contains the set number, key identifiers, fluence, irradiation temperature, transition temperature at $41 \mathrm{~J}$ and $68 \mathrm{~J}(30 \mathrm{ft}-\mathrm{lb}$ and $50 \mathrm{ft}-\mathrm{lb})$, upper and lower shelf energy (all in international units), the number of specimens in the set, and the number of successful iterations for each processed set. The "Covariance Output File" (default name FORT16) contains mean values, standard deviations, and correlations for all fitting parameters which include the transition temperature at the center of the curve and 1/slope, which is one-half of the impact energy range of the transition region. The "EDB_dBASE Output File" (default name FORT17) is intended for conversion to a dBASE file whose data are an alternative to the file SHFT_PR. This file can also be used as an "auxiliary" input file in the multiple fitting option (Sect. 5.3). Its data are given in U.S. units. A "status report" listing the results from all successful and unsuccessful iterations is placed on the screen during the procedure. The screen output can be redirected to a file as an option.

The complete file RAW_C_PR.dat has been processed with this program, with $10 \mathrm{~J}$ and $4{ }^{\circ} \mathrm{C}$ as input uncertainties for impact energy and test temperature, respectively, and 200 iterations.

\section{A.4.3.5.5 Extracting Selected Charpy Sets}

The raw data files for individual Charpy sets are quite large and thus require long search times in sequential access. It is, therefore, convenient and saves time to copy small subsets from a larger file, if such subsets are processed repeatedly. This is accomplished through the data- selection option. The user specifies the selection criteria and may, in addition, skip certain sets and terminate the procedure without going through the rest of the input file. No processing is done during this option, but the user-specified output file (default FORT20) can now serve as an input file for any subsequent processing step. 


\section{A.4.3.5.6 Selection of Input Files and Data Sets}

The four options require essentially the same input information that is requested in several input screens:

\section{A.4.3.5.6.1 Names of Input Data Files, Primary and Auxiliary}

The primary input file is RAW_C_PR.dat which is NOT included in the package has to be generated by the user one time using the instructions detailed in Sect 5.1. The multiple-fitting option permits the use of an additional, "auxiliary" input file that contains the values of the fitting parameters as generated by the Monte Carlo uncertainty analysis as EDB-dBASE output file.

\section{A.4.3.5.6.2 Selection Criteria}

Reactors and materials can be selected for processing by entering the selection criteria in the appropriate menu screen. These criteria are not used in Monte Carlo uncertainty analysis. The Monte Carlo uncertainty analysis is designed to process a large number of data sets in sequence without user intervention. Consequently, only the starting number and the number of sets to be processed can be given. The number associated with each set can be found in the (ASCII) file RAW_CPY.SUM. These numbers are entered in the input screen as discussed in Sect. 5.4.

\section{A.4.3.5.6.3 Selection of Symbols and Colors}

Data points that are excluded from the fitting procedure can be plotted using different symbols. Such points can also be completely eliminated from the plot by using the empty symbol (zero symbol) for rejected data points.

\section{A.4.3.6 Run MSACCESS}

This section allows the user to run the MSACCESS program without exiting PR-EDB package, provided Microsoft office 2000 or higher has been installed. The user can, in this manner easily switch between different options and edit or perform operations that are needed to be done on the PREDB for customization but had not been included in the package.

\section{A.4.4 EXAMPLE FOR PR-EDB MANIPULATION}

The following example is intended as exercise for the user for the EDB-Utilities to guide the user through the various options and to show typical applications of these processing steps. It is assumed that the user will try to duplicate the sequence if processing steps which are listed in the following pages and to verify the results. The reader of this report who is only interested in the capabilities of the EDB-Utilities may have difficulty in understanding the listing of processing steps without running the program and may safely skip these parts, concentrating on the general introductions.

File Manipulation Procedures with Plots.

In the following example, the relation between the shift in transition temperature and upper shelf energy drop will be investigated. This example was chosen because it makes use of the most of the file manipulation features and needs only one PR-EDB raw data table SHIFT_PR. For more in-depth investigations, chemistry data need to be added with would require additional processing with MSACCESS software. Creation of Plot tables and actual plotting required the EDB-Utilities software.

This example compares the values given in DTT30 for the shift of transition temperature at $30 \mathrm{ft}-\mathrm{lb}$ with the relative upper-shelf drop given in DUSE_REL in percent. However in many reports, these values are not listed directly and only the transition temperatures, UTT30 and ITT30, and upper shelf energies, UUSE and IUSE, for unirradiated conditions are given, from which the shift values can easily be calculated. Thus, two new fields are added to the input file, DTT and DUSE, which will contain either the reported or calculated value, whatever is available, with preference for the directly reported value. The values for base material (plates, forgings, and standard reference materials) and welds will be separated. Heat-affected-zone data will be ignored. 
Using the file-manipulation option, the following sequence of procedures will be performed:

\section{A.4.4.1.1.1.1.1.1 Step 1: Retrieval of the Table 'SHIFT_PR'}

Load the PR-EDB table SHIFT_PR for manipulation. In order to do this first click on the button 'Manipulate PR-EDB' to toggle to manipulation section. Then enter a name for storing the PR-EDB manipulations into a new table in the text box. Use a temporary name called 'TMP0'. The table is then brought into a grid view with all manipulation features available.

\section{A.4.4.1.1.1.1.1.2 Step 2: Deletion of Records}

Choose and click the menu item "Delete Records from Existing Table' from the Drop down menu 'File'. In the deletion screen perform the following functions.

1. Choose the Field to be 'PROD_ID', Operator to be '=', enter 'HAZ' in the search criteria box and click the button 'Mark records for Deletion'.

2. Choose the Field to be 'TEMP_U', Operator to be ' $<>$ ', enter ' $\mathbf{F}$ ' in the search criteria box and click the button 'Mark records for Deletion'.

3. Choose the Field to be 'USE_U', Operator to be ' $<>$ ', enter 'FT-LB' in the search criteria box and click the button 'Mark records for Deletion'. (Data with non-U.S units are eliminated; conversion to U.S units is another possibility.)

After these records have been marked for deletion, click the button 'Delete Records and Return'. The records are then deleted from the table and cannot be retrieved unless we restore the table from the proprietary table PR-EDB.

\section{A.4.4.1.1.1.1.1.3 Step 3: Adding User Fields}

Choose and click the menu item “Add User Fields' from the Drop down menu 'File'. In the Add user field perform the following functions.

1. Add a User Fields by entering the Field name and a Description in the text boxes.

Field Name: $\quad$ DTT

Field Description: Shift in Transition Temperature @ 30 ft-lb [Degree F]

Field Name: $\quad$ DUSE

Field Description: Upper Shelf Drop [Percent]

\section{A.4.4.1.1.1.1.1.4 Step 4: Save working file 'TMP0'}

After having done manipulations for the table 'TMPO' we have to save it back to the MSACCESS table to generate a new file and we can manipulate further by loading the new file and proceeding further. (Note: In contrast to the earlier version 2.0 the table has to be written back to the structure and further manipulation can be done by loading that table into another temp table.

To save the table choose and click the menu item 'Save Working Table' from the Drop down menu 'File'. In the save working file screen click the button 'Save working file generate plot file and close' and when a confirmation is asked for generating a plot file answer with a 'NO'.

\section{A.4.4.1.1.1.1.1.5 Step 5: Retrieval of the Table 'TMPO' into 'TMP01'}

Load the PR-EDB table 'TMPO' for manipulation. In order to do this first click on the button 'Manipulate PR-EDB' to toggle to manipulation section. Then enter a name for storing the PR-EDB manipulations into a new table in the text box. Use a temporary name 'TMP01'. The table is then brought into a grid view with all manipulation features available. 


\section{A.4.4.1.1.1.1.1.6 Step 6: Deletion of Records}

Choose and click the menu item "Delete Records from Existing Table' from the Drop down menu 'File'. In the deletion screen perform the following functions.

1. Choose the Field to be 'DUSE_REL', Operator to be ' $<=$ ', enter ' 0 ' in the search criteria box and click the button 'Mark records for Deletion'. ( To use reported USE_REL with positive drop only.)

After these records have been marked for deletion, click the button 'Delete Records and Return'. The records are then deleted from the table and cannot be retrieved unless we restore the table from the proprietary table PR-EDB.

\section{A.4.4.1.1.1.1.1.7 Step 7: Calculate User Fields}

To perform calculations and store the results into the user defined fields, choose and click the menu item 'Calculate User Fields' from the Drop down list 'File'. In the Calculation field perform the following operation.

1. Select the Source Field 1 to be 'DUSE_REL', Source Field 2 to be the first entry 'CONSTANT', enter the constant value 0 in the text box , choose operator '+', Destination Field to be 'DUSE' and click the button 'Calculate'. (Puts DUSE_REL into DUSE.)

\section{A.4.4.1.1.1.1.1.8 Step 8: Save working file 'TMP01'}

After having done manipulations for the table 'TMPO1' we have to save it back to the MSACCESS table to generate a new file and we can manipulate further by loading the new file and proceeding further. (Note: In contrast to the earlier version 2.0 the table has to be written back to the structure and further manipulation can be done by loading that table into another temp table.

To save the table choose and click the menu item 'Save Working Table' from the Drop down menu 'File'. In the save working file screen click the button 'Save working file generate plot file and close' and when a confirmation is asked for generating a plot file answer with a 'NO'.

\section{A.4.4.1.1.1.1.1.9 Step 9: Retrieval of the Table 'TMPO' into 'TMP1'}

Load the PR-EDB table 'TMPO' for manipulation. In order to do this first click on the button 'Manipulate PR-EDB' to toggle to manipulation section. Then enter a name for storing the PR-EDB manipulations into a new table in the text box. Use a temporary name 'TMP01'. The table is then brought into a grid view with all manipulation features available.

\section{A.4.4.1.1.1.1.1.10 Step 10: Deletion of Records}

Choose and click the menu item 'Delete Records from Existing Table' from the Drop down menu 'File'. In the deletion screen perform the following functions.

1. Choose the Field to be 'DUSE REL', Operator to be ' $<>$ ', enter ' 0 ' in the search criteria box and click the button 'Mark records for Deletion'. (Retain records without DUSE_REL.)

2. Choose the Field to be 'UUSE', Operator to be ' $<=$ ', enter ' 0 ' in the search criteria box and click the button 'Mark records for Deletion'.

3. Choose the Field to be 'IUSE', Operator to be ' $<=$ ', enter ' 0 ' in the search criteria box and click the button 'Mark records for Deletion'. (Eliminate missing UUSE and IUSE values)

After these records have been marked for deletion, click the button 'Delete Records and Return'. The records are then deleted from the table and cannot be retrieved unless we restore the table from the proprietary table PR-EDB. 


\section{A.4.4.1.1.1.1.1.11 Step 11: Calculate User Fields}

To perform calculations and store the results into the user defined fields, choose and click the menu item 'Calculate User Fields' from the Drop down list 'File'. In the Calculation field perform the following operation.

1. Select the Source Field 1 to be 'UUSE', Source Field 2 to be 'IUSE', choose operator '-', Destination Field to be 'DUSE', and click the button 'Calculate'.

2. Select the Source Field 1 to be 'DUSE', Source Field 2 to be 'UUSE'. Operator to be ' $/$ ', Destination Field to be 'DUSE' and click the button 'Calculate'.

3. Select the Source Field 1 to be 'DUSE', Source Field 2 to be the first entry 'CONSTANT', enter the constant value 100 in the text box, Operator to be '*', Destination Field to be 'DUSE' and click the button 'Calculate'. (Puts Calculated Values (UUSE-IUSE)/UUSE * 100 to DUSE)

\section{A.4.4.1.1.1.1.1.12 Step 12: Deletion of Records}

Choose and click the menu item 'Delete Records from Existing Table' from the Drop down menu 'File'. In the deletion screen perform the following functions.

1. Choose the Field to be 'DUSE', Operator to be ' $<=$ ', enter ' 0 ' in the search criteria box and click the button 'Mark records for Deletion'. (Eliminate negative USE values)

After these records have been marked for deletion, click the button 'Delete Records and Return'. The records are then deleted from the table and cannot be retrieved unless we restore the table from the proprietary table PR-EDB.

\section{A.4.4.1.1.1.1.1.13 Step 13: Adding Records from Another Table 'TMP01' to Present Table 'TMP1'.}

Choose and click the menu item 'Add records to Existing Table' from the Drop down menu 'File'. In the Records addition screen perform the following functions.

1. Select the table 'TMP01' from the drop down list and click 'Pull records from Table'.

2. In the Records merge screen click 'Merge'. After this the number of records being appended to the table is displayed and the records are appended.

The working file now contains both reported and calculated relative drop values for USE with preference for reported values and negative drop values eliminated. A similar sequence can be performed for shift in transition temperature.

\section{A.4.4.1.1.1.1.1.14 Step 14: Save Working File 'TMP1'.}

After having done manipulations for the table 'TMP1' we have to save it back to the MSACCESS table to generate a new file and we can manipulate further by loading the new file and proceeding further. (Note: In contrast to the earlier version 2.0 the table has to be written back to the structure and further manipulation can be done by loading that table into another temp table.

To save the table choose and click the menu item 'Save Working Table' from the Drop down menu 'File'. In the save working file screen click the button 'Save working file generate plot file and close' and when a confirmation is asked for generating a plot file answer with a 'NO'. 


\section{A.4.4.1.1.1.1.1.15 Step 15: Retrieval of the Table 'TMP1' into 'TMP11'}

Load the PR-EDB table 'TMP1' for manipulation. In order to do this first click on the button 'Manipulate PR-EDB' to toggle to manipulation section. Then enter a name for storing the PR-EDB manipulations into a new table in the text box. Use a temporary name 'TMP11'. The table is then brought into a grid view with all manipulation features available.

\section{A.4.4.1.1.1.1.1.16 Step 16: Deletion of Records}

Choose and click the menu item 'Delete Records from Existing Table' from the Drop down menu 'File'. In the deletion screen perform the following functions.

1. Choose the Field to be 'DTT30', Operator to be ' $<=$ ', enter ' 0 ' in the search criteria box and click the button 'Mark records for Deletion'.

After these records have been marked for deletion, click the button 'Delete Records and Return'. The records are then deleted from the table and cannot be retrieved unless we restore the table from the proprietary table PR-EDB.

\section{A.4.4.1.1.1.1.1.17 Step 17: Calculate User Fields}

To perform calculations and store the results into the user defined fields, choose and click the menu item 'Calculate User Fields' from the Drop down list 'File'. In the Calculation field perform the following operation.

1. Select the Source Field 1 to be 'DTT30', Source Field 2 to be the first entry 'CONSTANT', enter the constant value $\mathbf{0}$ in the text box, choose operator '+', Destination Field to be 'DTT' and click the button 'Calculate'. (Puts DTT30 into DTT.)

\section{A.4.4.1.1.1.1.1.18 Step 18: Save working file 'TMP11'}

After having done manipulations for the table 'TMP11' we have to save it back to the MSACCESS table to generate a new file and we can manipulate further by loading the new file and proceeding further. (Note: In contrast to the earlier version 2.0 the table has to be written back to the structure and further manipulation can be done by loading that table into another temp table.

To save the table choose and click the menu item 'Save Working Table' from the Drop down menu 'File'. In the save working file screen click the button 'Save working file generate plot file and close' and when a confirmation is asked for generating a plot file answer with a 'NO'.

\section{A.4.4.1.1.1.1.1.19 Step 19: Retrieval of the Table 'TMP1' into 'DTT_US'}

Load the PR-EDB table 'TMP1' for manipulation. In order to do this first click on the button 'Manipulate PR-EDB' to toggle to manipulation section. Then enter a name for storing the PR-EDB manipulations into a new table in the text box. Use a temporary name 'DTT_US'. The table is then brought into a grid view with all manipulation features available.

\section{A.4.4.1.1.1.1.1.20 Step 20: Deletion of Records}

Choose and click the menu item 'Delete Records from Existing Table' from the Drop down menu 'File'. In the deletion screen perform the following functions.

1. Choose the Field to be 'DTT30', Operator to be ' $<>$ ', enter ' 0 ' in the search criteria box and click the button 'Mark records for Deletion'. (Eliminate reported DTT30) 
After these records have been marked for deletion, click the button 'Delete Records and Return'. The records are then deleted from the table and cannot be retrieved unless we restore the table from the proprietary table PR-EDB.

\section{A.4.4.1.1.1.1.1.21 Step 21: Calculate User Fields}

To perform calculations and store the results into the user defined fields, choose and click the menu item 'Calculate User Fields' from the Drop down list 'File'. In the Calculation field perform the following operation.

1. Select the Source Field 1 to be 'ITT30', Source Field 2 to be 'UTT30', choose operator '-', Destination Field to be 'DTT', and click the button 'Calculate'. (Puts Calculated shift into DTT)

\section{A.4.4.1.1.1.1.1.22 Step 22: Deletion of Records}

Choose and click the menu item 'Delete Records from Existing Table' from the Drop down menu 'File'. In the deletion screen perform the following functions.

1. Choose the Field to be 'DTT', Operator to be ' $<=$ ', enter ' 0 ' in the search criteria box and click the button 'Mark records for Deletion'. (Eliminate negative shift)

After these records have been marked for deletion, click the button 'Delete Records and Return'. The records are then deleted from the table and cannot be retrieved unless we restore the table from the proprietary table PR-EDB.

\section{A.4.4.1.1.1.1.1.23 Step 23: Adding Records from Another Table 'TMP11' to Present Table 'DTT_US'}

Choose and click the menu item 'Add records to Existing Table' from the Drop down menu 'File'. In the Records addition screen perform the following functions.

1. Select the table 'TMP11' from the drop down list and click 'Pull records from Table'.

2. In the Records merge screen click 'Merge'. After this the number of records being appended to the table is displayed and the records are appended.

The working file now contains all the desired values for transition temperature shift and upper shelf drop in the two newly created fields DTT and DUSE. These values are ready for printing and plotting. Through the processes of deleting and adding. The original sequence of records has been destroyed. It may be desired to put the records in some new order before printing (the order of records is immaterial for plotting), for instance, through:

\section{A.4.4.1.1.1.1.1.24 Step 24: Sorting of Records}

Choose and click the menu item 'Sort Records' from the Drop down menu 'File'. In the sorting screen perform the following function.

1. Choose the field 'DTT' from the drop down list, 'ASCENDING' from the Drop down list which says 'Sorting order' and click the button 'Sort Records'.

\section{A.4.4.1.1.1.1.1.25 Step 25: Save working file 'DTT_US'}

After having done manipulations for the table 'DTT_US' we have to save it back to the MSACCESS table to generate a new file and we can manipulate further by loading the new file and proceeding 
further. (Note: In contrast to the earlier version 2.0 the table has to be written back to the structure and further manipulation can be done by loading that table into another temp table.

To save the table choose and click the menu item 'Save Working Table' from the Drop down menu 'File'. In the save working file screen click the button 'Save working file generate plot file and close' and when a confirmation is asked for generating a plot file answer with a 'NO'.

For plotting it maybe desired to have different symbols for base materials and welds. This can be accomplished by selecting subsets of records from the Table 'DTT_US' before exporting them to plot tables.

\section{A.4.4.1.1.1.1.1.26 Step 26: Retrieval of the Table 'DTT_US' into 'BASE'}

Load the PR-EDB table 'DTT_US' for manipulation. In order to do this first click on the button 'Manipulate PR-EDB' to toggle to manipulation section. Then enter a name for storing the PR-EDB manipulations into a new table in the text box. Use a temporary name 'BASE'. The table is then brought into a grid view with all manipulation features available.

\section{A.4.4.1.1.1.1.1.27 Step 27: Deletion of Records}

Choose and click the menu item 'Delete Records from Existing Table' from the Drop down menu 'File'. In the deletion screen perform the following functions.

1. Choose the Field to be 'PROD_ID', Operator to be '=', enter ' $\mathbf{W}$ ' in the search criteria box and click the button 'Mark records for Deletion'.

(Obtaining only Base Materials.)

After these records have been marked for deletion, click the button 'Delete Records and Return'. The records are then deleted from the table and cannot be retrieved unless we restore the table from the proprietary table PR-EDB.

\section{A.4.4.1.1.1.1.1.28 Step 28: Save working file 'BASE' \& Generate a Plot Table}

After having done manipulations for the table 'BASE' we have to save it back to the MSACCESS table to generate a plot table.

To save the table choose and click the menu item 'Save Working Table' from the Drop down menu 'File'. In the save working file screen click the button 'Save working file generate plot file and close' and when a confirmation is asked for generating a plot file answer with a 'YES'. After this step a Plot Table is generated and it available for plotting in the selection list of the plotting section.

\section{A.4.4.1.1.1.1.1.29 Step 29: Retrieval of the Table 'DTT_US' into 'WELD'}

Load the PR-EDB table 'DTT_US' for manipulation. In order to do this first click on the button 'Manipulate PR-EDB' to toggle to manipulation section. Then enter a name for storing the PR-EDB manipulations into a new table in the text box. Use a temporary name 'WELD'. The table is then brought into a grid view with all manipulation features available.

\section{A.4.4.1.1.1.1.1.30 Step 30: Deletion of Records}

Choose and click the menu item 'Delete Records from Existing Table' from the Drop down menu 'File'. In the deletion screen perform the following functions.

1. Choose the Field to be 'PROD_ID', Operator to be ' $<>$ ', enter 'W' in the search criteria box and click the button 'Mark records for Deletion'. (Obtaining only Weld Materials.)

After these records have been marked for deletion, click the button 'Delete Records and Return'. The records are then deleted from the table and cannot be retrieved unless we restore the table from the proprietary table PR-EDB. 


\section{A.4.4.1.1.1.1.1.31 Step 31: Save working file 'WELD' \& Generate a Plot Table}

After having done manipulations for the table 'WELD' we have to save it back to the MSACCESS table to generate a plot table.

To save the table choose and click the menu item 'Save Working Table' from the Drop down menu 'File'. In the save working file screen click the button 'Save working file generate plot file and close' and when a confirmation is asked for generating a plot file answer with a 'YES'. After this step a Plot Table is generated and it available for plotting in the selection list of the plotting section.

\section{A.4.4.1.1.1.1.1.32 Step 32: Deleting all Temporary Tables generated}

From the Manipulation main screen select the temporary tables generated one by one and click the button 'Click here to delete the Table'. After a confirmation is approved the table is deleted from the PR-EDB. The temporary table generated in this example which might not be needed are TMP0, TMP01, TMP1, TMP11, DTT_US, BASE, and WELD. The user might retain the tables needed for later use and can delete all other tables generated in the process.

The Data is now ready for plotting. After selecting the plotting option, the following input must be entered. To first select the plotting option toggle to the plotting section by clicking from the PR-EDB main screen the button 'Generate PR-EDB Plots'. Select the Plot data sets, in this present case the plots tables are 'WELD' \& 'BASE'. On selecting the plot datasets click the button 'Click here to Generate Plots'. In the plot selection screen perform the following function.

1. Select the $\mathrm{X}$ axis to be 'DTT', $\mathrm{Y}$ axis to be 'DUSE', enter Plot title in the text Box as 'Plot of Shift in Transition Temperature versus Upper Shelf Drop' and click the button 'Plot Data'.

The present plot needs no additional curves, hence when a confirmation is asked for generating curves answer a 'NO'. The user can optionally generate curves following the guidelines explained earlier in this Manual. The symbols and colors are assigned automatically by Excel and can be changed at any time using Excel. From this graph we can ascertain that there seems to be a near linear relation between transition temperature shift and Upper shelf drop for low shift values, although the USE drop appears to level off at high shift values. No obvious distinctions between Base metal and welds can be seen. The data scatter is rather large and suggests further investigation of additional factors which may influence the relation between CVT shift and USE drop. 


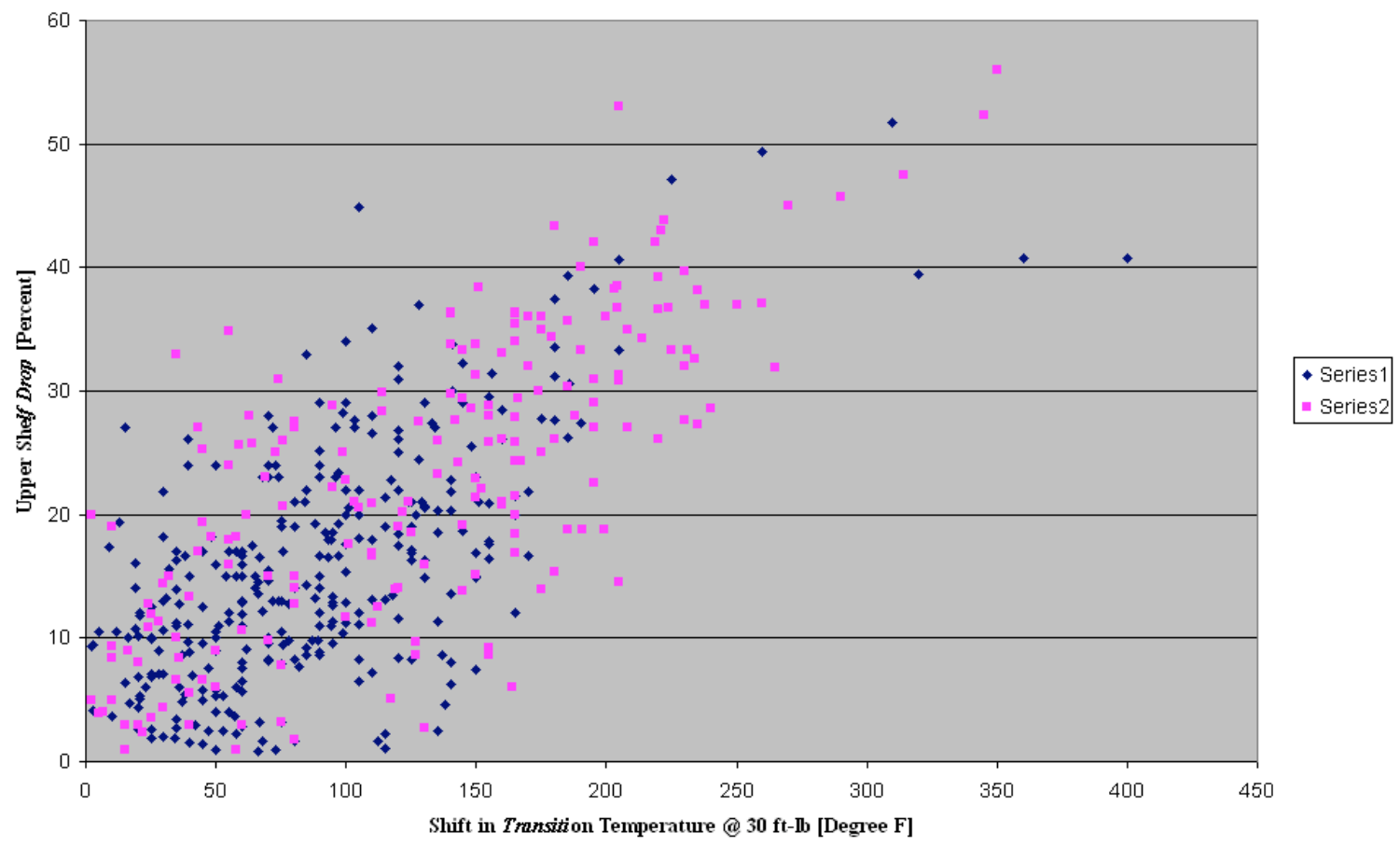

\section{A.5 EVALUATED RESIDUAL .FILE}

PR-EDB data as available is independent of each other and requires processing before it can be merged to form a composite file. The need for processing is higher, as the PR-EDB files are available in a RAW form i.e., contains special symbols, missing data etc. Further the data available does not form a 1-1 relationship associated to the key identifiers, which is an important requirement to make meaningful analysis.

Residual file generation is the first step towards development of Automated Program Libraries (APL). In general terms we extract RAW data and send it thro a pipeline for filtering and processing to obtain a dataset which are devoid special symbols and repetitions removed. After which the file is merged to form a composite file. It is this final composite file which can be used for meaningful data analysis.

Three tables which we use to generate this residual file are 'shft_pr', 'chem_pr' and 'reac_pr' namely. From these tables the residual file is generated, containing two separated tables 'shft_pr_u' Unirradiated data and 'shift_pr' -Irradiated data.

The flow of processing these tables would be as follows.

- First stage where the 'shft_pr' is loaded and is partially filtered and also a separate "shft_pr_u' table which contains a normalized Unirradiated data is generated.

In this stage first we generate a Unirradiated data table which contains only key identifiers and unirradiated data. Here we take an average selected average of data available in the repeating rows of information and generate a normalized Unirradiated table, which essentially contains a 1-1 relationship data. Then we proceed to partially process the Irradiated data i.e add extra columns and fill in with data manipulated from the present 'shft_pr' table itself. 
- Second stage where the 'reac_pr' is loaded and is filtered and processed. In this section we perform extensive calculation by splitting the data available into two depending upon CONFIG. These two split tables are then manipulated to evaluate the CAP_NOM from other fields CAP_MIN \& CAP_MAX, like wise F1_RATE is derived. Finally these two separate tables are merged to form one complete table with most of the data derived and filled. Then this table is filtered to remove the repetitions to form a 1-1 relationship data ready to be merged into the composite table.

- Third stage where the 'chem_pr' is loaded and filtered to evaluate average of all the available chemistry data for the materials $\mathrm{C}, \mathrm{MN}, \mathrm{P}, \mathrm{S}, \mathrm{SI}, \mathrm{MO}, \mathrm{CU}, \mathrm{NI}$ to generate an intermediate table 'chem_pr_all'. In this stage the columns with blank data are derived from other matching rows, then a separate intermediate table is constructed which contains an average of all the chemistry data, the number of occurrences of the data and the standard deviation. This intermediate table is constructed in such a way that it's a 1-1 relationship data table ready to be merged into the composite table.

- Fourth stage where the 'chem_pr' is loaded and filtered to evaluate average of Manufacturer chemistry data for the materials $\mathrm{C}, \mathrm{MN}, \mathrm{P}, \mathrm{S}, \mathrm{SI}, \mathrm{MO}, \mathrm{CU}, \mathrm{NI}$ to generate an intermediate table 'chem_pr_manu'. In this stage the columns with blank data are derived from other matching rows, then a separate intermediate table is constructed which contains an average of manufacturing chemistry data, the number of occurrences of the data and the standard deviation. This intermediate table is constructed in such a way that it's a 1-1 relationship data table ready to be merged into the composite table.

- Fifth stage where the 'chem_pr' is loaded and filtered to evaluate average of Specimen chemistry data for the materials $\mathrm{C}, \mathrm{MN}, \mathrm{P}, \mathrm{S}, \mathrm{SI}, \mathrm{MO}, \mathrm{CU}, \mathrm{NI}$ to generate an intermediate table 'chem_pr_spec'. In this stage the columns with blank data are derived from other matching rows, then a separate intermediate table is constructed which contains an average of specimen chemistry data, the number of occurrences of the data and the standard deviation. This intermediate table is constructed in such a way that it's a 1-1 relationship data table ready to be merged into the composite table.

- Sixth stage where the data from the intermediate tables 'chem_pr_all', 'chem_pr_manu', 'chem_pr_spec' and the 'reac_pr' table is merged into the table "shft_pr" to form a composite table 'shift_pr". Merging data from other tables to 'shift_pr' is based on the key identifier match concept.

- Seventh stage where the data from the composite table 'shift_pr' is filtered to remove repetitions and generate a 1-1 relationship table which can be used for data analysis.

- Finally the 'shift_pr' containing irradiated data and the 'shft_pr_u' containing unirradiated data are saved into a separate database with name 'PROCESSEDPR-EDB' and is brought into view. 


\section{Residual File Generation}
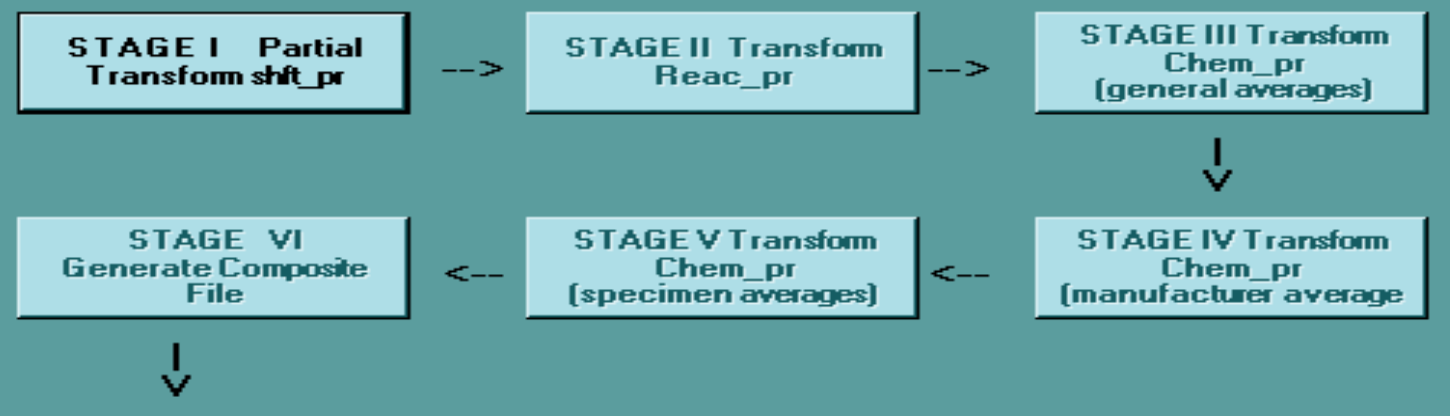

Imanufachmer average

STAGE VII Filter Composite File

Numerous fields were added to the 'shift_pr' for manipulation process and to keep in record how the manipulated data was obtained and from where. Found below is the list of fields added to the 'shift_pr' table and its description.

\section{SHIFT_PR}

Additional Fields added into the SHIFT_PR structure.

\begin{tabular}{l} 
Field Name \\
\hline CAP_F1_RT \\
CSP_TEMP \\
DTT30_REG_ALL \\
DTT30_REG_MANU \\
DTT30_REG_SPEC \\
CU_ALL \\
available) \\
CU_MANU \\
CU_SPEC \\
NI_ALL \\
NI_MANU
\end{tabular}

\section{Field Description} FLUENCE RATE $>1$ MEV AT CAPSULE CENTER [ N/(CM $2 \cdot \mathrm{S})$ ] IRRADIATION TEMPERATURE OF CHARPY SPECIMEN [ ${ }^{\circ} \mathrm{F}$ ] CVT SHIFT AT 30 FT-LB ACCORDING TO REG.GUIDE 1.99 REV.2 $\left[{ }^{\circ} \mathrm{F}\right]$ (Average from all chemistry data available)

CVT SHIFT AT 30 FT-LB ACCORDING TO REG.GUIDE 1.99 REV.2 $\left[{ }^{\circ} \mathrm{F}\right]$ (Average from all manufacturer chemistry data available)

CVT SHIFT AT 30 FT-LB ACCORDING TO REG.GUIDE 1.99 REV.2 $\left[{ }^{\circ} \mathrm{F}\right]$ (Average from all specimen chemistry data available)

WEIGHT PERCENT COPPER (Average from all chemistry data

WEIGHT PERCENT COPPER (Average from manufacturer chemistry data available)

WEIGHT PERCENT COPPER (Average from specimen chemistry data available)

WEIGHT PERCENT NICKEL (Average from all chemistry data available)

WEIGHT PERCENT NICKEL (Average from manufacturer chemistry data available) 


NI_SPEC
P_ALL
P_MANU
P_SPEC
ITT30_T
ITT50_T
ILE35_T
IUSE_T
UTT30_T
UTT50_T
UUSE_T
DUSE_T
DTT30_T

WEIGHT PERCENT NICKEL (Average from specimen chemistry data available)

WEIGHT PERCENT PHOSPHORUS (Average from all chemistry data available)

WEIGHT PERCENT PHOSPHORUS (Average from manufacturer chemistry data available)

WEIGHT PERCENT PHOSPHORUS (Average from specimen chemistry data available)

ITT30: As R_eported, T_an-Fit, high U_ncertainty, I_nferred, M_pc

ITT50: As R_eported, T_an-Fit, high U_ncertainty, I_nferred, M_pc

ILE35: As R_eported, T_an-Fit, high U_ncertainty, I_nferred, M_pc

IUSE: As R_eported, T_an-Fit, high U_ncertainty, I_nferred, M_pc

UTT30: As R_eported, T_an-Fit, high U_ncertainty, I_nferred, M_pc

UTT50: As R_eported, T_an-Fit, high U_ncertainty, I_nferred, M_pc

UUSE: As R_eported, T_an-Fit, high U_ncertainty, I_nferred, M_pc

DUSE: As R_eported, T_an-Fit, high U_ncertainty, I_nferred, M_pc

DTT30: As R_eported, T_an-Fit, high U_ncertainty, I_nferred, M_pc

\section{A.6 GETTING ACQUAINTED WITH PEDB}

\section{A.6.1 OVERVIEW}

This section of the document is an operating manual for the PEDB Version 1.0(Demo), also known as the Processed Embrittlement Database. It includes the software Package tour giving explanation about package features, screen shot explanations and examples.

PEDB Version 1.0(Demo) is a pure evaluation version and is still under development.

The Embrittlement data is essentially obtained from many reports and is first available in a raw form, which has to be processed to produce meaningful data that can be used in Modeling, Plotting etc. The PEDB is yet another milestone in this direction. With the help of Relational Database concepts of the newer Database systems this has been made possible. User defined data can be obtained on a composite data table from various tables of processed data using the relationship connectivity. The PEDB contains data from both the TEST Reactors as well as the POWER Reactors.

At this point of time the conversion of Embrittlement raw data from reports to processed data is being done manually, and is expected to be done through a computer program in the near future. Processing these data forms one-one, one-many relationships which are then incorporated into a relational database.

The data tables are connected with one and other using relationships. The connectors used for this purpose are the Primary keys. Primary keys are the columns (can be a single column of a combination of multiple columns jointly used for connecting), whose values DO NOT have repeating values (duplicates) and DO NOT contain NULL values. Such columns (single or a combination) is referenced to another table, which contains one or more columns similar to Primary Key Column known as the Foreign Key columns. Columns fulfilling these two main objectives only can be used as a Primary Key. 
The Foreign Keys are used to provide references between the two tables needed to be connected. When the columns in the second table contain many values row values in other columns and is being referenced to the first table through this Primary key, it forms a One-Many relationship (like a branch) and is denoted by the symbol (1- $\infty$ ). Meaning a single value in the first table would have many corresponding values for other data in the second table. For example a single Material can have many reported values for Tensile and Charpy data. Alternately the values in the primary key columns can also contain only one value in the foreign key columns forming One-One relationships (1-1). Another Important Point is, values in the foreign keys should be contained in the primary keys , in essence the Primary keys CANNOT have missing values for the foreign keys.

After these connections have been established between all the Embrittlement tables we can obtain information from different tables using JOIN queries. These joins can retrieve selected data from the selected tables on a UNION or an INTERSECTION combination.

A composite data view can be obtained as a result of these UNION and INTERSECTION join queries. We can select different columns from different tables. i.e can Select plant identification, reactor name, reactor location from one table, with capsule details from another table and charpy readings for those capsules present in yet another table to form a composite table containing all the details the user needs.

This methodology of combination paves way for User Defined Data Mining within the large pool of Embrittlement data available. The user has now the ability to get his own definition of composite data which he can further refine for usage in research. This step marks a Milestone in the Data mining of embrilttlement data.

The join query feature is harnessed in this package to form a new table whenever the user selects information from a single or multiple tables to form a new structure with the retrieved data and provide meaningful information, thereby reducing lot of manipulations needed for this purpose. At this point of time the demo version can handle only the UNION join queries, in which 154 combinations of joins have been handled. The INTERSECTION join queries have been set to be added in the near future.

More over the PEDB package in at this point of time is limited to only retrieving data from the various PEDB tables to form composite table and does not have the facility to further manipulate the retrieved data. This manipulation facility will be provided in the BETA release of PEDB. However the PEDB composite tables generated on run time can be saved into MSACCESS tables and can be retrieved any time for viewing.

The PEDB tables differ a little from the PR-EDB tables, some of the tables have been split and some of them merged to form new tables. The PEDB contain 11 different tables which constitute the Embrittlement Database.

Similar to the PR-EDB the PEDB has a central control file called 'STRUCT' which contains all the Meta data about the entire database. It essentially contains the Fields, Field types, Field Storage types, Field Description, tables in which the field appears etc.

In PEDB the data extraction is broken up into two main categories namely TENSILE DATA and CHARPY DATA. The central pillar of information will be these two categories and all other details surrounding each of these two categories can be aggregated to form a composite data table.

A relationship diagram of the PEDB can be found below which shows how the different tables of the PEDB are connected and what type of relationship it has formed i.e. one-one, one-many etc. The lines connecting the tables are the relationships and the number on top of them indicates if it's a 1-1 or $1-\infty$ relationship. The Fields to which the lines connect are the Primary and Foreign Key columns. 


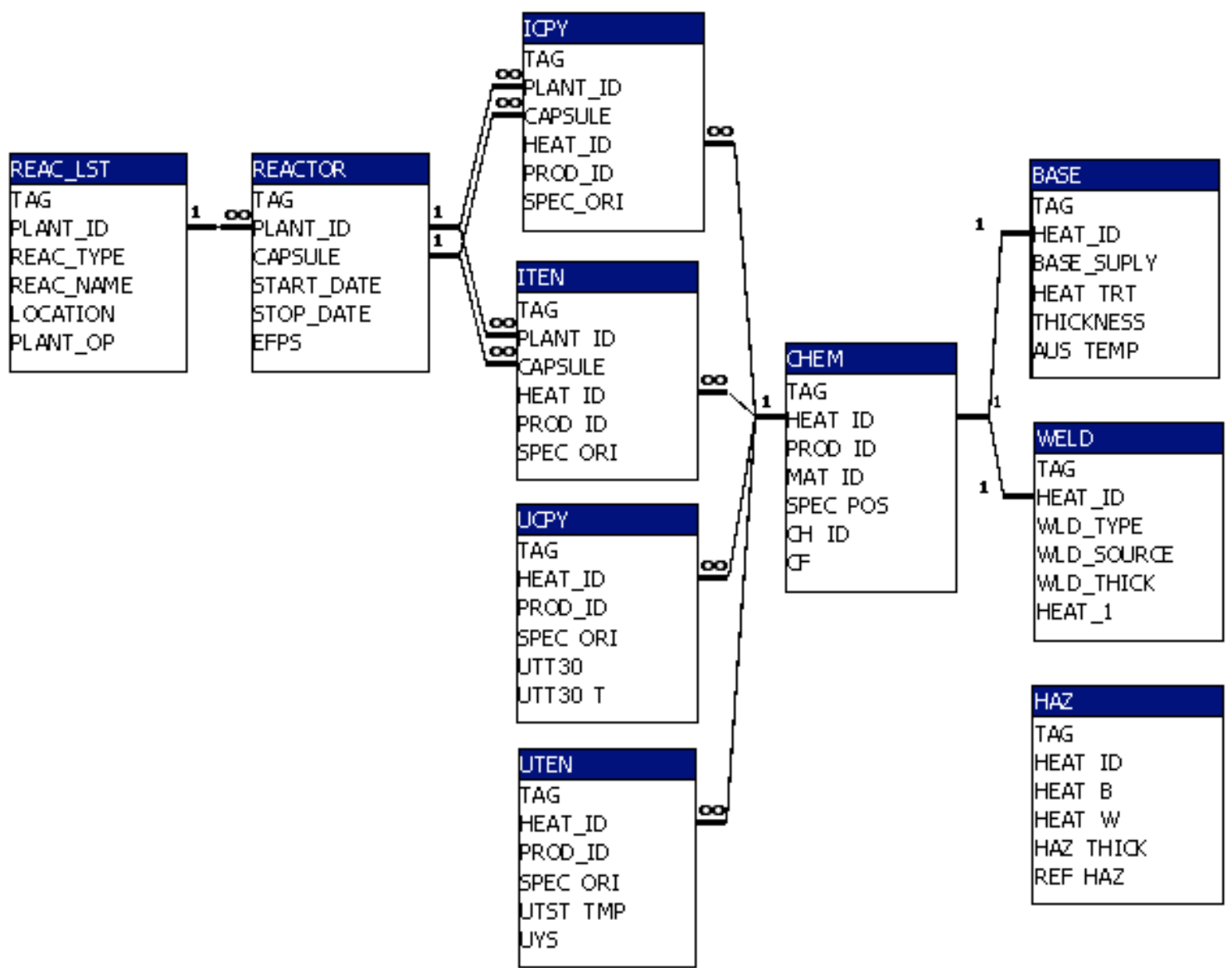

Relationship diagram for PEDB

\section{A.6.2 LIST OF PEDB TABLES}

\section{REACT_LST}

Structure for REACT_LST.

\section{Field Name}

TAG

PLANT_ID

REAC TYPE

REAC_NAME

LOCATION

PLANT_OP

PLANT_DES

ARCH_ENG
Field Description

USED FOR INTERNAL OPERATION

REACTOR IDENTIFICATION

REACTOR TYPE: PWR, BWR, or TR

REACTOR NAME

REACTOR LOCATION

REACTOR OPERATOR OR UTILITY

REACTOR DESIGNER OR VENDOR

REACTOR ARCHITECT/ENGINEER 
VESSEL_MFG

\section{REACTOR}

Structure for REACTOR.

\section{Field Name \\ TAG \\ PLANT_ID \\ CAPSULE \\ START_DATE \\ STOP_DATE \\ EFPS \\ CAP_TEMP \\ TEMP_TAG \\ CAP_F1 \\ F1_TAG \\ E_stimate \\ CAP_F1_RT \\ CAP_FP1 \\ CAP_DPA \\ REF_REAC}

\section{ICPY}

Structure for ICPY.

\section{Field Name}

TAG

PLANT_ID

CAPSULE

HEAT_ID

PROD_ID

SPEC_ORI

CSP_F1

CSP_F1_RT

$\left[\mathrm{N} /\left(\mathrm{CM}^{2} \cdot \mathrm{S}\right)\right]$

CSP_TEMP

ITT30
REACTOR VESSEL MANUFACTURER

\section{Field Description}

USED FOR INTERNAL OPERATION

REACTOR IDENTIFICATION

SUREILLANCE CAPSULE OR EXPERIMENT IDENTIFICATION

DATE AT START OF IRRADIATION [MM/DD/YYYY]

DATE AT END OF IRRADIATION [ MM/DD/YYYY ]

EFFECTIVE FULL POWER SECONDS

RRADIATION TEMPERATURE AT CAPSULE CENTER [ ${ }^{\circ} \mathrm{F}$ ]

TEMPERATURE MEASURED BY: M_elt Wire, T_hermocouples, N_ominal

FLUENCE $>1$ MEV AT CAPSULE CENTER [ N/CM ${ }^{2}$ ]

FLUENCE DETERMINED BY: C_alculation, F_ERRET-SAND,

FLUENCE RATE $>1$ MEV AT CAPSULE CENTER [ N/(CM².S) ]

FLUENCE > 0.1 MEV AT CAPSULE CENTER [ N/CM ${ }^{2}$ ]

DISPLACEMENTS PER ATOM OF IRON AT CAPSULE CENTER

REFERENCE IDENTIFIER FOR CAPSULE IRRADIATION DATA

\section{Field Description}

USED FOR INTERNAL OPERATION

REACTOR IDENTIFICATION

SUREILLANCE CAPSULE OR EXPERIMENT IDENTIFICATION

IDENTIFICATION CODE FOR GIVEN MATERIAL

MATERIAL TYPE: P_late, F_orging, W_eld, HAZ, or SRM

SPECIMEN ORIENTATION: TL, LT, TS, etc.

FLUENCE $>1$ MEV AT CHARPY SPECIMEN LOCATION [N/CM $\left.{ }^{2}\right]$

FLUENCE RATE $>1$ MEV AT CHARPY SPECIMEN LOCATION

IRRADIATION TEMPERATURE OF CHARPY SPECIMEN $\left[{ }^{\circ} \mathrm{F}\right]$

CVT AT 30 FT-LB, IRRADIATED CHARPY SPECIMEN [ ${ }^{\circ} \mathrm{F}$ ] 


\begin{tabular}{|c|c|}
\hline ITT30_T & ITT30: As R_eported, T_an-Fit, high U_ncertainty, I_nferred, M_pc \\
\hline DTT30 & CVT SHIFT AT 30 FT-LB $\left[{ }^{\circ} \mathrm{F}\right]$ \\
\hline DTT30_REG & $\begin{array}{l}\text { CVT SHIFT AT } 30 \text { FT-LB ACCORDING TO REG.GUIDE } 1.99 \text { REV.2 } \\
{\left[{ }^{\circ} \mathrm{F}\right]}\end{array}$ \\
\hline ITT50 & CVT AT 50 FT-LB, IRRADIATED CHARPY SPECIMEN $\left[{ }^{\circ} \mathrm{F}\right]$ \\
\hline ITT50_T & ITT50: As R_eported, T_an-Fit, high U_ncertainty, I_nferred, M_pc \\
\hline DTT50 & CVT SHIFT AT 50 FT-LB $\left[{ }^{\circ} \mathrm{F}\right]$ \\
\hline $\begin{array}{l}\text { ILE35 } \\
\text { SPEC }\left[{ }^{\circ} \mathrm{F}\right]\end{array}$ & CVT AT LATERAL EXPANSION = 35 MILS, IRRAD CHARPY \\
\hline ILE35_T & ILE35: As R_eported, T_an-Fit, high U_ncertainty, I_nferred, M_pc \\
\hline DLE35 & CVT SHIFT AT LATERAL EXPANSION $=35$ MILS $\left[{ }^{\circ} \mathrm{F}\right]$ \\
\hline $\begin{array}{l}\text { IUSE } \\
\text { LB ] }\end{array}$ & UPPER SHELF ENERGY, IRRADIATED CHARPY SPECIMEN [ FT- \\
\hline IUSE_T & IUSE: As R_eported, T_an-Fit, high U_ncertainty, I_nferred, M_pc \\
\hline DUSE_ABS & ABSOLUTE DROP IN UPPER SHELF ENERGY [ FT-LB ] \\
\hline DUSE_REL & PERCENT DROP IN UPPER SHELF ENERGY \\
\hline REF_ICPY & REFERENCE IDENTIFIER FOR IRRADIATED CHARPY DATA \\
\hline \multicolumn{2}{|l|}{ UCPY } \\
\hline \multicolumn{2}{|c|}{ Structure for UCPY. } \\
\hline Field Name & Field Description \\
\hline TAG & USED FOR INTERNAL OPERATION \\
\hline HEAT_ID & IDENTIFICATION CODE FOR GIVEN MATERIAL \\
\hline PROD_ID & MATERIAL TYPE: P_late, F_orging, W_eld, HAZ, or SRM \\
\hline SPEC_ORI & SPECIMEN ORIENTATION: TL, LT, TS, etc \\
\hline UTT30 & CVT AT 30 FT-LB, UNIRRADIATED CHARPY SPECIMEN [ ${ }^{\circ} \mathrm{F}$ ] \\
\hline UTT30_T & UTT30: As R_eported, T_an-Fit, high U_ncertainty, I_nferred, M_pc \\
\hline UTT50 & CVT AT 50 FT-LB, UNIRRADIATED CHARPY SPECIMEN [ ${ }^{\circ} \mathrm{F}$ ] \\
\hline UTT50_T & UTT50: As R_eported, T_an-Fit, high U_ncertainty, I_nferred, M_pc \\
\hline $\begin{array}{l}\text { ULE35CVT } \\
{\left[{ }^{\circ} \mathrm{F}\right]}\end{array}$ & AT LATERAL EXPANSION = 35 MILS, UNIRRAD CHARPY SPEC \\
\hline ULE35_T & ULE35: As R_eported, T_an-Fit, high U_ncertainty, I_nferred, M_pc \\
\hline UUSE & $\begin{array}{l}\text { UPPER SHELF ENERGY, UNIRRADIATED CHARPY SPECIMEN } \\
\text { [FT-B] }\end{array}$ \\
\hline UUSE_T & UUSE: As R_eported, T_an-Fit, high U_ncertainty, I_nferred, M_pc \\
\hline REF_UCPY & REFERENCE IDENTIFIER FOR UNIRRADIATED CHARPY DATA \\
\hline
\end{tabular}




\section{ITEN}

Structure for ITEN.

\section{Field Name}

TAG

Field Description

PLANT_ID

USED FOR INTERNAL OPERATION

CAPSULE

REACTOR IDENTIFICATION

HEAT_ID

PROD_ID

SPEC_ORI

SUREILLANCE CAPSULE OR EXPERIMENT IDENTIFICATION

IDENTIFICATION CODE FOR GIVEN MATERIAL

MATERIAL TYPE: P_late, F_orging, W_eld, HAZ, or SRM

SPECIMEN ORIENTATION: TL, LT, TS, etc

TSP_F1

TSP_F1_RT

$\left[\mathrm{N} /\left(\overline{\mathrm{CM}^{2}} \cdot \mathrm{S}\right)\right]$

FLUENCE $>1$ MEV AT TENSILE SPECIMEN LOCATION [ N/CM ${ }^{2}$ ]

FLUENCE RATE $>1$ MEV AT TENSILE SPECIMEN LOCATION

TSP_TEMP

IRRADIATION TEMPERATURE OF TENSILE SPECIMEN [ ${ }^{\circ} \mathrm{F}$ ]

ITST_TMP

$\left[{ }^{\circ} \mathrm{F}\right]$

TEST TEMPERATURE FOR IRRADIATED TENSILE SPECIMEN

IYS

YIELD STRENGTH OF IRRADIATED TENSILE SPECIMEN [ KSI ]

IUTS

ULTIMATE TENSILE STRENGTH OF IRRADIATED TENSILE SPECIMEN [ KSI ]

IULG

$[\%]$

UNIFORM ELONGATION OF IRRADIATED TENSILE SPECIMEN

ITLG

]

TOTAL ELONGATION OF IRRADIATED TENSILE SPECIMEN [ \%

IRA

REFERENCE IDENTIFIER FOR UNIRRADIATED TENSILE DATA

REF_ITEN

REFERENCE IDENTIFIER FOR IRRADIATED TENSILE DATA

\section{UTEN}

Structure for UTEN.

\section{Field Name}

\section{Field Description}

TAG

USED FOR INTERNAL OPERATION

HEAT_ID

IDENTIFICATION CODE FOR GIVEN MATERIAL

PROD_ID

MATERIAL TYPE: P_late, F_orging, W_eld, HAZ, or SRM

SPEC_ORI

UTST_TMP

SPECIMEN ORIENTATION: TL, LT, TS, etc

TEST TEMPERATURE FOR UNIRRADIATED TENSILE SPECIMEN $\left[{ }^{\circ} \mathrm{F}\right]$

UYS

YIELD STRENGTH OF UNIRRADIATED TENSILE SPECIMEN

[KSI]

ULTIMATE TENSILE STRENGTH OF UNIRRAD TENSILE SPECIMEN [KSI] 
UULG

UTLG

[\% ]

URA

[\% ]

REF_UTEN

\section{CHEM}

Structure for CHEM.

\section{Field Name}

TAG

HEAT_ID

PROD_ID

MAT_ID

SPEC_POS

CH_ID

$\mathrm{CF}$

C

$\mathrm{MN}$

P

S

SI

NI

CR

MO

$\mathrm{CU}$

V

B

TI

$\mathrm{CO}$

SB

AS

ZR

$\mathrm{AL}$

PB
UNIFORM ELONGATION OF UNIRRADIATED TENSILE SPECIMEN [\%]

TOTAL ELONGATION OF UNIRRADIATED TENSILE SPECIMEN

REDUCTION IN AREA OF UNIRRADIATED TENSILE SPECIMEN

REFERENCE IDENTIFIER FOR UNIRRADIATED TENSILE DATA

\section{Field Description}

USED FOR INTERNAL OPERATION

IDENTIFICATION CODE FOR GIVEN MATERIAL

MATERIAL TYPE: P_late, F_orging, W_eld, HAZ, or SRM

MATERIAL CLASSIFICATION: A302B, A5082, A533B1, etc.

SPECIMEN POSITION: 1/4T, 1/2T, 3/4T, etc.

CHEMISTRY IDENTIFIER: S_pecimen or H_eat/ladle

CHEMISTRY FACTOR ACCORDING TO REG.GUIDE 1.99 REV.2

WEIGHT PERCENT CARBON

WEIGHT PERCENT MANGANESE

WEIGHT PERCENT PHOSPHORUS

WEIGHT PERCENT SULFUR

WEIGHT PERCENT SILICON

WEIGHT PERCENT NICKEL

WEIGHT PERCENT CHROMIUM

WEIGHT PERCENT MOLYBDENUM

WEIGHT PERCENT COPPER

WEIGHT PERCENT VANADIUM

WEIGHT PERCENT BORON

WEIGHT PERCENT TITANIUM

WEIGHT PERCENT COBALT

WEIGHT PERCENT ANTIMONY

WEIGHT PERCENT ARSENIC

WEIGHT PERCENT ZIRCONIUM

WEIGHT PERCENT ALUMINUM

WEIGHT PERCENT LEAD 
W
SN
ZN
TA
NB
REF_CHEM
WELD
Structure for WELD.

\section{Field Name}

TAG

HEAT_ID

WLD_TYPE

WLD_SOURCE

WLD_THICK

HEAT_1

HEAT_2

WELD_SUPLY

SR_TEMP_W1

[ $\left.{ }^{\circ} \mathrm{F}\right]$

SR_RANG_W1

[ $\left.{ }^{\circ} \mathrm{F}\right]$

SR_HOUR_W1

[HÖURS]

SR_QCHM_W1

SR_TEMP_W2

[ ${ }^{\circ} \mathrm{F}$ ]

SR_RANG_W2

${ }^{\circ} \mathrm{F}$ ]

SR_HOUR_W2

[HŌURS]

SR_QCHM_W2

WIRE_TYPE

WIRE_HEAT

FLUX_TYPE

FLUX_LOT

REF_WELD
WEIGHT PERCENT TUNGSTEN

WEIGHT PERCENT TIN

WEIGHT PERCENT ZINC

WEIGHT PERCENT TANTALUM

WEIGHT PERCENT NIOBIUM

REFERENCE IDENTIFIER FOR MATERIAL CHEMISTRY DATA

\section{Field Description}

USED FOR INTERNAL OPERATION

IDENTIFICATION CODE FOR GIVEN MATERIAL

WELD TYPE

SOURCE OF WELD MATERIAL: From V_essel, N_ozzle Cutout, S_imulated

THICKNESS OF WELD MATERIAL [ INCHES ]

HEAT_ID OF THE PLATE ON ONE SIDE OF THE WELD

HEAT_ID OF THE PLATE ON THE OTHER SIDE OF THE WELD SUPPLIER OF WELD MATERIAL

STRESS RELIEF TEMPERATURE FOR WELD MATERIAL, RUN 1

STRESS RELIEF TEMP. RANGE FOR WELD MATERIAL, RUN 1

STRESS RELIEF DURATION FOR WELD MATERIAL, RUN 1

QUENCH METHOD AFTER STRESS RELIEF OF WELD, RUN1

STRESS RELIEF TEMPERATURE FOR WELD MATERIAL, RUN 2

STRESS RELIEF TEMP. RANGE FOR WELD MATERIAL, RUN 2 [

STRESS RELIEF DURATION FOR WELD MATERIAL, RUN 2

QUENCH METHOD AFTER STRESS RELIEF OF WELD, RUN 2

TYPE OF WELD WIRE USED IN THE WELD

WELD WIRE HEAT IDENTIFIER

TYPE OF FLUX USED IN THE WELD

WELD FLUX LOT IDENTIFIER

REFERENCE IDENTIFIER FOR WELD DATA 


\section{BASE}

Structure for BASE.

\section{Field Name}

TAG

HEAT_ID

BASE_SUPLY

HEAT_TRT

THICKNESS

AUS_TEMP

AUS_RANGE

AUS_HOURS

AUS_QCHM

TEMP_TEMP

TEMP_RANGE

TEMP_HOURS

TEMP_QCHM

SR_TEMP

SR_RANGE

$\left[{ }^{\circ} \mathrm{F}\right]$

SR_HOURS

SR_QCHM

REF_HEAT

\section{HAZ}

Structure for HAZ.

\section{Field Name}

TAG

HEAT_ID

HEAT_B

HEAT_W

HAZ

HAZ_THICK

REF_HAZ

\section{Field Description}

USED FOR INTERNAL OPERATION

IDENTIFICATION CODE FOR GIVEN MATERIAL

SUPPLIER OF BASE MATERIAL

FACILITY PERFORMING HEAT TREATMENT

THICKNESS OF BASE MATERIAL [INCHES]

AUSTENIZING TEMPERATURE $\left[{ }^{\circ} \mathrm{F}\right]$

AUSTENIZING TEMPERATURE RANGE [ $\left.{ }^{\circ} \mathrm{F}\right]$

AUSTENIZING DURATION [HOURS]

QUENCH METHOD AFTER AUSTENIZING

TEMPERING TEMPERATURE $\left[{ }^{\circ} \mathrm{F}\right]$

TEMPERING TEMPERATURE RANGE [ ${ }^{\circ} \mathrm{F}$ ]

TEMPERING DURATION [HOURS]

QUENCH METHOD AFTER TEMPERING

STRESS RELIEF TEMPERATURE FOR BASE MATERIAL [ $\left.{ }^{\circ} \mathrm{F}\right]$

STRESS RELIEF TEMPERATURE RANGE FOR BASE MATERIAL

STRESS RELIEF DURATION FOR BASE MATERIAL [HOURS]

QUENCH METHOD AFTER STRESS RELIEF

REFERENCE IDENTIFIER FOR BASE MATERIAL DATA

\section{Field Description}

USED FOR INTERNAL OPERATION

IDENTIFICATION CODE FOR GIVEN MATERIAL

HEAT_ID OF THE BASE MATERIAL USED IN THE HAZ

HEAT_ID OF THE WELD MATERIAL CONNECTED WITH THE

THICKNESS OF HEAT-AFFECTED-ZONE [INCHES]

REFERENCE IDENTIFIER FOR HEAT-AFFECTED-ZONE DATA 


\section{A.7 EXAMPLE FOR PEDB DATA RETRIEVAL}

In this section we will see a screen by screen explanation of how to retrieve PEDB information. As explained earlier in the overview section the PEDB contains Embrittlement data from both, the Power Reactors and the Test Reactors. Information that can be retrieved from the PEDB can be classified into two broad categories, namely the TENSILE information and the CHARPY information.

Users can generate either a TENSILE or a CHARPY composite file from the PEDB. In the demo Version the Composite file can be generated for either a BASE or WELD or HAZ material. Facility for obtaining a combination of these three materials has not been provided in the demo Version and will be available in the next release.

Since method of obtaining TENSILE and CHARPY information is one and the same, here we would explain retrieval of CHARPY information and the user can replicate the same process for obtaining a TENSILE composite file.

Let us now see how to obtain a CHARPY composite file from the PEDB. First step is to start up the package by clicking the Desktop icon which says 'PR-EDB 3.0' or the Programs menu shortcut which is present in the folder 'PR-EDB' with name 'PR-EDB 3.0'.

The package then starts and brings up a Disclaimer statement, click 'OK' after reading the statement (Note: Users are strongly recommended to read the Disclaimer statement once.). The Main menu is then brought into view; click the button 'PEDB Version 1.0 (Demo)'.

Now we would enter the PEDB Main screen, which displays the options to create a CHARPY or a TENSILE file, just like the screen found below.

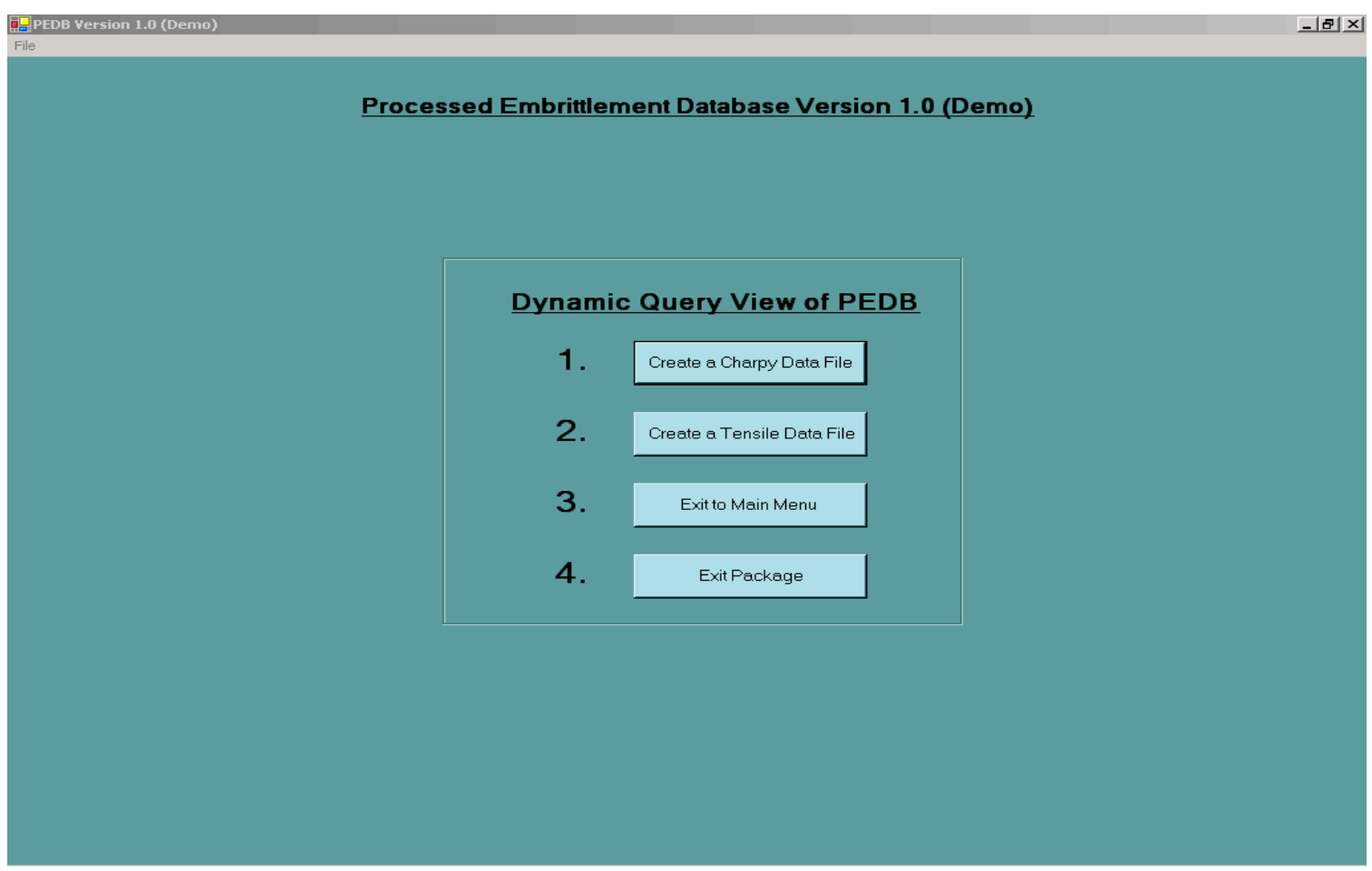

This screen has options to generate a TENSILE or a CHARPY file, toggle back and forth the PEDB and PR-EDB Modules, and the option to Exit the package. 
To create the CHARPY composite file click the button 'Create a Charpy Data File', this brings up the screen found below.

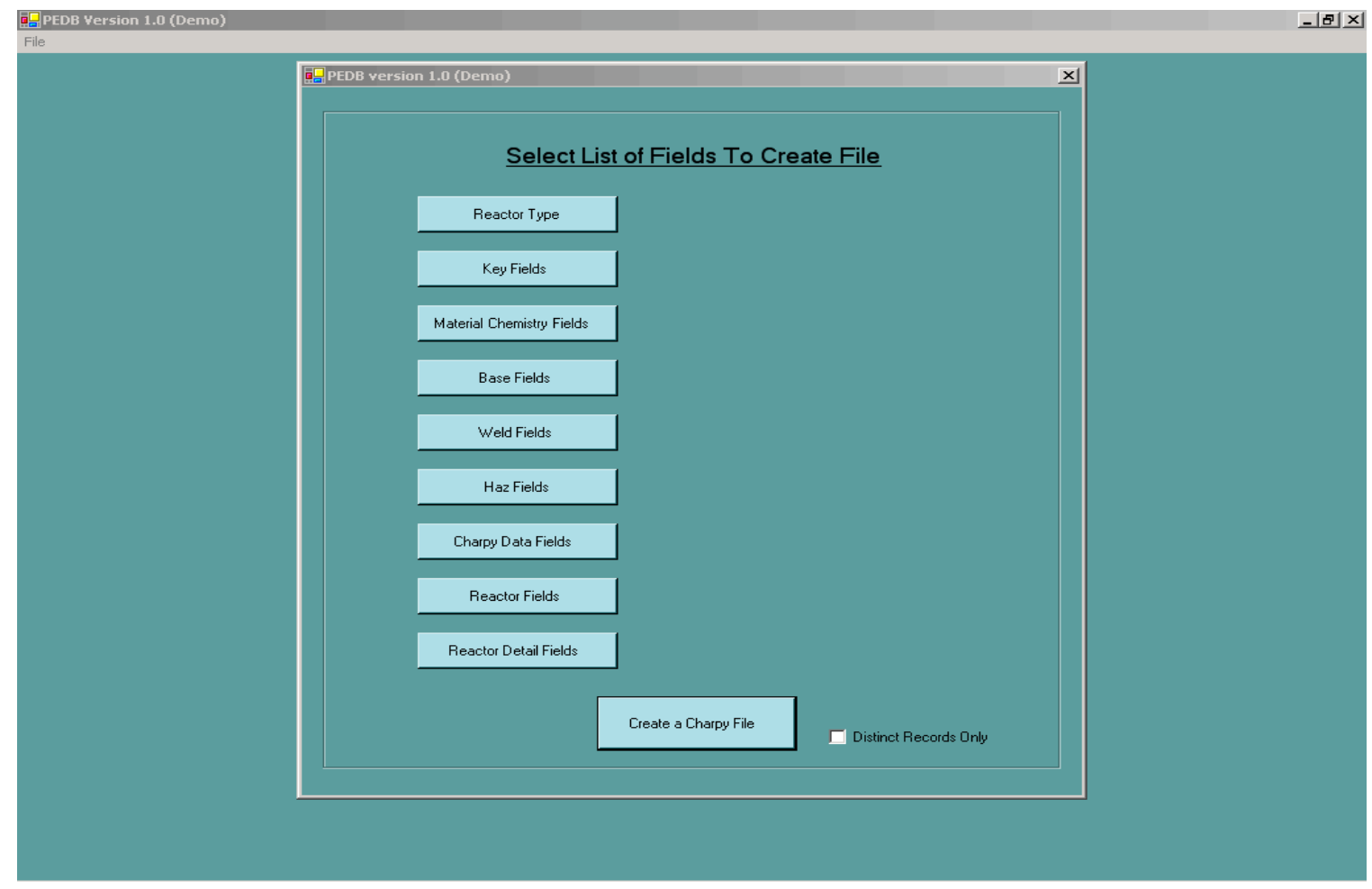

The list of buttons found on the Left side of the screen indicates the various categories of fields. For the purpose of making User selection of Fields and to give the user a better understanding of what the fields are about, they have been categorized into blocks.

An important point to be noted here is that the block categorization of the Fields does not imply that the fields are present in the same order and the blocks are found in the same table. The categorization has been performed for user ease of handling.

To view the Fields of each block, click on the appropriate button and it would bring up a List box on the right side of the screen containing a list of fields, like the one shown below. 


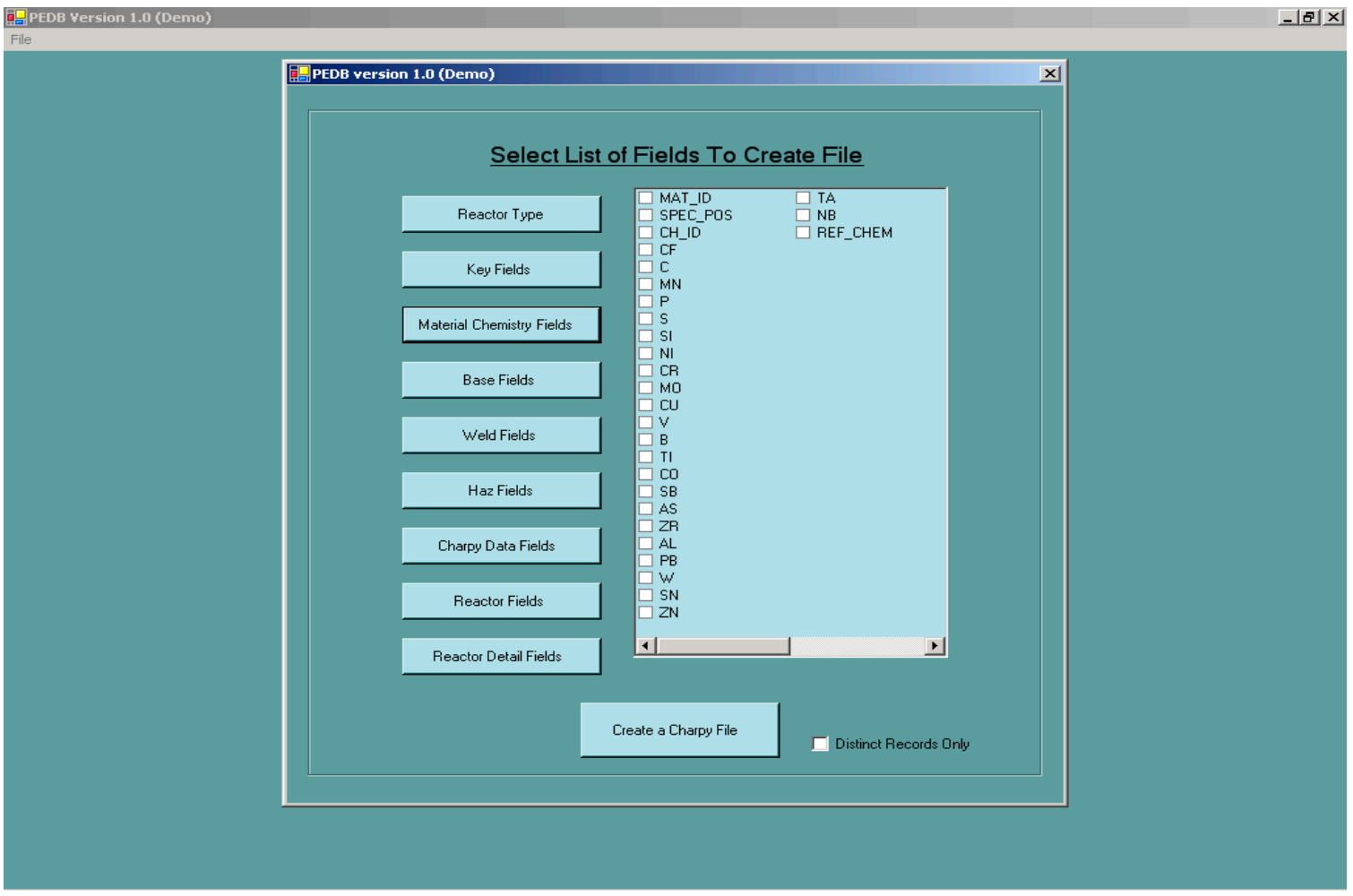

Now check all the fields needed to be included into the composite file, then toggle to other blocks using appropriate buttons and selecting the fields from those blocks. The demo version allows adding fields from either the BASE or WELD or HAZ blocks and not a combination of these materials, hence add Fields only from one type of material.

After selection of all the needed fields to generate a composite file, toggle to the Reactor type block by clicking the button "Reactor Type'. In this block select the reactor type about which the information needs to be obtained. This is a filter to obtain selected information. Selection can be made on PWR and/or BWR and/or TR. User can select also a combination of these three types of reactors.

After selection of all the fields and types of reactors click the button 'Create a Charpy File', on clicking this button the screen found below is brought into view. 


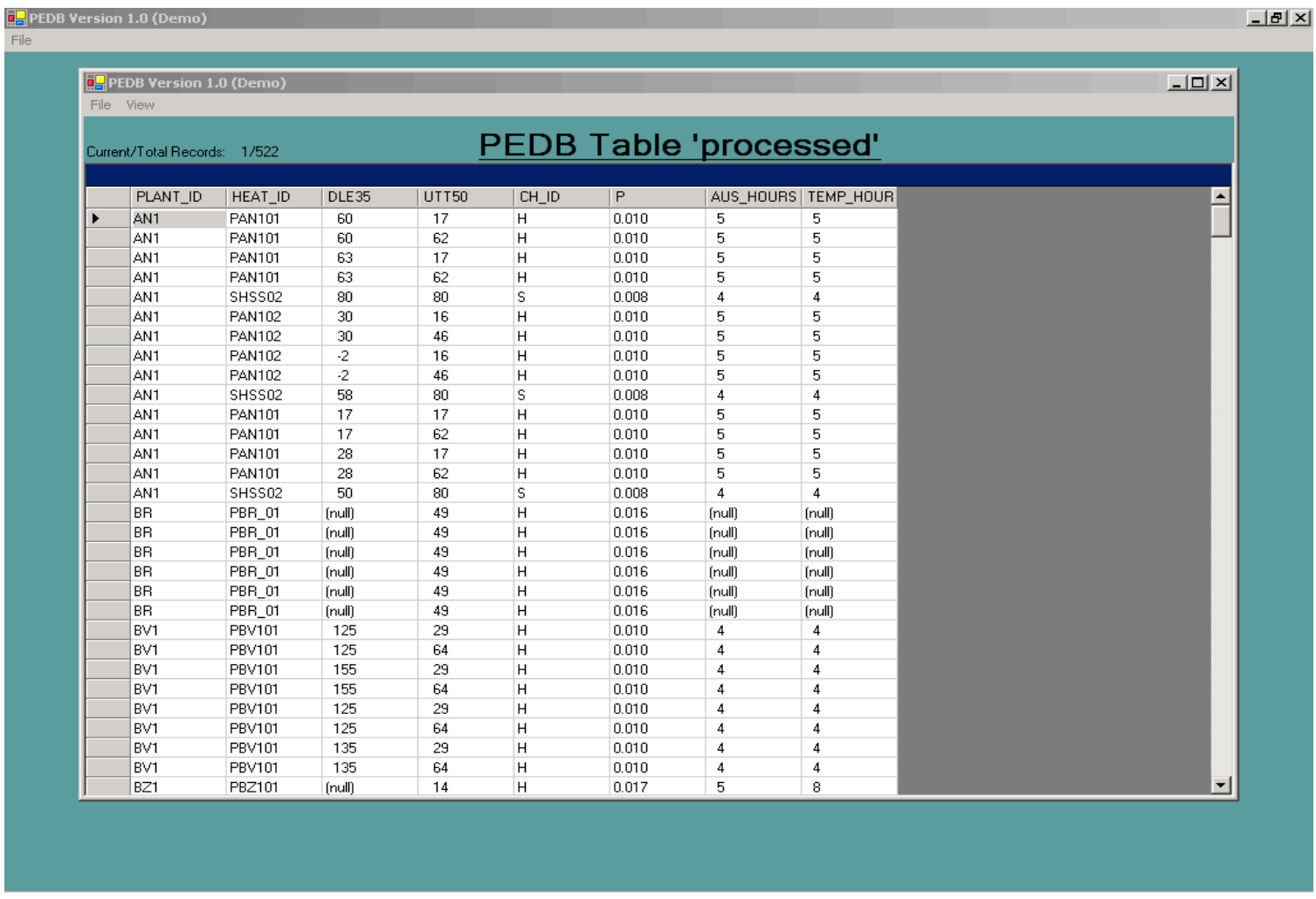

In the background before this screen was brought into view, the Joins were chosen depending on what the user selection was and it was applied to the PEDB to extract the resultant dataset into memory.

Now the dataset is ready to be printed onto a printer or can be saved back to an MSACCESS table. To get a print preview, click on the menu item 'Print Preview' from the drop down menu 'File', which provides a print preview in multiple pages and single page format and also print option to print the data to a printer.

After obtaining this dataset the fields can be viewed on a selective basis using the View select Fields option. Click the menu item 'View Selected Fields' from the drop down menu 'View' and select all the fields that needed to in the view. On enabling this option all other fields are hidden from the view but are not deleted from the table.

The dataset can alternatively be saved back to a fresh MSACCESS table inside a package generated MSACCESS file called 'WORK.MDB'. To save the table close this page by clicking the cross or the exit item 'Close' from the drop down menu 'File'. A confirmation is then asked if the table in memory needs to be saved to a table in an MSACCESS file.

Once the user confirms the save table option, a blank structure is generated and the data is saved into the table.

\section{Demo Form view of data}

The example we just saw above is the grid view of the extracted data and here we have introduced a Form view of the Dynamic Query data which we obtain using the Joins. This demo of Form view has been enabled for one combination of Field selection and would be available for all combinations in the next release.

To see the data in a form view select a combination of fields from particular blocks, namely Reactor Details Fields, Reactor Fields, only ICPY items from the Charpy Fields block, weld material fields, chemistry fields and the key Fields. The form view option is triggered only if at least one field for each of the above said blocks is selected. 
After this selection is done and the button 'Create a Charpy file' is clicked the user is asked for a choice, if he wants a form view of data or a grid view. When the Form view is selected the screen found below is brought into view.

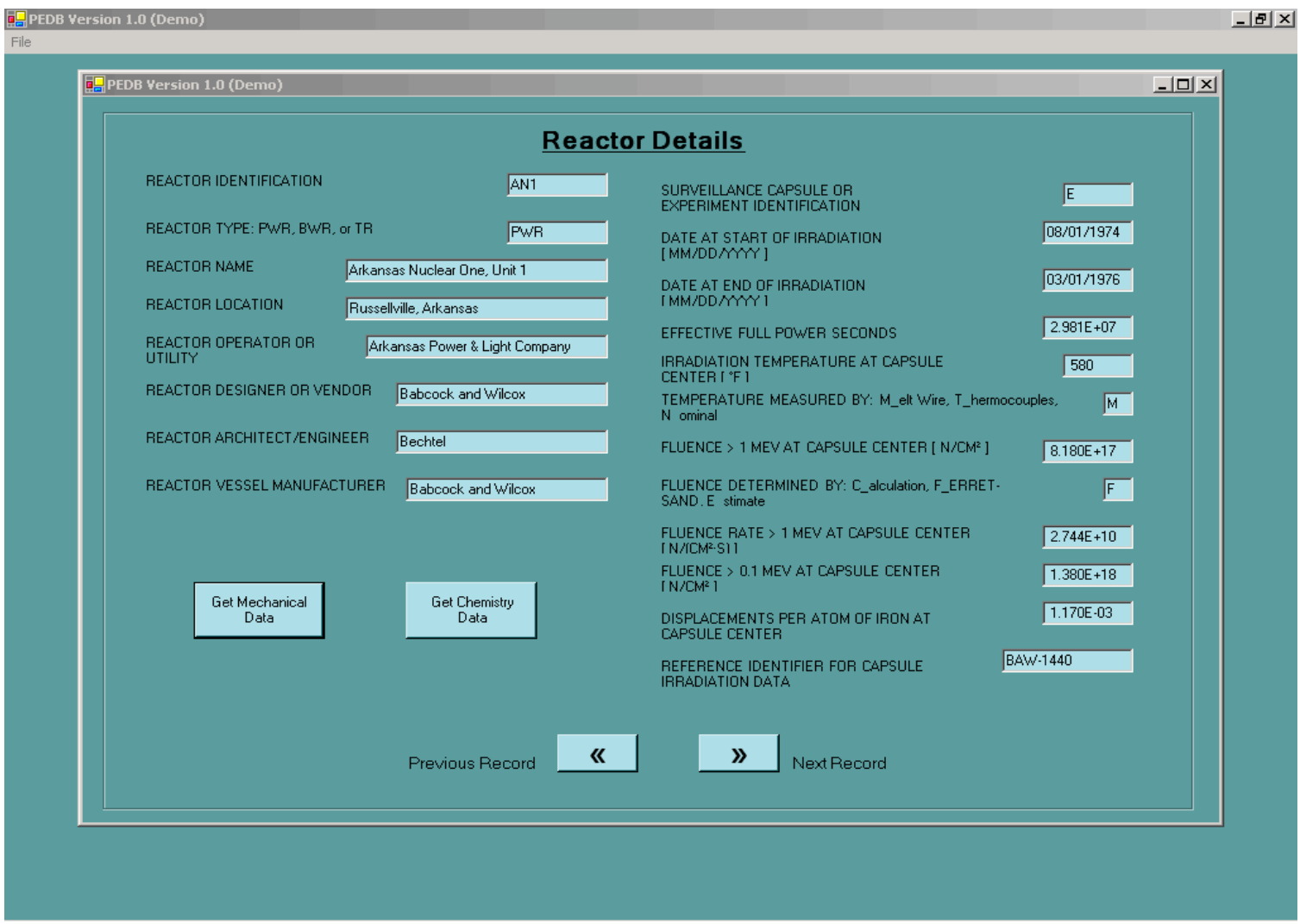

In this screen the data extracted is found in the text boxes record by record and can be navigated back and forth using the buttons '" ' and '»' respectively.

This main screen provides details about the reactor, its location, manufacturer and other details pertaining to the reactor. It also contains the details of the capsules found in the reactor. This form shows details about one capsule at a time and the user can view details of other by navigating thro the records one by one. Once all the capsules of a reactor are finished the records move to the first capsule of the next reactor and so on.

The chemistry and Mechanical details for each of the capsule can be obtained on a similar form by clicking the buttons 'Get Mechanical data' or 'Get chemistry data'. On clicking the button 'Get Chemistry data the screen found below is brought into view. 


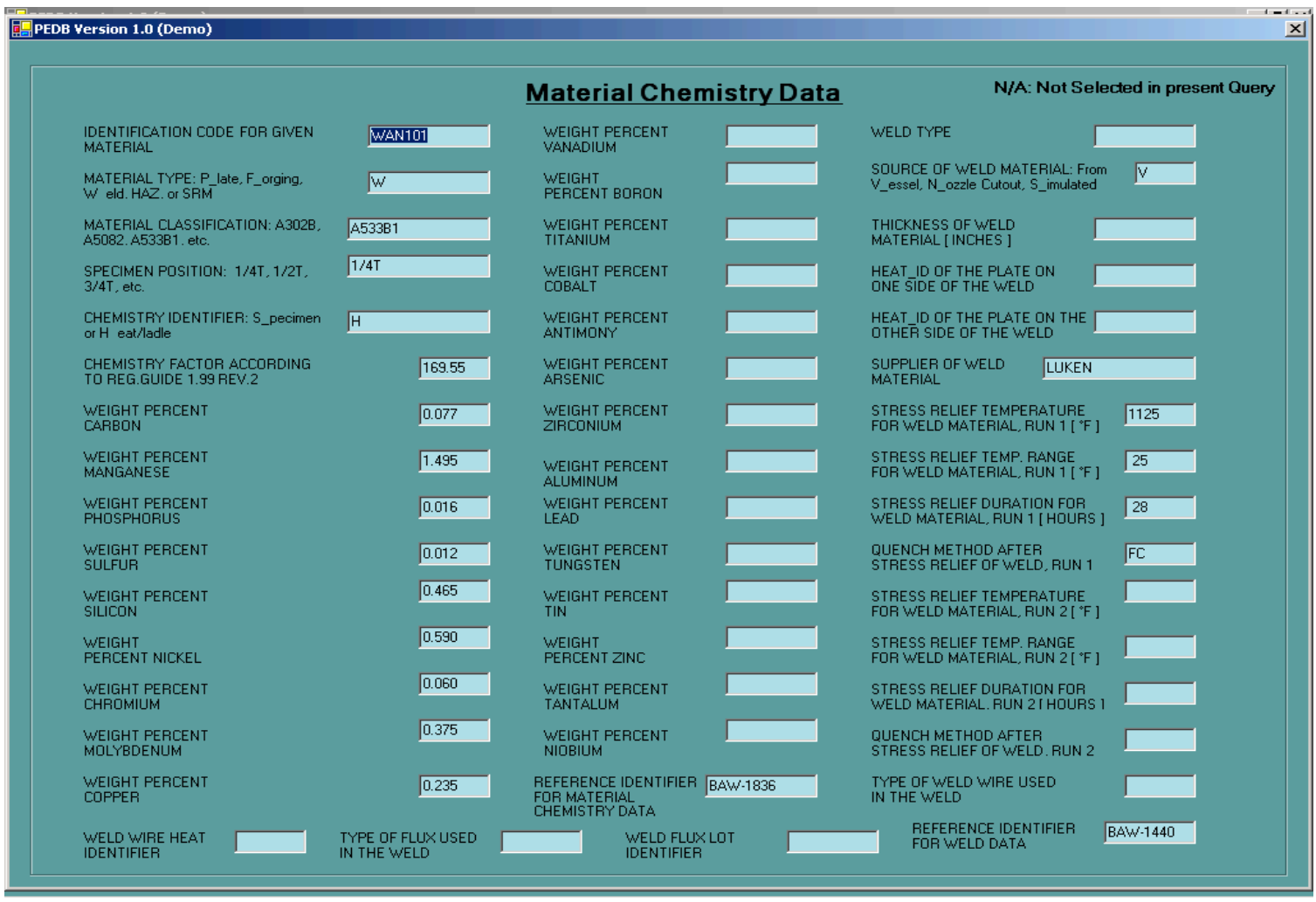

In this screen we can find all the chemistry data associated with that particular capsule. The blank text boxes indicate that the values are not known i.e. Null values present for the current records under view. When a grayed out string N/A is found is the text boxes it means that field was not selected during the selection of fields to form the composite file.

In a similar way the Mechanical data can be obtained in a form by clicking the button 'Get Mechanical data'. 


\section{APPENDIX B. PUBLICATIONS LIST}

Information from radiation embrittlement research on nuclear reactor pressure vessel (RPV) steels and from power-reactor surveillance reports has been gathered to assist the US Nuclear Regulatory Commission effectively monitor current procedures and databases used by vendors, utilities, and service laboratories in the pressure vessel irradiation surveillance program. The radiation embrittlement of reactor pressure vessel (RPV) materials depends on factors such as flux, fluence, neutron energy spectrum, irradiation temperature, and preirradiation material history and chemical compositions. These factors must be considered to reliably predict pressure vessel embrittlement. Based on embrittlement predictions, decisions must be made concerning operating parameters and issues such as low-leakage-fuel management, possible life extension, and the need for annealing the pressure vessel. Large amounts of data from surveillance capsules are needed to develop generally applicable damage prediction models that can be used for industry standards and regulatory guides. Furthermore, the investigations of regulatory issues such as vessel integrity over plant life, vessel failure, and sufficiency of current codes, Standard Review Plans (SRPs), and Guides for license renewal can be greatly expedited by the use of a well-designed computerized database. The Power Reactor Embrittlement Database (PR-EDB) is such a comprehensive collection of data for U. S.-designed commercial nuclear reactors.

This report is also a record of work performed in part at ORNL under the Heavy-Section Steel Irradiation (HSSI) Program, which is sponsored by the NRC Office of Nuclear Regulatory Research. A list of publications for the ORNL HSSI Program is given in Sect. B.1.

The HSSI Program includes both follow-on research and the direct continuation of work that was performed under the Heavy-Section Steel Technology (HSST) Program. Previous HSST reports related to irradiation effects in pressure vessel materials and those containing unirradiated properties of materials used in HSSI and HSST irradiation programs are listed in Sect. B.2.

\section{B.1 HSSI PROGRAM REPORTS}

1. F. M. Haggag, W. R. Corwin, and R. K. Nanstad, Martin Marietta Energy Systems, Inc., Oak Ridge Natl. Lab., Oak Ridge, Tenn., Irradiation Effects on Strength and Toughness of Three-Wire Series-Arc Stainless Steel Weld Overlay Cladding, USNRC Report NUREG/CR-5511 (ORNL/TM-11439), February 1990.

2. L. F. Miller, C. A. Baldwin, F. W. Stallman, and F. B. K. Kam, Martin Marietta Energy Systems, Inc., Oak Ridge Natl. Lab., Oak Ridge, Tenn., Neutron Exposure Parameters for the Metallurgical Test Specimens in the Sixth Heavy-Section Steel Irradiation Series, USNRC Report NUREG/CR-5409 (ORNL/TM-11267), March 1990.

3. S. K. Iskander, W. R. Corwin, and R. K. Nanstad, Martin Marietta Energy Systems, Inc., Oak Ridge Natl. Lab., Oak Ridge, Tenn., Results of Crack-Arrest Tests on Two Irradiated HighCopper Welds, USNRC Report NUREG/CR-5584 (ORNL/TM-11575), December 1990.

4. R. K. Nanstad and R. G. Berggren, Martin Marietta Energy Systems, Inc., Oak Ridge Natl. Lab., Oak Ridge, Tenn., Irradiation Effects on Charpy Impact and Tensile Properties of Low UpperShelf Welds, HSSI Series 2 and 3, USNRC Report NUREG/CR-5696 (ORNL/TM-11804), August 1991.

5. R. E. Stoller, Martin Marietta Energy Systems, Inc., Oak Ridge Natl. Lab., Oak Ridge, Tenn., Modeling the Influence of Irradiation Temperature and Displacement Rate on Radiation-Induced 
Hardening in Ferritic Steels, USNRC Report NUREG/CR5859 (ORNL/TM-12073), August 1992.

6. R. K. Nanstad, D. E. McCabe, and R. L. Swain, Martin Marietta Energy Systems, Inc., Oak Ridge Natl. Lab., Oak Ridge, Tenn., Chemical Composition RTNDT Determinations for Midland Weld WF-70, USNRC Report NUREG/CR-5914 (ORNL-6740), December 1992.

7. R. K. Nanstad, F. M. Haggag, D. E. McCabe, S. K. Iskander, K. O. Bowman, and B. H. Menke, Martin Marietta Energy Systems, Inc., Oak Ridge Natl. Lab., Oak Ridge, Tenn., Irradiation Effects on Fracture Toughness of Two High-Copper Submerged-Arc Welds, USNRC Report NUREG/CR-5913 (ORNL/TM-12156/V1), October 1992.

8. S. K. Iskander, W. R. Corwin, and R. K. Nanstad, Martin Marietta Energy Systems, Inc., Oak Ridge Natl. Lab., Oak Ridge, Tenn., Crack-Arrest Tests on Two Irradiated High-Copper Welds, USNRC Report NUREG/CR-6139 (ORNL/TM-12513), March 1994.

9. R. E. Stoller, Martin Marietta Energy Systems, Inc., Oak Ridge Natl. Lab., Oak Ridge, Tenn., $A$ Comparison of the Relative Importance of Copper Precipitates and Point Defects in Reactor Pressure Vessel Embrittlement, USNRC Report NUREG/CR-6231 (ORNL/TM-6811), December 1994.

10. D. E. McCabe, R. K. Nanstad, S. K. Iskander, and R. L. Swain, Martin Marietta Energy Systems, Inc., Oak Ridge Natl. Lab., Oak Ridge, Tenn., Unirradiated Material Properties of Midland Weld WF-70, USNRC Report NUREG/CR-6249 (ORNL/TM-12777), October 1994.

11. P. M. Rice and R. E. Stoller, Lockheed Martin Energy Systems, Oak Ridge Natl. Lab., Oak Ridge, Tenn., Microstructural Characterization of Selected AEA/UCSB Model FeCuMn Alloys, USNRC Report NUREG/CR-6332 (ORNL/TM-12980), June 1996.

12. J. H. Giovanola and J. E. Crocker, SRI International, Fracture Toughness Testing with Cracked Round Bars: Feasibility Study, USNRC Report NUREG/CR-6342 (ORNL/SUB/94-DHK60), April 2000.

13. F. M. Haggag and R. K. Nanstad, Lockheed Martin Energy Systems, Oak Ridge Natl. Lab., Oak Ridge, Tenn., Effects of Thermal Aging and Neutron Irradiation on the Mechanical Properties of Three-Wire Stainless Steel Weld Overlay Cladding, USNRC Report NUREG/CR-6363 (ORNL/TM-13047), May 1997.

14. M. A. Sokolov and D. J. Alexander, Lockheed Martin Energy Systems, Oak Ridge Natl. Lab., Oak Ridge, Tenn., An Improved Correlation Procedure for Subsize and Full-Size Charpy Impact Specimen Data, USNRC Report NUREG/CR-6379 (ORNL/TM-13088), March 1997.

15. S. K. Iskander and R. E. Stoller, Lockheed Martin Energy Research Corporation, Oak Ridge Natl. Lab., Oak Ridge, Tenn., Results of Charpy V-Notch Impact Testing of Structural Steel Specimens Irradiated at $\sim 30^{\circ} \mathrm{C}$ to $1 \times 10^{6}$ Neutrons/cm2 in a Commercial Reactor Cavity, USNRC Report NUREG/CR-6399 (ORNL-6886), April 1997.

16. S. K. Iskander, P. P. Milella, and A. Pini, Lockheed Martin Energy Research Corporation, Oak Ridge Natl. Lab., Oak Ridge, Tenn., Results of Crack-Arrest Tests on Irradiated A 503 Class 3 Steel, USNRC Report NUREG/CR-6447 (ORNL-6894), February 1998.

17. P. Pareige, K. F. Russell, R. E. Stoller, and M. K. Miller, Lockheed Martin Energy Research Corporation, Oak Ridge Natl. Lab., Oak Ridge, Tenn., Influence of Long-Term Thermal Aging on the Microstructural Evolution of Nuclear Reactor Pressure Vessel Materials: An Atom Probe Study, USNRC Report NUREG/CR-6537(ORNL-13406), March 1998.

18. I. Remec, C. A. Baldwin, and F. B. K. Kam, Lockheed Martin Energy Research Corporation, Oak Ridge Natl. Lab., Oak Ridge, Tenn., Neutron Exposure Parameters for Capsule 10.05 in the 
Heavy-Section Steel Irradiation Program Tenth Irradiation Series, USNRC Report NUREG/CR6600 (ORNL/TM-13548), October 1998.

19. I. Remec, C. A. Baldwin, and F. B. K. Kam, Lockheed Martin Energy Research Corporation, Oak Ridge Natl. Lab., Oak Ridge, Tenn., Neutron Exposure Parameters for the Dosimetry Capsule in the Heavy-Section Steel Irradiation Program Tenth Irradiation Series, USNRC Report NUREG/CR-6601 (ORNL/TM-13549), October 1998.

20. D. E. McCabe, R. K. Nanstad, S. K. Iskander, D. W. Heatherly, and R. L. Swain, Lockheed Martin Energy Research Corporation, Oak Ridge Natl. Lab., Oak Ridge, Tenn., Evaluation of WF-70 Weld Metal from the Midland Unit 1 Reactor Vessel-Final Report, USNRC Report NUREG/CR-5736 (ORNL/TM-13748), November 2000.

21. Mikhail A. Sokolov and Randy K. Nanstad, Lockheed Martin Energy Research Corporation, Oak Ridge Natl. Lab., Oak Ridge, Tenn., Comparison of Irradiation-Induced Shifts of $K_{J c}$ and Charpy Impact Toughness for Reactor Pressure Vessel Steels, USNRC Report NUREG/CR-6609 (ORNL/TM-13755), November 2000.

22. S. K. Iskander, C. A. Baldwin, D. W. Heatherly, D. E. McCabe, I. Remec, and R. L. Swain, UTBattelle, LLC, Oak Ridge Nat'1. Lab., Oak Ridge, Tenn., Detailed Results of Testing Unirradiated and Irradiated Crack-Arrest Toughness Specimens from the Low-Upper-ShelfEnergy, High-Copper Weld, WF-70, (ORNL/TM-13764). Submitted July 2004 and September 2006 as USNRC Report NUREG/CR-6621, to be published.

23. D. J. Alexander, K. B. Alexander, M. K. Miller, and R. K. Nanstad, Lockheed Martin Energy Research Corporation, Oak Ridge Natl. Lab., Oak Ridge, Tenn., The Effect of Aging at $343^{\circ} \mathrm{C}$ on the Microstructure and Mechanical Properties of Type 308 Stainless Steel Welds, USNRC Report NUREG/CR-6628 (ORNL/TM-13767), November 2000.

24. M. K. Miller, P. Pariege, K. F. Russell, and R. E. Stoller, Lockheed Martin Energy Research Corporation, Oak Ridge Natl. Lab., Oak Ridge, Tenn., An Atom Probe Tomography Characterization of the Solute Distributions in a Neutron Irradiated and Annealed Pressure Vessel Steel, USNRC Report NUREG/CR-6629 (ORNL/TM-13768), November 2000.

25. I. Remec, C. A. Baldwin, and E. D. Blakeman, Lockheed Martin Energy Research Corporation, Oak Ridge Natl. Lab., Oak Ridge, Tenn., Characterization of the Neutron Field in the HSSI/UCSB Irradiation Facility at the Ford Nuclear Reactor, (ORNL/TM-1999/140), April 2005. Also submitted September 1999 as USNRC Report NUREG/CR-6646, to be published.

26. P. M. Rice and R. E. Stoller, UT-Battelle, LLC, Oak Ridge Natl. Lab., Oak Ridge, Tenn., Hardening Behavior of Ferritic Alloys at High Doses and After Thermal Aging, (ORNL/TM1999/297), November 2004. Also submitted August 2000 as USNRC Report NUREG/CR-6643, to be published.

27. S. K. Iskander, J. T. Hutton, L. E. Creech, M. Suzuki, K. Onizawa, E. T. Manneschmidt, R. K. Nanstad, T. M. Rosseel, and P. S. Bishop, UT-Battelle, LLC, Oak Ridge Natl. Lab., Oak Ridge, Tenn., Attenuation of Charpy Impact Toughness Through the Thickness of a JPDR Pressure Vessel Weldment, (ORNL/TM-2000-343). Submitted January 2001 as USNRC Report NUREG/CR-6709, to be published.

28. K. Onizawa, E. van Walle, W. Pavinich, and R. K. Nanstad, UT-Battelle, LLC, Oak Ridge Natl. Lab., Oak Ridge, Tenn., Results and Analysis of The ASTM Round Robin On Reconstitution, USNRC Report NUREG/CR-6777, (ORNL/TM-2001/34) August 2002.

29. D. W. Heatherly, K. R. Thoms, M. T. Hurst, and G. E. Giles, UT-Battelle, LLC, Oak Ridge Natl. Lab., Oak Ridge, Tenn., Heavy-Section Steel Irradiation Program's Reusable Irradiation Facilities, (ORNL/TM-2002/77), April 2005. Also submitted February 2002 as USNRC Report NUREG/CR-6779, to be published. 
30. R. K. Nanstad and D. E. McCabe, UT-Battelle, LLC, Oak Ridge Natl. Lab., Oak Ridge, Tenn., Preliminary Evaluation of Precracked Charpy Specimens for Determining Fracture Toughness of Reactor Pressure Vessel Weldment, New Coordinated Research Program, USNRC Report NUREG/CR-tbd (ORNL/TM-2001/tbd). Submitted July 2001, to be published.

31. M. A. Sokolov, R. K. Nanstad, I. Remec, C. A. Baldwin, and R. L. Swain, UT-Battelle, LLC, Oak Ridge Natl. Lab., Oak Ridge, Tenn., Fracture Toughness of an Irradiated, Highly Embrittled Reactor Pressure Vessel Weld, (ORNL/TM-2002/293). Submitted January 2004 and resubmitted November 2005 as USNRC Report NUREG/CR-tbd, to be published.

32. M. K. Miller et al., UT-Battelle, LLC, Oak Ridge Natl. Lab., Oak Ridge, Tenn., APT Characterization of Highly Irradiated High-Nickel RPV Welds and Low-Upper-Shelf Midland Weld Materials, (ORNL/TM-2006/531). Also submitted September 2006 as USNRC Report NUREG/CR-tbd, ORNL/TM-2006/531, to be published.

33. M. A. Sokolov et al., UT-Battelle, LLC, Oak Ridge Natl. Lab., Oak Ridge, Tenn., The Effects of Radiation on Fracture Toughness Curve Shape on a Low-Upper-Shelf Weld, ORNL/TM2006/532). Also submitted September 2006 as USNRC Report NUREG/CR-tbd, to be published.

34. E. D. Eason, M\&CS; G. R. Odette, UCSB; R. K. Nanstad, UT-Battelle, LLC, Oak Ridge Natl. Lab., Oak Ridge, Tenn; and T. Yamamato UCSB, A Physically Based Correlation of IrradiationInduced Transition Temperature Shifts for RPV Steels, (ORNL/TM-2006/530). Submitted October 2006 and February 2007 as USNRC Report NUREG/CR-tbd.

35. S. K. Iskander, R. K. Nanstad, C. A. Baldwin, D. W. Heatherly, M. K. Miller, and I. Remec, UTBattelle, LLC, Oak Ridge Natl. Lab., Oak Ridge, Tenn., Reirradiation Response of Irradiated and Thermally Treated Reactor Pressure Vessel Steels, (ORNL/TM-2006/533). Also to be submitted as USNRC Report NUREG/CR-tbd.

36. M. A. Sokolov, et al., UT-Battelle, LLC, Oak Ridge Natl. Lab., Oak Ridge, Tenn., Evaluation of the Effects of Post-Weld Heat Treatment (PWHT) on the Copper Solubility and Fracture Toughness of Unirradiated RPV Steels, (ORNL/TM-2007/tbd). To be published.

37. R. K. Nanstad, et al., UT-Battelle, LLC, Oak Ridge Natl. Lab., Oak Ridge, Tenn., The Effects of Re-irradiation on A533B Steel, Heat JRQ, (ORNL/TM-2007/tbd), to be published. USNRC Report NUREG/CR-tbd.

38. M. A. Sokolov, et al., UT-Battelle, LLC, Oak Ridge Natl. Lab., Oak Ridge, Tenn., The Applicability of Sub-size Specimens to the Master Curve Methodology, (ORNL/TM-2007/tbd), to be published. USNRC Report NUREG/CR-tbd.

39. This Report: J. A. Wang and R. Subramani, UT-Battelle, LLC, Oak Ridge Natl. Lab., Oak Ridge, Tenn., PR-EDB 3.0 Beta Version and User Guide, (ORNL/TM-2006/605).

40. M. A. Sokolov, et al., UT-Battelle, LLC, Oak Ridge Natl. Lab., Oak Ridge, Tenn., The Effects of Radiation on Fracture Toughness Curve Shape of a High-Nickel Steel (Palisades and UCSB), (ORNL/TM-2007/tbd), to be published. USNRC Report NUREG/CR-tbd.

41. R. K. Nanstad, et al., Evaluation of the Bias Term imposed for PCVN Specimens, (ORNL/TM2007/tbd), to be published. USNRC Report NUREG/CR-tbd.

42. R. K. Nanstad, and M. A. Sokolov, Effects of Irradiation and Thermal Annealing on Propensity for Temper Embrittlement in RPV Weld Heat-Affected-Zones, (ORNL/TM-2007/tbd), to be published. USNRC Report NUREG/CR-tbd. 


\section{B.2 REPORTS RELATED TO IRRADIATION EFFECTS IN PRESSURE VESSEL MATERIALS AND TO THE PROPERTIES OF UNIRRADIATED MATERIALS USED IN THE HSSI AND HSST PROGRAMS}

C. E. Childress, Union Carbide Corp. Nuclear Div., Oak Ridge Natl. Lab., Oak Ridge, Tenn., Fabrication History of the First Two 12-in.-Thick A-533 Grade B, Class 1 Steel Plates of the Heavy-Section Steel Technology Program, ORNL-4313, February 1969.

T. R. Mager and F. O. Thomas, Westinghouse Electric Corporation, PWR Systems Division, Pittsburgh, Pa., Evaluation by Linear Elastic Fracture Mechanics of Radiation Damage to Pressure Vessel Steels, WCAP-7328 (Rev.), October 1969.

P. N. Randall, TRW Systems Group, Redondo Beach, Calif., Gross Strain Measure of Fracture Toughness of Steels, HSSTP-TR-3, Nov. 1, 1969.

L. W. Loechel, Martin Marietta Corporation, Denver, Colo., The Effect of Testing Variables on the Transition Temperature in Steel, MCR-69-189, Nov. 20, 1969.

W. O. Shabbits, W. H. Pryle, and E. T. Wessel, Westinghouse Electric Corporation, PWR Systems Division, Pittsburgh, Pa., Heavy-Section Fracture Toughness Properties of A533 Grade B Class 1 Steel Plate and Submerged Arc Weldment, WCAP-7414, December 1969.

C. E. Childress, Union Carbide Corp. Nuclear Div., Oak Ridge Natl. Lab., Oak Ridge, Tenn., Fabrication History of the Third and Fourth ASTM A-533 Steel Plates of the Heavy-Section Steel Technology Program, ORNL-4313-2, February 1970.

P. B. Crosley and E. J. Ripling, Materials Research Laboratory, Inc., Glenwood, Ill., Crack Arrest Fracture Toughness of A533 Grade B Class 1 Pressure Vessel Steel, HSSTP-TR-8, March 1970.

F. J. Loss, Naval Research Laboratory, Washington, D.C., Dynamic Tear Test Investigations of the Fracture Toughness of Thick-Section Steel, NRL-7056, May 14, 1970.

T. R. Mager, Westinghouse Electric Corporation, PWR Systems Division, Pittsburgh, Pa., PostIrradiation Testing of 2T Compact Tension Specimens, WCAP-7561, August 1970.

F. J. Witt and R. G. Berggren, Union Carbide Corp. Nuclear Div., Oak Ridge Natl. Lab., Oak Ridge, Tenn., Size Effects and Energy Disposition in Impact Specimen Testing of ASTM A533 Grade B Steel, ORNL/TM-3030, August 1970.

D. A. Canonico, Union Carbide Corp. Nuclear Div., Oak Ridge Natl. Lab., Oak Ridge, Tenn., Transition Temperature Considerations for Thick-Wall Nuclear Pressure Vessels, ORNL/TM3114, October 1970.

T. R. Mager, Westinghouse Electric Corporation, PWR Systems Division, Pittsburgh, Pa., Fracture Toughness Characterization Study of A533, Grade B, Class 1 Steel, WCAP-7578, October 1970.

W. O. Shabbits, Westinghouse Electric Corporation, PWR Systems Division, Pittsburgh, Pa., Dynamic Fracture Toughness Properties of Heavy-Section A533 Grade B Class 1 Steel Plate, WCAP-7623, December 1970.

C. E. Childress, Union Carbide Corp. Nuclear Div., Oak Ridge Natl. Lab., Oak Ridge, Tenn., Fabrication Procedures and Acceptance Data for ASTM A-533 Welds and a 10-in.-Thick ASTM A-543 Plate of the Heavy Section Steel Technology Program, ORNL-TM-4313-3, January 1971. 
D. A. Canonico and R. G. Berggren, Union Carbide Corp. Nuclear Div., Oak Ridge Natl. Lab., Oak Ridge, Tenn., Tensile and Impact Properties of Thick-Section Plate and Weldments, ORNL/TM3211, January 1971.

C. W. Hunter and J. A. Williams, Hanford Eng. Dev. Lab., Richland, Wash., Fracture and Tensile Behavior of Neutron-Irradiated A533-B Pressure Vessel Steel, HEDL-TME-71-76, Feb. 6, 1971.

C. E. Childress, Union Carbide Corp. Nuclear Div., Oak Ridge Natl. Lab., Oak Ridge, Tenn., Manual for ASTM A533 Grade B Class 1 Steel (HSST Plate 03) Provided to the International Atomic Energy Agency, ORNL/TM-3193, March 1971.

P. N. Randall, TRW Systems Group, Redondo Beach, Calif., Gross Strain Crack Tolerance of A533B Steel, HSSTP-TR-14, May 1, 1971.

C. L. Segaser, Union Carbide Corp. Nuclear Div., Oak Ridge Natl. Lab., Oak Ridge, Tenn., Feasibility Study, Irradiation of Heavy-Section Steel Specimens in the South Test Facility of the Oak Ridge Research Reactor, ORNL/TM-3234, May 1971.

H. T. Corten and R. H. Sailors, University of Illinois, Urbana, Ill., Relationship Between Material Fracture Toughness Using Fracture Mechanics and Transition Temperature Tests, T\&AM Report 346, Aug. 1, 1971.

L. A. James and J. A. Williams, Hanford Eng. Dev. Lab., Richland, Wash., Heavy Section Steel Technology Program Technical Report No. 21, The Effect of Temperature and Neutron Irradiation Upon the Fatigue-Crack Propagation Behavior of ASTM A533 Grade B, Class 1 Steel, HEDL-TME 72-132, September 1972.

P. B. Crosley and E. J. Ripling, Materials Research Laboratory, Inc., Glenwood, Ill., Crack Arrest in an Increasing K-Field, HSSTP-TR-27, January 1973.

W. J. Stelzman and R. G. Berggren, Union Carbide Corp. Nuclear Div., Oak Ridge Natl. Lab., Oak Ridge, Tenn., Radiation Strengthening and Embrittlement in Heavy-Section Steel Plates and Welds, ORNL-4871, June 1973.

J. M. Steichen and J. A. Williams, Hanford Eng. Dev. Lab., Richland, Wash., High Strain Rate Tensile Properties of Irradiated ASTM A533 Grade B Class 1 Pressure Vessel Steel, HEDLTME 73-74, July 1973.

J. A. Williams, Hanford Eng. Dev. Lab., Richland, Wash., The Irradiation and Temperature Dependence of Tensile and Fracture Properties of ASTM A533, Grade B, Class 1 Steel Plate and Weldment, HEDL-TME 73-75, August 1973.

J. A. Williams, Hanford Eng. Dev. Lab., Richland, Wash., Some Comments Related to the Effect of Rate on the Fracture Toughness of Irradiated ASTM A553-B Steel Based on Yield Strength Behavior, HEDL-SA 797, December 1974.

J. A. Williams, Hanford Eng. Dev. Lab., Richland, Wash., The Irradiated Fracture Toughness of ASTM A533, Grade B, Class 1 Steel Measured with a Four-Inch-Thick Compact Tension Specimen, HEDL-TME 75-10, January 1975.

J. G. Merkle, G. D. Whitman, and R. H. Bryan, Union Carbide Corp. Nuclear Div., Oak Ridge Natl. Lab., Oak Ridge, Tenn., An Evaluation of the HSST Program Intermediate Pressure Vessel Tests in Terms of Light-Water-Reactor Pressure Vessel Safety, ORNL/TM-5090, November 1975.

J. A. Davidson, L. J. Ceschini, R. P. Shogan, and G. V. Rao, Westinghouse Electric Corporation, Pittsburgh, Pa., The Irradiated Dynamic Fracture Toughness of ASTM A533, Grade B, Class 1 Steel Plate and Submerged Arc Weldment, WCAP-8775, October 1976. 
J. A. Williams, Hanford Eng. Dev. Lab., Richland, Wash., Tensile Properties of Irradiated and Unirradiated Welds of A533 Steel Plate and A508 Forgings, NUREG/CR-1158 (ORNL/SUB79/50917/2), July 1979.

J. A. Williams, Hanford Eng. Dev. Lab., Richland, Wash., The Ductile Fracture Toughness of HeavySection Steel Plate, NUREG/CR-0859, September 1979.

K. W. Carlson and J. A. Williams, Hanford Eng. Dev. Lab., Richland, Wash., The Effect of Crack Length and Side Grooves on the Ductile Fracture Toughness Properties of ASTM A533 Steel, NUREG/CR-1171 (ORNL/SUB-79/50917/3), October 1979.

G. A. Clarke, Westinghouse Electric Corp., Pittsburgh, Pa., An Evaluation of the Unloading Compliance Procedure for J-Integral Testing in the Hot Cell, Final Report, NUREG/CR-1070 (ORNL/SUB-7394/1), October 1979.

P. B. Crosley and E. J. Ripling, Materials Research Laboratory, Inc., Glenwood, Ill., Development of a Standard Test for Measuring KIa with a Modified Compact Specimen, NUREG/CR-2294 (ORNL/SUB-81/7755/1), August 1981.

H. A. Domian, Babcock and Wilcox Company, Alliance, Ohio, Vessel V-8 Repair and Preparation of Low Upper-Shelf Weldment, NUREG/CR-2676 (ORNL/SUB/81-85813/1), June 1982.

R. D. Cheverton, S. K. Iskander, and D. G. Ball, Union Carbide Corp. Nuclear Div., Oak Ridge Natl. Lab., Oak Ridge, Tenn., PWR Pressure Vessel Integrity During Overcooling Accidents: A Parametric Analysis, NUREG/CR-2895 (ORNL/TM-7931), February 1983.

J. G. Merkle, Union Carbide Corp. Nuclear Div., Oak Ridge Natl. Lab., Oak Ridge, Tenn., An Examination of the Size Effects and Data Scatter Observed in Small Specimen Cleavage Fracture Toughness Testing, NUREG/CR-3672 (ORNL/TM-9088), April 1984.

W. R. Corwin, Martin Marietta Energy Systems, Inc., Oak Ridge Natl. Lab., Oak Ridge, Tenn., Assessment of Radiation Effects Relating to Reactor Pressure Vessel Cladding, NUREG/CR3671 (ORNL-6047), July 1984.

W. R. Corwin, R. G. Berggren, and R. K. Nanstad, Martin Marietta Energy Systems, Inc., Oak Ridge Natl. Lab., Oak Ridge, Tenn., Charpy Toughness and Tensile Properties of a Neutron Irradiated Stainless Steel Submerged-Arc Weld Cladding Overlay, NUREG/CR-3927 (ORNL/TM-9709), September 1984.

J. J. McGowan, Martin Marietta Energy Systems, Inc., Oak Ridge Natl. Lab., Oak Ridge, Tenn., Tensile Properties of Irradiated Nuclear Grade Pressure Vessel Plate and Welds for the Fourth HSST Irradiation Series, NUREG/CR-3978 (ORNL/TM-9516), January 1985.

J. J. McGowan, Martin Marietta Energy Systems, Inc., Oak Ridge Natl. Lab., Oak Ridge, Tenn., Tensile Properties of Irradiated Nuclear Grade Pressure Vessel Welds for the Third HSST Irradiation Series, NUREG/CR-4086 (ORNL/TM-9477), March 1985.

W. R. Corwin, G. C. Robinson, R. K. Nanstad, J. G. Merkle, R. G. Berggren, G. M. Goodwin, R. L. Swain, and T. D. Owings, Martin Marietta Energy Systems, Inc., Oak Ridge Natl. Lab., Oak Ridge, Tenn., Effects of Stainless Steel Weld Overlay Cladding on the Structural Integrity of Flawed Steel Plates in Bending, Series 1, NUREG/CR-4015 (ORNL/TM-9390), April 1985.

W. J. Stelzman, R. G. Berggren, and T. N. Jones, Martin Marietta Energy Systems, Inc., Oak Ridge Natl. Lab., Oak Ridge, Tenn., ORNL Characterization of Heavy-Section Steel Technology Program Plates 01, 02, and 03, NUREG/CR-4092 (ORNL/TM-9491), April 1985. 
G. D. Whitman, Martin Marietta Energy Systems, Inc., Oak Ridge Natl. Lab., Oak Ridge, Tenn., Historical Summary of the Heavy-Section Steel Technology Program and Some Related Activities in Light-Water Reactor Pressure Vessel Safety Research, NUREG/CR-4489 (ORNL6259), March 1986.

R. H. Bryan, B. R. Bass, S. E. Bolt, J. W. Bryson, J. G. Merkle, R. K. Nanstad, and G. C. Robinson, Martin Marietta Energy Systems, Inc., Oak Ridge Natl. Lab., Oak Ridge, Tenn., Test of 6-in.Thick Pressure Vessels. Series 3: Intermediate Test Vessel V-8A - Tearing Behavior of Low Upper-Shelf Material, NUREG-CR-4760 (ORNL-6187), May 1987.

D. B. Barker, R. Chona, W. L. Fourney, and G. R. Irwin, University of Maryland, College Park, Md., A Report on the Round Robin Program Conducted to Evaluate the Proposed ASTM Standard Test Method for Determining the Plane Strain Crack Arrest Fracture Toughness, $\mathrm{K}_{\mathrm{Ia}}$, of Ferritic Materials, NUREG/CR-4966 (ORNL/SUB/79-7778/4), January 1988.

L. F. Miller, C. A. Baldwin, F. W. Stallman, and F. B. K. Kam, Martin Marietta Energy Systems, Inc., Oak Ridge Natl. Lab., Oak Ridge, Tenn., Neutron Exposure Parameters for the Metallurgical Test Specimens in the Fifth Heavy-Section Steel Technology Irradiation Series Capsules, NUREG/CR-5019 (ORNL/TM-10582), March 1988.

J. J. McGowan, R. K. Nanstad, and K. R. Thoms, Martin Marietta Energy Systems, Inc., Oak Ridge Natl. Lab., Oak Ridge, Tenn., Characterization of Irradiated Current-Practice Welds and A533 Grade B Class 1 Plate for Nuclear Pressure Vessel Service, NUREG/CR-4880 (ORNL-6484/V1 and V2), July 1988.

R. D. Cheverton, W. E. Pennell, G. C. Robinson, and R. K. Nanstad, Martin Marietta Energy Systems, Inc., Oak Ridge Natl. Lab., Oak Ridge, Tenn., Impact of Radiation Embrittlement on Integrity of Pressure Vessel Supports for Two PWR Plants, NUREG/CR-5320 (ORNL/TM10966), February 1989.

J. G. Merkle, Martin Marietta Energy Systems, Inc., Oak Ridge Natl. Lab., Oak Ridge, Tenn., An Overview of the Low-Upper-Shelf Toughness Safety Margin Issue, NUREG/CR-5552 (ORNL/TM-11314), August 1990.

R. D. Cheverton, T. L. Dickson, J. G. Merkle, and R. K. Nanstad, Martin Marietta Energy Systems, Inc., Oak Ridge Natl. Lab., Oak Ridge, Tenn., Review of Reactor Pressure Vessel Evaluation Report for Yankee Rowe Nuclear Power Station (YAEC No. 1735), NUREG/CR-5799 (ORNL/TM-11982), March 1992. 


\section{INTERNAL DISTRIBUTION}

\begin{tabular}{|c|c|}
\hline 1. $\quad$ B. R. Bass & 11. R. K. Nanstad \\
\hline 2. M. V. Buchanan & 12. T. M. Rosseel \\
\hline 3. J. T. Busby & 13. J. J. Simpson \\
\hline 4. T. S. Byun & 14. L. L. Snead \\
\hline 5. D. C. Christensen & 15. M. A. Sokolov \\
\hline 6. W. R. Corwin & 16. R. E. Stoller \\
\hline $\begin{array}{ll}\text { 7. } & \text { S. K. Iskander } \\
\end{array}$ & 17-18. J. A. Wang \\
\hline 8. $\quad$ E Lara-Curzio & 19. S. J. Zinkle \\
\hline 9. D. E. McCabe & \multirow{2}{*}{$\begin{array}{l}\text { 20. Office of Technical Information } \\
\text { and Classification }\end{array}$} \\
\hline 10. J. G. Merkle & \\
\hline
\end{tabular}

\section{EXTERNAL DISTRIBUTION}

21. AEA Technology Nuclear Science, Harwell, Didcot, Oxforshire OX1100QJ, United Kingdom

$$
\text { C. A. English }
$$

22. ATI, Inc., Suite 160, 210 Crow Canyon Place, San Ramon, CA 94583

$$
\text { W. L. Server }
$$

23-24. Areva, N. P., 25589 Fishers Hill Ct., Chantilly, VA 20152
B. Hall
K. Yoon

25. BWXT Services, Inc., 2016 Mount Athos Rd., Lynchburg, VA 24504

$$
\text { K. Hour }
$$

26-28. Central Institute for Nuclear Studies, CEN/SCK, Reactor Physics Department, Boeretang 200, B-2400 Mol. Belgium
M. Scibetta
E. Van Walle
E. Lucon 
29. DOE Oak Ridge Operation Office, P. O. Box 2001, Oak Ridge, TN 37831-6269

S. R. Martin

30-32. EPRI, 1300 West W.T. Harris Blvd., Charlotte, NC 28262

S. T. Rosinski

R. G. Carter

J. Spanner

33. Health \& Safety Executive, Nuclear Safety Directorate, HM Nuclear Installation Inspectorate, St. Peter's House, Stanley Precinct, Bootle, Merseyside L203LZ, United Kingdom

\section{R. D. Nicholson}

34. Joint Research Center, Institute for Advanced Materials, P. O. Box 2 Petten, 1775 Petten, The Netherlands

L. Debarberis

35. Korea Atomic Energy Research Institute, Nuclear Material Technology Division, 150 Dukjin-dong, Yusong-ku, 305-353 Daejon, Korea

Bong Sang Lee

36-45. Modeling and Computer Services, LLC, 6560 Gunpark Dr., Suite B, Boulder, CO 80301

E. D. Eason

46. Nuclear Research Institute, Division of Nuclear Materials, 25068 REZ, Czech Republic M. Brumovsky

47-54. NRC, RES/DFERR, Washington, DC, 20555-0001
J. Uhle
D. A. Jackson
M. T. EricksonKirk
S. M. Malik
E. Focht
C. E. Moyer
R. O. Hardies
R. L. Tregoning

55-58. NRC, NRR/DE, Washington, DC, 20555-0001

B. J. Elliot

C. J. Fairbanks

A. L Hiser

M. A. Mitchell 
59. NRC/NRO/DE, Washington, DC, 20555-0001

M. E. Mayfield

60. NRC, NMSS, SPPO, Washington, DC, 20555-0001

E. M. Hackett

61. NRC, ACRS, ITSB, Washington, DC, 20555-0001

$$
\text { C. G. Santos }
$$

62. Pavinich, W. A., 1113 Laurel Hill Road, Knoxville, TN 37923

63. Prometey, Central Research, Institute of Structural Materials, 193167 Sankt Petersburg, Russia

$$
\text { V. A. Nikolaev }
$$

64. Rolls-Royce and Associates LTD., P. O. Box 31, Raynesway, Derby DE24 8BJ, United Kingdom

$$
\text { T. J. Williams }
$$

65. Russian Research Center-Kurchatov Institute, 1 Kurchatov Sq., Moscow 123182, Russia
A. A. Chernobaeva

66. Paul Scherrer Institute, CH-5233 VILLIGEN SPI, Switzerland

\section{J. Bertsch}

67. Siemens AG, KWU S514, Freyeslebenstrasse 1, D-8520 Erlangen, Germany

$$
\text { E. Keim }
$$

68-71. Staatliche Materialprufungsanstalt and Der Universitat Stuttgart, Pfaffenwaldring 32, 70569 Stuttgart, Germany
U. Eisele
J. Fohl
E. Roos
R. Gillot

72-73. Swiss Federal Nuclear Safety Inspectorate, CH 5232 Villigen-HSK, Switzerland

D. Kalkhof

P. Tipping 
74. The Welding Institute, Abington Hall, Abington, Cambridge, CB1 6 AL, United Kingdom

\author{
C. S. Wiesner
}

75-76. Tokai Research Establishment, Japan Atomic Energy Research Institute, 2-4 Shirakatashirane, Tokai-mura, Naka-gun, Ibaraki 319-1195, Japan
M. Suzuki
K. Onizawa

77. Tokai University, Dept. of Nuclear Engineering, 1117, Kitakaname, Hiratsuka-shi, Kanagawa-Ken 259-12, Japan

Prof. Shiori Ishino

78-91. University of California, Department of Chemical and Nuclear Engineering, Ward Memorial Drive, Santa Barbara, CA 93106
G. E. Lucas
T. Yamamoto
G. R. Odette

92. U.S. Department of Energy, Office of Nuclear Science and Technology, 19901 Germantown Rd., Germantown, MD 20874-1290

R. M. Versluis

93. VTT Manufacturing Technology, P. O. Box 1704, FIN-02044 VTT, Finland

M. Valo

K. Wallin

94. Westinghouse, P. O. Box, 500, Mail Code 9483-1903, Windsor, CT 60695

\title{
S. T. Byrne
}

95. Westinghouse Electric Corporation, P. O. Box 335, Pittsburgh, PA 15230

W. Bamford

96. Westinghouse R\&D Center, 1310 Beulah Rd., Pittsburgh, PA 15325

R. G. Lott 